\title{
CONTAIN Assessment of the NUPEC Mixing Experiments
}

\section{Douglas W. Stamps}

Prepared by

Sandia National Laboratories

Albuquerque, New Mexico 87185 and Livermore, California 94550 for the United States Department of Energy

under Contract DE-AC04-94AL85000

Approved for public release; distribution is unlimited.

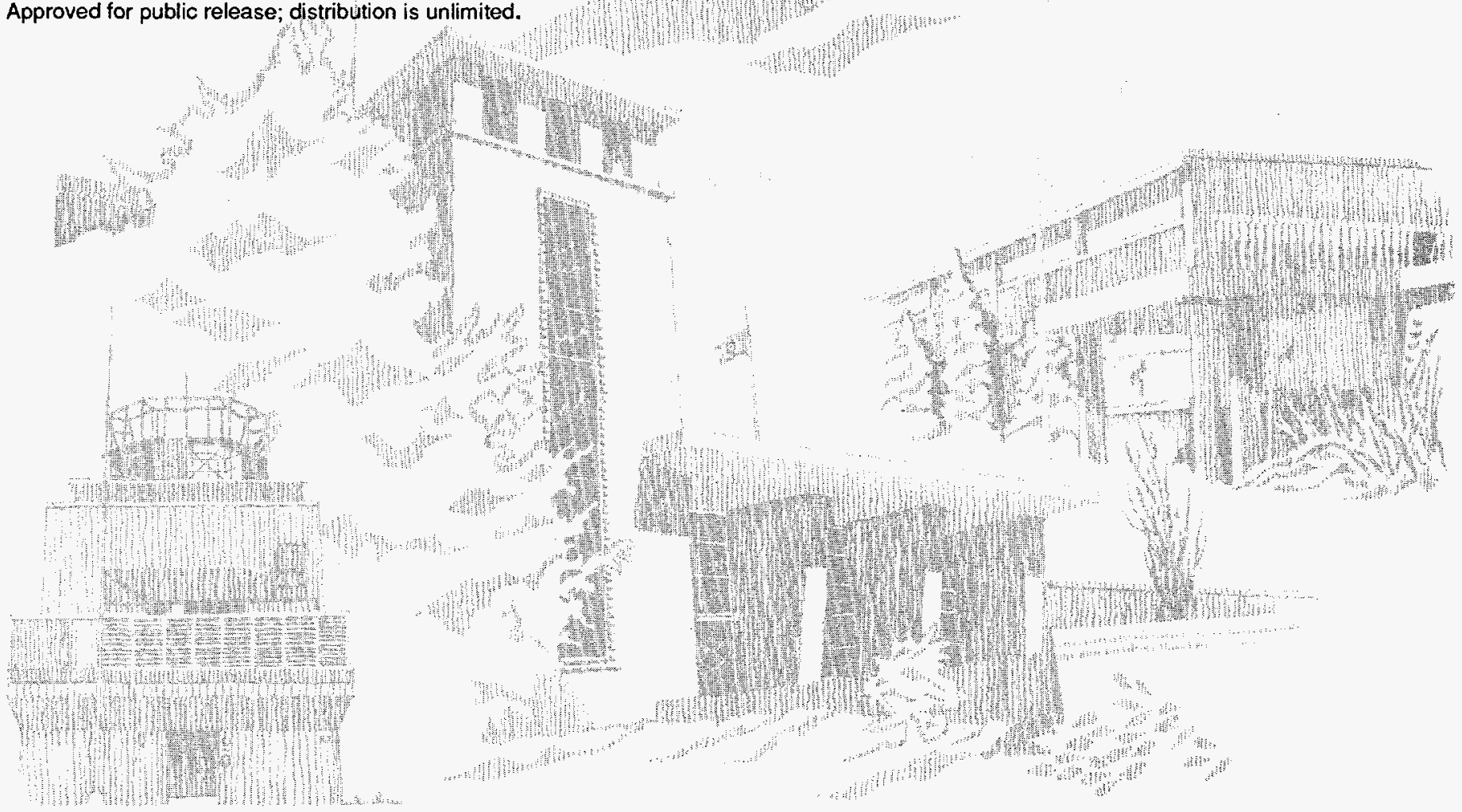


Issued by Sandia National Laboratories, operated for the United States Department of Energy by Sandia Corporation.

NOTICE: This report was prepared as an account of work sponsored by an agency of the United States Government. Neither the United States Government nor any agency thereof, nor any of their employees, nor any of their contractors, subcontractors, or their employees, makes any warranty, express or implied, or assumes any legal liability or responsibility for the accuracy, completeness, or usefulness of any information, apparatus, product, or process disclosed, or represents that its use would not infringe privately owned rights. Reference herein to any specific commercial product, process, or service by trade name, trademark, manufacturer, or otherwise, does not necessarily constitute or imply its endorsement, recommendation, or favoring by the United States Government, any agency thereof or any of their contractors or subcontractors. The views and opinions expressed herein do not necessarily state or reflect those of the United States Government, any agency thereof or any of their contractors.

Printed in the United States of America. This report has been reproduced directly from the best available copy.

Available to DOE and DOE contractors from

Office of Scientific and Technical Information

PO Box 62

Oak Ridge, TN 37831

Prices available from (615) 576-8401, FTS 626-8401

Available to the public from

National Technical Information Service

US Department of Commerce

5285 Port Royal Rd

Springfield, VA 22161

NTIS price codes

Printed copy: A05

Microfiche copy: A01 


\section{DISCLAIMER}

\section{Portions of this document may be illegible in electronic image products. Images are produced from the best available original document.}


SAND94-2880

Distribution

Unlimited Release

Category UC-505

Printed August 1995

\title{
CONTAIN Assessment of the NUPEC Mixing Experiments*
}

\author{
Douglas W. Stamps \\ Modeling and Analysis Department \\ Sandia National Laboratories \\ Albuquerque, NM 87185
}

\begin{abstract}
The ability of the CONTAIN code to predict the thermal hydraulics of five experiments performed in the NUPEC 1/4-scale model containment was assessed. These experiments simulated severe accident conditions in a nuclear power plant in which helium (as a nonflammable substitute for hydrogen) and steam were coinjected at different locations in the facility with and without the concurrent injection of water sprays in the dome. Helium concentrations, gas temperatures and pressures, and wall temperatures were predicted and compared with the data. The use of different flow solvers, nodalization schemes, and analysis methods for the treatment of water sprays was emphasized. As a result, a general procedure was suggested for lumped-parameter code analyses of problems in which the thermal hydraulics are dominated by water sprays.
\end{abstract}

*This work was supported by the U.S. Nuclear Regulatory Commission and performed at Sandia National Laboratories, which is operated for the U.S. Department of Energy under Contract No. DE-AC04-94AL85000. 
TABLE OF CONTENTS

1.0 OVERVIEW 1

1.1 Introduction 1

1.2 Description of NUPEC Facility and Tests 1

2.0 SOLUTION METHOD 9

3.0 RESULTS 12

3.1 CONTAIN Assessment of NUPEC Test M-4-3 13

3.2 CONTAIN Assessment of NUPEC Test M-5-5 19

3.3 CONTAIN Assessment of NUPEC Test M-7-1 25

3.4 CONTAIN Assessment of NUPEC Test M-8-1 35

3.5 CONTAIN Assessment of NUPEC Test M-8-2 41

$\begin{array}{ll}4.0 \text { SENSITIVITY STUDIES } & 47\end{array}$

4.1 Flow Solvers and Nodalization Schemes $\quad 47$

4.2 Sensitivity Studies of NUPEC Test M-7-1 60

4.2.1 Preheat Phase $\quad 60$

4.2.2 Test Phase 62

$\begin{array}{ll}\text { 5.0 SUMMARY } & 68\end{array}$

6.0 REFERENCES 


\section{LIST OF FIGURES}

Figure 1.1. Schematic of the NUPEC facility [1]. 4

Figure 1.2. CONTAIN 35-node scheme of the NUPEC facility. 5

Figure 1.3. NUPEC facility numbering system [1] used in the CONTAIN assessment.

Figure 1.4. Location of the helium sampling locations and pressure measurement points in the NUPEC facility [1].

Figure 1.5. Location of the temperature measurement points in the NUPEC facility [1].

Figure 3.1. Comparison between the CONTAIN predictions and data of the NUPEC Test M-4-3 helium concentrations for Compartments 8, 15, 21 , and 25 .

Figure 3.2. Comparison between the CONTAIN predictions and data of the NUPEC Test M-4-3 helium concentrations for Compartments 4, 12, and 25.

Figure 3.3. Comparison between the CONTAIN predictions and data of the NUPEC Test M-4-3 helium concentrations for Compartments 1, 2, 16,19 , and 22.

Figure 3.4. Comparison between the CONTAIN predictions and data of the NUPEC Test M-4-3 gas temperatures for Compartments 8, 15, 21, and 25.

Figure 3.5. Comparison between the CONTAIN predictions and data of the NUPEC Test M-4-3 gas temperatures for Compartments 4, 12, and 25.

Figure 3.6. Comparison between the CONTAIN predictions and data of the NUPEC Test M-4-3 gas temperatures for Compartments 1,2, 16, 19, and 22.

Figure 3.7. Comparison between the CONTAIN predictions and data of the NUPEC Test M-4-3 wall temperatures for Compartments 6, 13, and 25.

Figure 3.8. Comparison between the CONTAIN prediction and data of the NUPEC Test M-4-3 gas pressure for Compartment 25.

Figure 3.9. Comparison between the CONTAIN predictions and data of the NUPEC Test M-5-5 helium concentrations for Compartments 8, 15, 21 , and 25.

Figure 3.10. Comparison between the CONTAIN predictions and data of the NUPEC Test M-5-5 helium concentrations for Compartments 4, 12, and 25.

Figure 3.11. Comparison between the CONTAIN predictions and data of the NUPEC Test M-5-5 helium concentrations for Compartments 2, 16, 19 , and 22.

Figure 3.12. Comparison between the CONTAIN predictions and data of the NUPEC Test M-5-5 gas temperatures for Compartments 8, 15, 21, and 25 . 
Figure 3.13. Comparison between the CONTAIN predictions and data of the NUPEC Test M-5-5 gas temperatures for Compartments 4, 12, and 25.

Figure 3.14. Comparison between the CONTAIN predictions and data of the NUPEC Test M-5-5 gas temperatures for Compartments 1,2,16, 19, and 22.

Figure 3.15. Comparison between the CONTAIN predictions and data of the NUPEC Test M-5-5 wall temperatures for Compartments 6, 13, and 25.

Figure 3.16. Comparison between the CONTAIN prediction and data of the NUPEC Test M-5-5 gas pressure for Compartment 25.

Figure 3.17. Comparison between the CONTAIN predictions and data of the preheat phase of NUPEC Test M-7-1 gas pressure for Compartment 25.

Figure 3.18. Comparison between the CONTAIN predictions and data of the preheat phase of NUPEC Test M-7-1 gas temperatures for Compartments 2,19 , and 25 .

Figure 3.19. Numerical simulation of the water droplet and air velocity patterns for water sprays in an unobstructed containment [2].

Figure 3.20. Comparison between the CONTAIN predictions and data of the NUPEC Test M-7-1 helium concentrations for Compartments 8, 15, 21 , and 25.

Figure 3.21. Comparison between the CONTAIN predictions and data of the NUPEC Test M-7-1 helium concentrations for Compartments 4, 12, and 25 .

Figure 3.22. Comparison between the CONTAIN predictions and data of the NUPEC Test M-7-1 helium concentrations for Compartments 2, 16, 19 , and 22 .

Figure 3.23. Comparison between the CONTAIN predictions and data of the NUPEC Test M-7-1 gas temperatures for Compartments 8, 15, 21, and 25.

Figure 3.24. Comparison between the CONTAIN predictions and data of the NUPEC Test M-7-1 gas temperatures for Compartments 4, 12, and 25.

Figure 3.25. Comparison between the CONTAIN predictions and data of the NUPEC Test M-7-1 gas temperatures for Compartments 2, 16, 19, and 22.

Figure 3.26. Comparison between the CONTAIN predictions and data of the NUPEC Test M-7-1 wall temperatures for Compartments 4, 8, 12, and 25.

Figure 3.27. Comparison between the CONTAIN prediction and data of the NUPEC Test M-7-1 gas pressure for Compartment 25.

Figure 3.28. Comparison between the CONTAIN predictions and data of the NUPEC Test M-8-1 helium concentrations for Compartments 8,15 , 21 , and 25 . 
Figure 3.29. Comparison between the CONTAIN predictions and data of the NUPEC Test M-8-1 helium concentrations for Compartments 4, 12, and 25.

Figure 3.30. Comparison between the CONTAIN predictions and data of the NUPEC Test M-8-1 helium concentrations for Compartments 1, 2, 16,19 , and 22.

Figure 3.31. Comparison between the CONTAIN predictions and data of the NUPEC Test M-8-1 gas temperatures for Compartments 8, 15, 21, and 25.

Figure 3.32. Comparison between the CONTAIN predictions and data of the NUPEC Test M-8-1 gas temperatures for Compartments 4, 12, and 25.

Figure 3.33. Comparison between the CONTAIN predictions and data of the NUPEC Test M-8-1 gas temperatures for Compartments 1, 2, 16, 19, and 22.

Figure 3.34. Comparison between the CONTAIN predictions and data of the NUPEC Test M-8-1 wall temperatures for Compartments 6, 8, 13, and 25.

Figure 3.35. Comparison between the CONTAIN prediction and data of the NUPEC Test M-8-1 gas pressure for Compartment 25.

Figure 3.36. Comparison between the CONTAIN predictions and data of the NUPEC Test M-8-2 helium concentrations for Compartments 8,15 , 21 , and 25 .

Figure 3.37. Comparison between the CONTAIN predictions and data of the NUPEC Test M-8-2 helium concentrations for Compartments 4, 12, and 25.

Figure 3.38. Comparison between the CONTAIN predictions and data of the NUPEC Test M-8-2 helium concentrations for Compartments 1, 2, 16,19 , and 22.

Figure 3.39. Comparison between the CONTAIN predictions and data of the NUPEC Test M-8-2 gas temperatures for Compartments $8,15,21$, and 25.

Figure 3.40. Comparison between the CONTAIN predictions and data of the NUPEC Test M-8-2 gas temperatures for Compartments 4, 12, and 25.

Figure 3.41. Comparison between the CONTAIN predictions and data of the NUPEC Test M-8-2 gas temperatures for Compartments 1, 2, 16, 19, and 22.

Figure 3.42. Comparison between the CONTAIN predictions and data of the NUPEC Test M-8-2 wall temperatures for Compartments $6,8,13$, and 25.

Figure 3.43. Comparison between the CONTAIN prediction and data of the NUPEC Test M-8-2 gas pressure for Compartment 25.

Figure 4.1. Comparison between the dome helium concentration data of NUPEC Test M-4-3 and the CONTAIN predictions using the $\mathrm{W}$ and 
XBG code versions and the 28 -node and 35 -node schemes.

Figure 4.2. Comparison between the dome gas pressure data of NUPEC Test M4-3 and the CONTAIN predictions using the $W$ and XBG code versions and the 28-node and 35-node schemes.

Figure 4.3. Comparison between the dome gas temperature data of NUPEC Test M-4-3 and the CONTAIN predictions using the W and XBG code versions and the 28 -node and 35 -node schemes.

Figure 4.4. Comparison between the dome wall temperature data of NUPEC Test $\mathrm{M}-4-3$ and the CONTAIN predictions using the $\mathrm{W}$ and XBG code versions and the 28-node and 35-node schemes.

Figure 4.5. Comparison between the dome helium concentration data of NUPEC Test M-7-1 and the CONTAIN predictions using the $\mathrm{W}$ and XBG code versions and the 28 -node and 35 -node schemes.

Figure 4.6. Comparison between the dome gas pressure data of NUPEC Test M7-1 and the CONTAIN predictions using the $\mathrm{W}$ and XBG code versions and the 28 -node and 35 -node schemes.

Figure 4.7. Comparison between the dome gas temperature data of NUPEC Test $\mathrm{M}-7-1$ and the CONTAIN predictions using the $\mathrm{W}$ and XBG code versions and the 28 -node and 35 -node schemes.

Figure 4.8. Comparison between the dome wall temperature data of NUPEC Test $\mathrm{M}-7-1$ and the CONTAIN predictions using the $\mathrm{W}$ and XBG code versions and the 28-node and 35-node schemes.

Figure 4.9. Comparison between the dome helium concentration data of NUPEC Test $\mathrm{M}-8-1$ and the CONTAIN predictions using the $\mathrm{W}$ and XBG code versions and the 28 -node and 35 -node schemes.

Figure 4.10. Comparison between the dome gas pressure data of NUPEC Test M8-1 and the CONTAIN predictions using the $\mathrm{W}$ and XBG code versions and the 28-node and 35-node schemes.

Figure 4.11. Comparison between the dome gas temperature data of NUPEC Test $\mathrm{M}-8-1$ and the CONTAIN predictions using the $\mathrm{W}$ and XBG code versions and the 28 -node and 35 -node schemes.

Figure 4.12. Comparison between the dome wall temperature data of NUPEC Test $\mathrm{M}-8-1$ and the CONTAIN predictions using the $\mathrm{W}$ and XBG code versions and the 28 -node and 35 -node schemes.

Figure 4.13. Comparison between the CONTAIN predictions using the $W$ version and the 28-node scheme and data of the NUPEC Test M-8-1 helium concentrations for Compartments 8, 15, 21, and 25.

Figure 4.14. Comparison between the CONTAIN predictions using the XBG version and the 28-node scheme and data of the NUPEC Test M-8-1 helium concentrations for Compartments 8, 15, 21, and 25.

Figure 4.15. Comparison between the CONTAIN predictions using the $W$ version and the 35-node scheme and data of the NUPEC Test M-8-1 helium concentrations for Compartments 8, 15, 21, and 25 .

Figure 4.16. Comparison between the CONTAIN predictions using the XBG version and the 35-node scheme and data of the NUPEC Test M-8-1 he- 
lium concentrations for Compartments $8,15,21$, and 25 .

Figure 4.17. Comparison between the dome helium concentration data of NUPEC Test $\mathrm{M}-8-2$ and the CONTAIN predictions using the $\mathrm{W}$ and XBG code versions and the 28 -node and 35 -node schemes.

Figure 4.18. Comparison between the dome gas pressure data of NUPEC Test M8-2 and the CONTAIN predictions using the $\mathrm{W}$ and XBG code versions and the 28-node and 35-node schemes.

Figure 4.19. Comparison between the dome gas temperature data of NUPEC Test M-8-2 and the CONTAIN predictions using the $\mathrm{W}$ and XBG code versions and the 28 -node and 35 -node schemes.

Figure 4.20. Comparison between the dome wall temperature data of NUPEC Test $\mathrm{M}-8-2$ and the CONTAIN predictions using the $\mathrm{W}$ and XBG code versions and the 28-node and 35 -node schemes.

Figure 4.21. Comparison between the predicted and measured dome gas pressure in the preheat phase of test M-7-1: Case 1--best-estimate calculation; Case 2--enthalpy of the injected steam was reduced by $10 \%$; Case 3--insulation thermal conductivity was increased by a factor of 5; Case 4--heat and mass transfer coefficients were increased by a factor of 10 ; Case 5--heat capacity was increased by $25 \%$; Case 6-28-cell nodalization scheme.

Figure 4.22. Comparison of the predicted results for the dome helium concentration using different methods for treating the water spray flow pattern in the facility: Case 1 (best estimate)--sprays were assumed to drive a large convection loop which concentrated the water drops into the center of the facility and enhanced wall to gas heat transfer; Case 2-spray pattern based on flow in unconfined geometries and included impingement of water sprays on the containment wall; Case 3--uniform spray pattern in the dome was assumed with no spray impingement or forced convection; Case 4--same as Case 3 except 28-cell nodalization was used.

Figure 4.23. Comparison of the predicted results for the dome gas temperature using different methods for treating the water spray flow pattern in the facility. Refer to Figure 4.22 for a description of each case.

Figure 4.24. Comparison of the predicted results for the dome gas pressure using different methods for treating the water spray flow pattern in the facility. Refer to Figure 4.22 for a description of each case.

Figure 4.25. Comparison of the predicted results for the dome wall temperature using different methods for treating the water spray flow pattern in the facility. Refer to Figure 4.22 for a description of each case. 


\section{LIST OF TABLES}

Table 4.1 Comparison of the differences that had the largest effect on the thermal hydraulics between the tests M-4-3, M-7-1, M-8-1, and M-8-2. 


\section{ACKNOWLEDGMENTS}

The author would especially like to thank K. Murata for his extremely useful advice and insights during the course of the calculations and analysis of the results. The author also thanks J. Tills, S. Dingman, and E. Tadios for their valuable technical comments. Special thanks is extended to A. Notafrancesco, K. Washington, and R. Griffith for their support and the opportunity to perform this work.

This work was supported by the U.S. Nuclear Regulatory Commission and performed at Sandia National Laboratories, which is operated for the U.S. Department of Energy under Contract No. DE-AC04-94AL85000. 


\section{EXECUTIVE SUMMARY}

The thermal hydraulic modeling capabilities of the CONTAIN code were assessed with five tests performed in the NUPEC 1/4-scale model containment. The tests were intended to simulate the thermal hydraulics of a severe accident in a nuclear power plant when helium (as a nonflammable substitute for hydrogen) and steam are injected into a containment with water sprays. The NUPEC model containment somewhat resembles U.S. pressurized water reactors (PWR) in terms of overall geometry and internal configuration although there are some important differences. For example, the NUPEC facility does not contain any concrete.

The five NUPEC tests that were assessed included tests M-4-3, M-5-5, M-7-1, M-8-1, and M8-2. Test M-4-3 had a low-point injection of helium and steam, no water sprays, and the containment was initially at ambient temperature. Test M-5-5 had a low-point injection of helium only, water sprays, and the entire test was conducted at ambient temperature. Test M-7-1 had a low-point injection of helium and steam, water sprays, and was preheated by steam injection prior to the conduct of the test. Test M-7-1 was designated as International Standard Problem 35 (ISP-35). Test M-8-1 had a midpoint injection of helium and steam, no water sprays, and the containment was initially at ambient temperature when the test began. Test M-8-2 had a midpoint injection, water sprays, and was preheated by steam injection prior to the test.

Two different flow solvers and two different nodalization schemes were assessed. One flow solver, part of the CONTAIN $1.12 \mathrm{~W}$ version, assumes the flow path density is the average of the density in the upstream and downstream cells. The other flow solver, part of the CONTAIN 1.12 XBG version, is a hybrid formulation. The hybrid flow solver interpolates between the average density formulation and a formulation which assumes the flow path density is equal to the upstream, or donor, cell density. These two flow solvers were each assessed using two different nodalization schemes. In the 28 -node scheme, each physical room in the model containment was represented by a computational node. The 35 -node scheme was similar to the 28-node scheme except that the dome and pressurizer were subdivided. The dome was subdivided into 7 volumes, including central and annular cells, to allow circulation in the dome. The pressurizer was subdivided into 2 volumes to allow gases to circulate with a deadend compartment connected to it.

CONTAIN predicted the helium concentrations well in most of the compartments. The most difficult compartments to predict were the in-core chase, which is an irregularly shaped room at the bottom of the facility; the pressurizer rooms, which include the dead-end compartment; and the source rooms. CONTAIN also predicted the gas temperatures well in most rooms. Similar to the helium concentration predictions, it was often difficult to predict gas temperatures in the in-core chase, the pressurizer rooms, and the source rooms. In addition, for tests with water sprays, it was difficult to predict the gas temperature in the lower outer rooms. This was because CONTAIN could not model the forced flow through these rooms owing to the spray-induced air convection loop. CONTAIN always overpredicted the gas pressure except for the nearly perfect agreement in the isothermal test when helium only was added. CONTAIN generally predicted the wall temperatures well except for the lower outer compartments. A detailed discussion of the difference between the calculations and the data is given in Section 3. 
The discrepancies between the predicted and measured values in test M-7-1 were analyzed as part of the ISP-35 exercise. For the preheat phase, no single source was identified that could account for all of the discrepancies. Some of the difference could be attributed to the nodalization scheme. The state of the injected steam was another possible source. The water sprays dominated the thermal hydraulics in the test phase. Because of their importance, three different methods for treating the water sprays were considered. One approach was the simple application of the CONTAIN spray model. The sprays had an effect only in the cell in which they were used: droplets did not automatically fall into the compartment below but collected in a pool on the floor of the room. The sprays interacted thermally with the gas only in the cell and not with the cell's walls or structures. The second approach assumed the water spray pattern was the same as in an unconfined geometry. The amount of spray impingement on the containment walls was estimated by simple geometrical considerations. The third approach was based on numerical simulations of water sprays in a confined geometry. In this approach, the sprays drove large air convection loops. The air pattern concentrated the sprays in the center of the dome until they fell to the bottom of the containment. CONTAIN could not model the hydrodynamics of the air convection loop per se but could account for the increased heat transfer to the surfaces. In the third approach, the effect of the sprays falling down the center of the containment was modeled by having a pump draw water from the pool of an upper room to feed the spray water into a lower room. This approach gave the best results and is therefore recommended for lumped parameter code analyses of problems where water sprays dominate the thermal hydraulics.

The two different flow solvers were assessed with the NUPEC tests. Results were quite similar when the helium was well mixed throughout the facility. Significant differences existed between the two flow solvers for test M-8-1, which had stratified conditions. For test M-8-1, the donor cell method (XBG version) produced superior results but only when the 35-node scheme was used, which allowed mixing to occur above the injection location. 


\subsection{OVERVIEW}

\subsection{Introduction}

Several series of tests were performed in the NUPEC 1/4-scale model containment to investigate the thermal hydraulics of coinjecting helium and steam into a containment with and without the operation of water sprays. The tests simulated severe accident conditions in a nuclear power plant under simplified conditions in which helium (as a nonflammable substitute for hydrogen) and steam were released into a containment. The NUPEC model containment was a 1/4 linearly scaled model of a 4-loop PWR containment as shown in Figure 1.1. The test series were conducted to determine the mixing behavior of helium throughout the containment, determine the thermal hydraulics, and to produce data to assess analysis codes. The effects of mixing from natural convection as a result of density differences, forced convection as a result of the steam release and water sprays, and break location, were tested.

The main objective of this work was to assess the CONTAIN code using the data from the NUPEC tests. CONTAIN has models to predict the thermal hydraulic conditions tested in the NUPEC facility and its lumped-parameter formulation is well suited for analyzing simultaneous physical effects in complicated multiple-compartment geometries. In particular, the ability of the CONTAIN code to predict gas temperature and pressure, wall temperature, and helium mixing throughout the containment was assessed. Different flow solvers, nodalization schemes, and analysis methods for the treatment of water sprays were emphasized in the assessment. Another objective was to develop a procedure for lumped-parameter codes to calculate the thermal hydraulics in a containment under conditions dominated by water sprays.

\subsection{Description of NUPEC Facility and Tests}

The NUPEC facility is a domed cylinder, approximately $10.8 \mathrm{~m}$ in diameter, $17.4 \mathrm{~m}$ high, and $1310 \mathrm{~m}^{3}$ in volume [1]. The facility contains 28 compartments of which only 25 are interconnected. The dome compartment constitutes approximately $71 \%$ of the total containment volume. The containment is constructed entirely of carbon steel. The containment shell and floors are $12 \mathrm{~mm}$ thick except for the first floor, which is $16 \mathrm{~mm}$ thick. The compartment walls are $4.5 \mathrm{~mm}$ thick. The outside of the containment is covered with a layer of insulation, which is covered by a thin metal sheet to protect the insulation from weather damage. The insulation around the cylinder and hemisphere is $125 \mathrm{~mm}$ and $150 \mathrm{~mm}$ thick, respectively. A water storage tank is located below the first floor of the containment so that condensate and spray water can drain. The tank is separated from the rest of the containment by $100 \mathrm{~mm}$ of insulation. Water is pumped from the tank to 21 spray nozzles in the dome. The stored water could be heated. The facility is equipped with a remote boiler to supply saturated steam, a helium supply system, and a mixing chamber for coinjecting steam and helium.

Nine different series of tests were performed to determine the effect of mixing as a result of density differences due to differences in molecular weights and temperature, forced convection due to water sprays, and different release locations. Tests were performed injecting helium and steam individually as well as together, injecting helium with water sprays, and injecting helium and steam with water sprays. The gases were injected in either a steam gener- 
ator room or pressurizer relief tank at the bottom of the containment or in the pressurizer compartment in the middle of the containment.

Selected tests from series M-4, M-5, M-7, and M-8 were used in the current assessment. Helium and steam were coinjected into a room in the bottom of the containment in series M-4. Typically the containment was initially at room temperature. Helium was injected into a room in the bottom of the containment concurrent with the injection of water sprays in the dome in series M-5. The containment, helium, and water sprays were all at room temperature (approximately $10^{\circ} \mathrm{C}$ ). Series M-7 were integral effects tests and included all of the separate effects tested in series $\mathrm{M}-1$ through M-6. Helium and steam were coinjected into a room at the bottom of a preheated containment at the same time the water sprays were operating. Series M-8 repeated selected tests in Series M-4 and M-7 except the gases were released in the pressurizer compartment in the middle of the containment.

Two nodalization schemes were used to analyze the NUPEC tests. In one scheme based on a 35-node representation of the facility, each room was represented by a computational node except for the dome and pressurizer rooms, which were subdivided. A schematic of the 35cell representation of the facility is shown in Figure 1.2. The cell volumes and flow paths were represented by the boxes and the interconnected lines, respectively. The dome was subdivided into central and annular cells. This nodalization scheme allowed convection loops to form during the calculation and was motivated by the ring vortices that were predicted when water sprays were injected into an unobstructed confined container [2]. The pressurizer room (Cells 22 and 35) was also subdivided to allow circulation of gases from the pressurizer room to the pressurizer compartment (Cell 16), which is a dead-end room. Figure 1.2 also illustrates the other scheme, a 28-node representation of the facility, except that the dome (Cells 25 and 2934 ) is a single computational cell (identified only as Cell 25) and the pressurizer (Cells 22 and 35 ) is a single computational cell (identified only as Cell 22). Except for the subdivided rooms, the 35-cell representation and the 28 -cell representation were identical.

In tests M-4-3, M-5-5, and M-7-1, helium and steam were coinjected into the steam generator foundation (D loop) compartment (Cell 8). In tests M-8-1 and M-8-2, the gases were injected into the pressurizer compartment (Cell 22 in the 28-node scheme and Cells 22 and 35 in the 35 -node scheme). In the 35-node scheme, the mass flow rates of the coinjected gases were equally split between Cells 22 and 35 . In all tests in which sprays were operated, the sprays were injected into the top of the dome in Cell 25. Source tables giving mass flow rates and enthalpies as a function of time were used to input the injected gases and spray water into their respective computational cells.

Except for the subdivided rooms, the numbering system shown in Figure 1.2 is the same as specified in [1]. Figure 1.3 shows the numbering system for the flow paths and rooms used by NUPEC [1]. The closed rooms, which included the water storage tank, the reactor vessel, and the primary shield, were represented by Cells 26-28, respectively. The closed rooms were included to account for the thermal effects of structures in those rooms and are not shown in Figures 1.2 and 1.3.

The helium concentrations were sampled from the center of 24 rooms and at 5 locations in the dome. Samples were drawn through tubes, cooled, dried by passing through a desiccant, and analyzed by gas chromatography. Because of the gas sampling technique, the predicted results 
were normalized to the volume percentage of helium at 1 atmosphere and $0^{\circ} \mathrm{C}$ in dry air to compare with the data. Actual volume percentages of helium on a wet basis were less owing to the presence of steam. The sample tubes were at the center of each room and the specific locations of each of the helium sample tubes are shown in Figure 1.4. The sample tubes were different lengths but the lag time was compensated for in the analysis of the helium data. The dome sample tube elevations were all above the two different source elevations. However, at these sample locations, the dome region was fairly well mixed since the helium concentration at each location was within approximately $\pm 5 \%$ of the average for each of the tests at the end of the injection period. Since CONTAIN predicted well-mixed values for each node, the CONTAIN predictions provided a fair representation for those rooms, or sections of rooms represented by nodes, that were fairly well-mixed. Except for the dome, variations in the helium concentration within each room were not measured. It would be difficult, if not impossible, to estimate the uncertainty between a CONTAIN prediction, which represented a wellmixed condition, and the data measured at the center of a room that may contain helium concentration gradients. However, in general, there is no reason to believe that strong concentration gradients existed in any of the rooms, with the possible exception of the source room and any interconnected rooms directly above it. With this understanding, it is sufficient to note that CONTAIN may have underpredicted the concentration of helium measured at the center of these rooms, although it may have fairly represented an average helium concentration, which was not measured.

The gas temperatures, wall temperatures, and stored water temperature were measured with approximately $200 \mathrm{Cr}-\mathrm{Al}$ thermocouples. Thermocouple locations are shown in Figure 1.5. Because of the large number of locations, a limited number of temperature measurements were selected to illustrate CONTAIN's temperature predictions. The largest gas temperature gradients were measured in the vertical direction. Radial and azimuthal gas temperature variations were not that large at a given elevation. Exceptions to this include the source room and rooms above it, dead-ended compartments, and the in-core chase compartment. Because of this, the predicted gas temperature trends were illustrated for three vertical columns of rooms: inner, middle, and outer. The choice of each column of rooms was not critical. The set of rooms along a radius from the center of the facility to the rooms above D loop lower general compartment (compartment 4) was chosen since it included the source rooms. Predicted wall temperatures were compared with measured values in rooms diametrically opposed to the rooms selected for gas temperature comparisons. This was done to emphasize any asymmetrical trends that may have been predicted. The predicted wall temperatures were compared with the containment wall temperatures in the B loop lower general compartment (compartment 6) and all of the rooms above it. When comparing predicted dome wall temperatures with measured values, the wall temperature measurement in the " $\mathrm{B}$ " quadrant at an elevation of 16.704 $\mathrm{m}$ was used. The predicted value for this comparison was based on an average wall temperature in the spherical dome region above the 14.036-m elevation. The gas pressure was measured by a pressure gauge in the top of the dome. The steam and helium flow rates were measured by a differential pressure transducer across a venturi. 


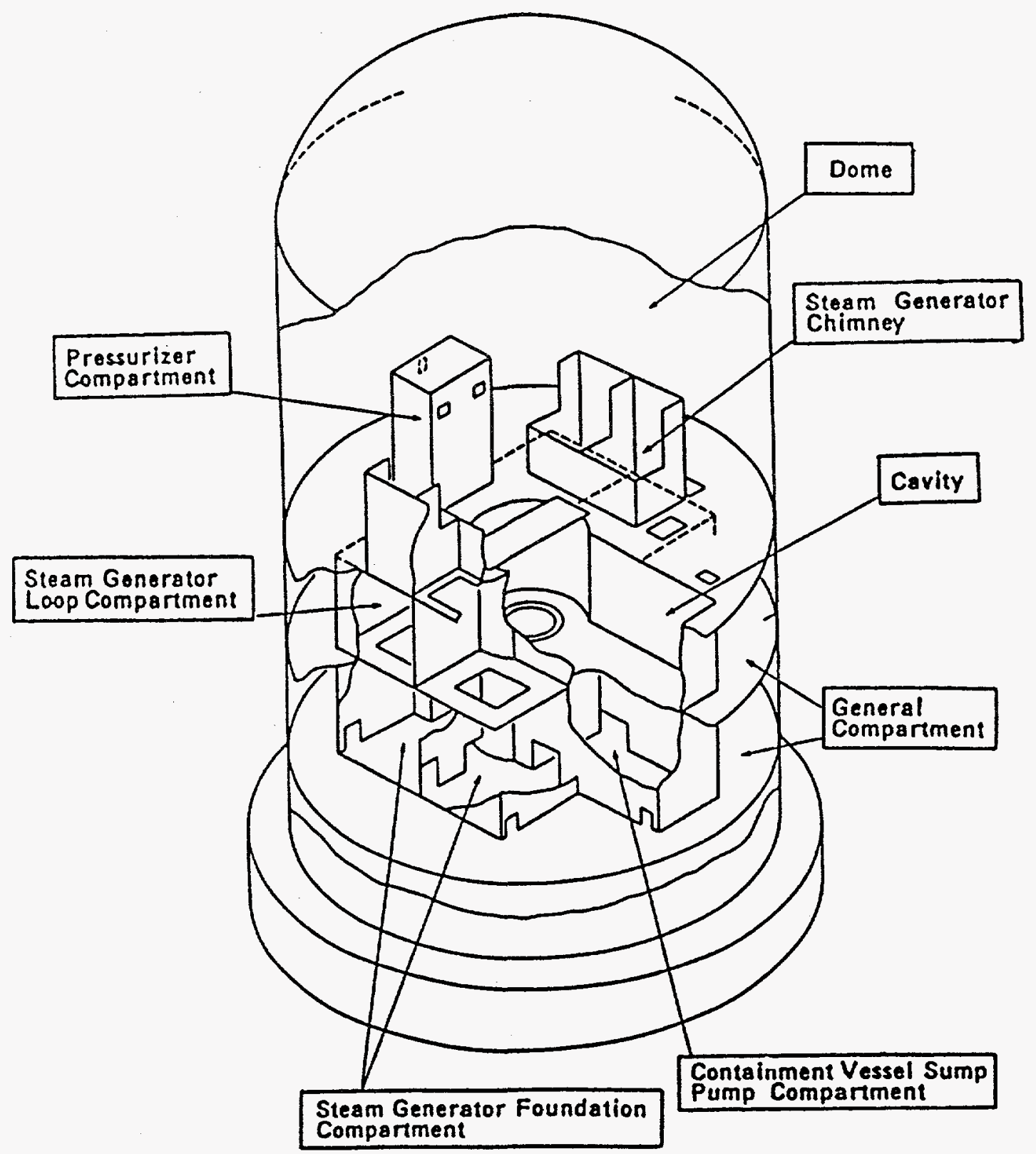

Figure 1.1. Schematic of the NUPEC facility [1]. 


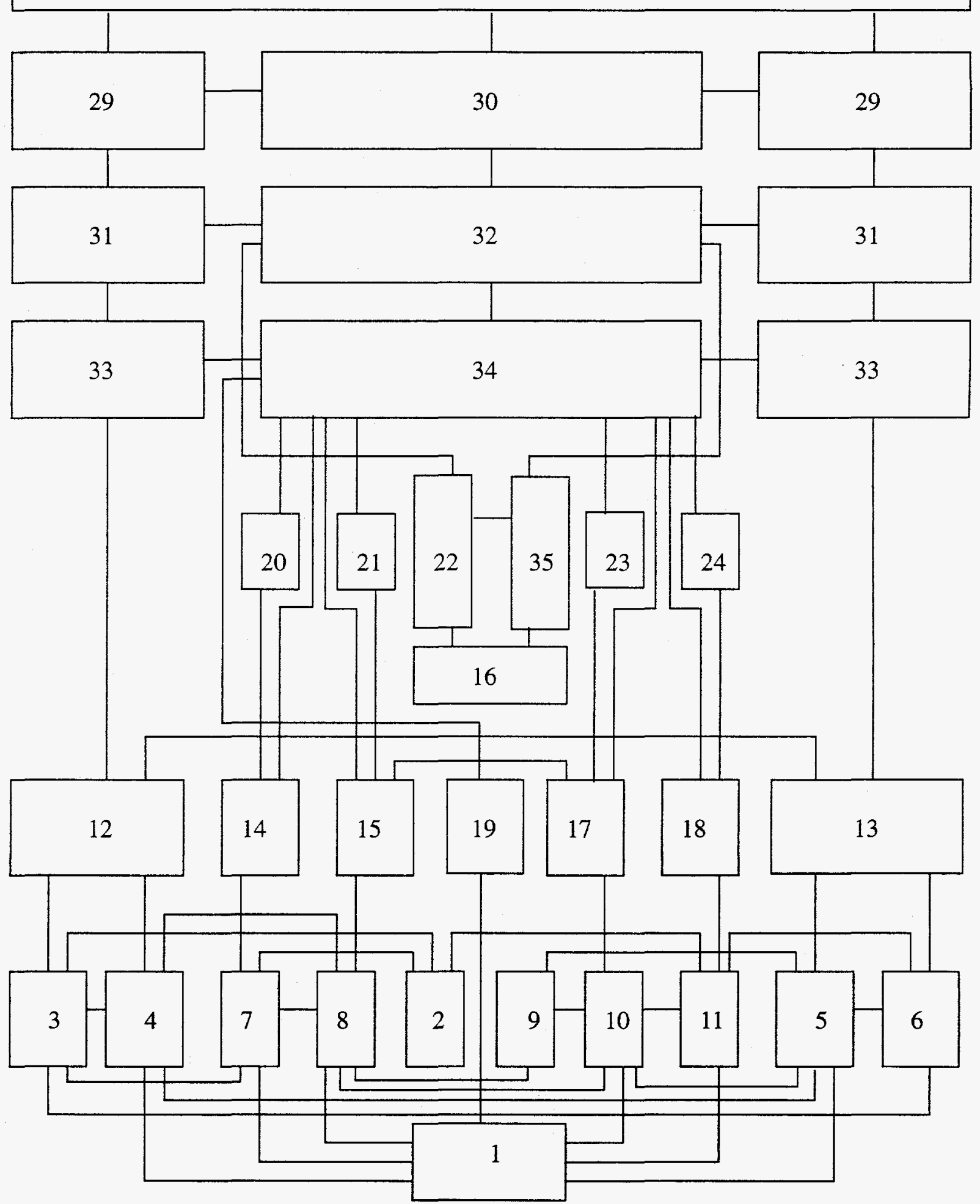

Figure 1.2. CONTAIN 35-node scheme of the NUPEC facility. 

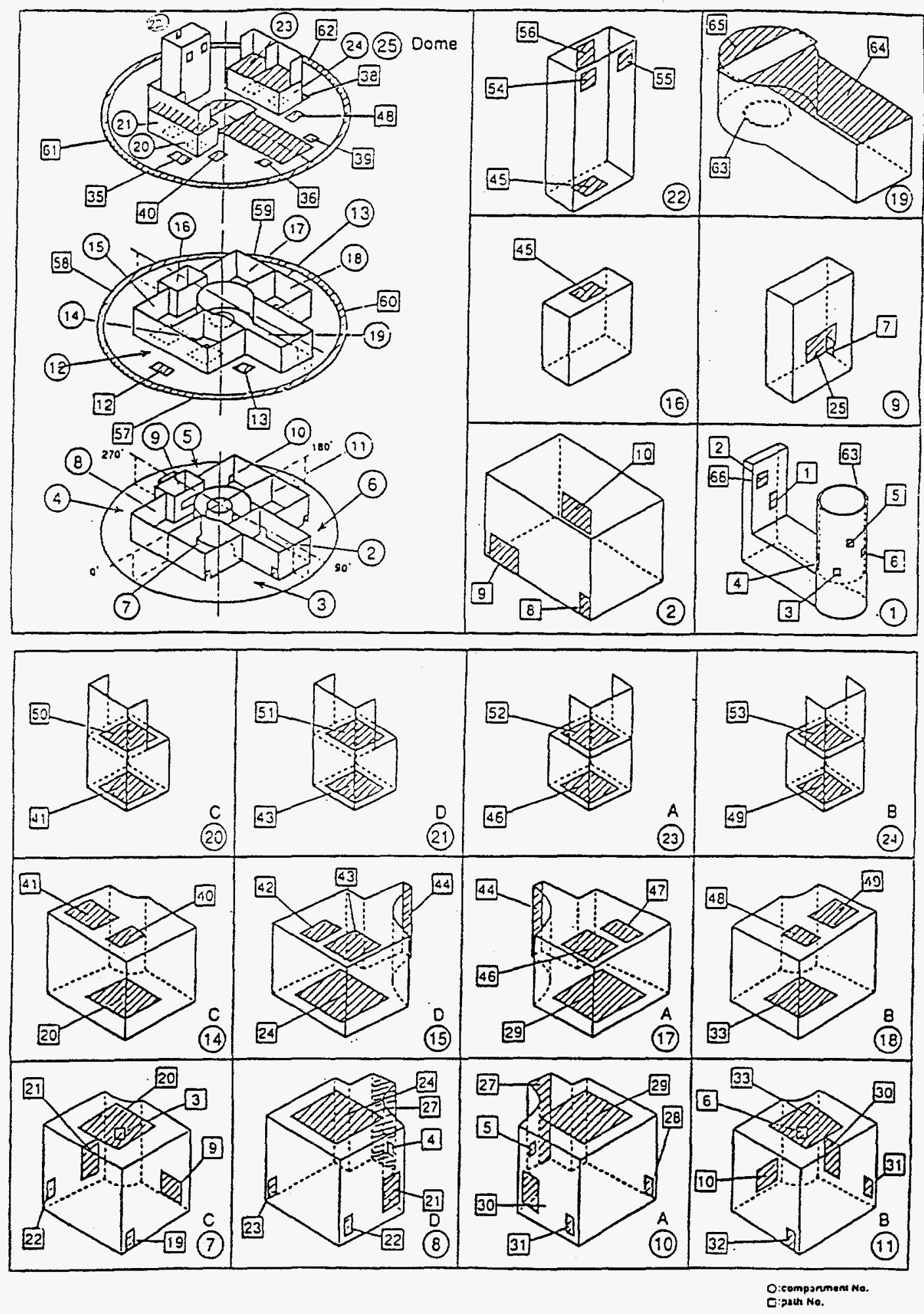

Figure 1.3. NUPEC facility numbering system [1] used in the CONTAIN assessment. 


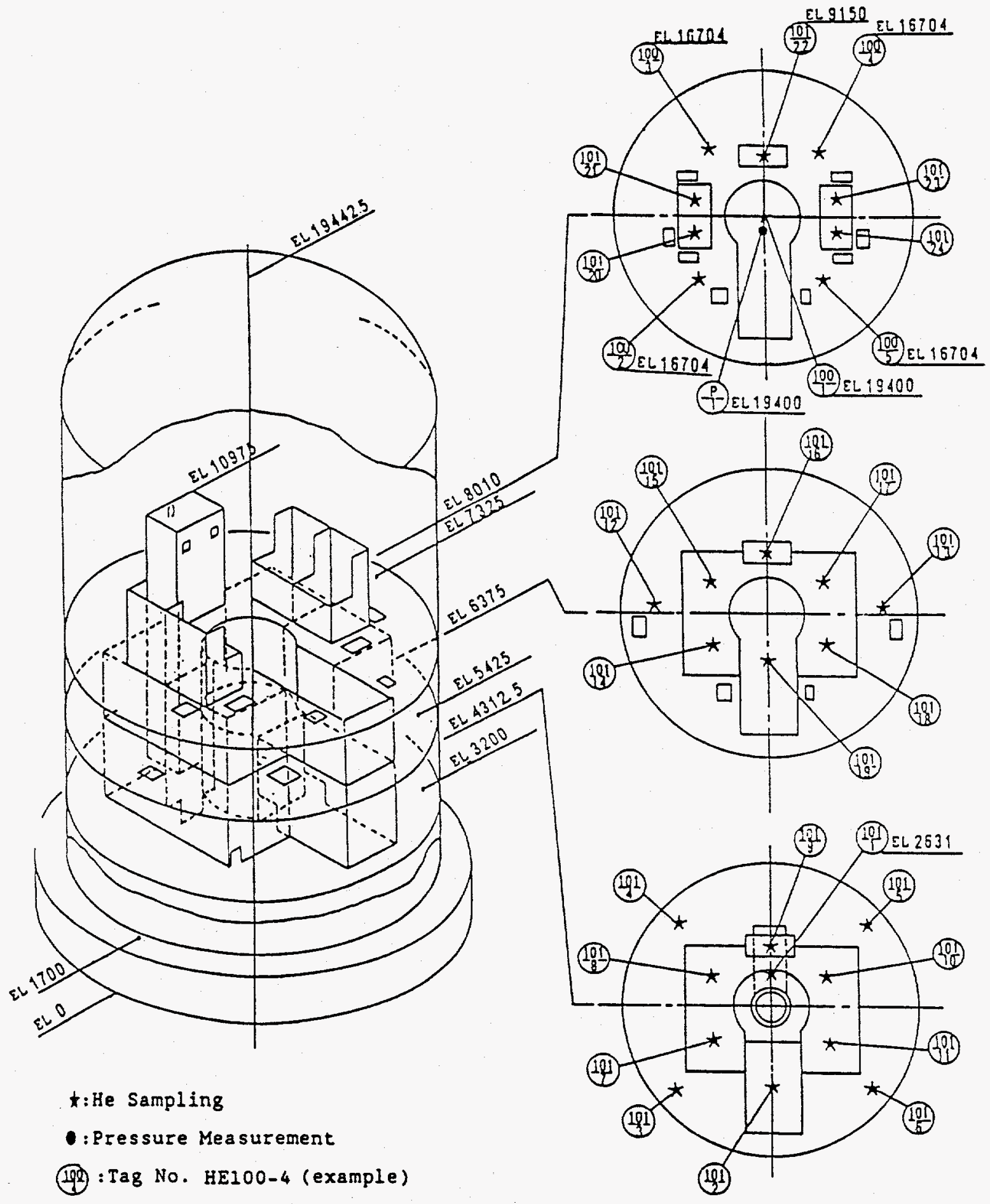

Figure 1.4. Location of the helium sampling locations and pressure measurement points in the NUPEC facility [1]. 


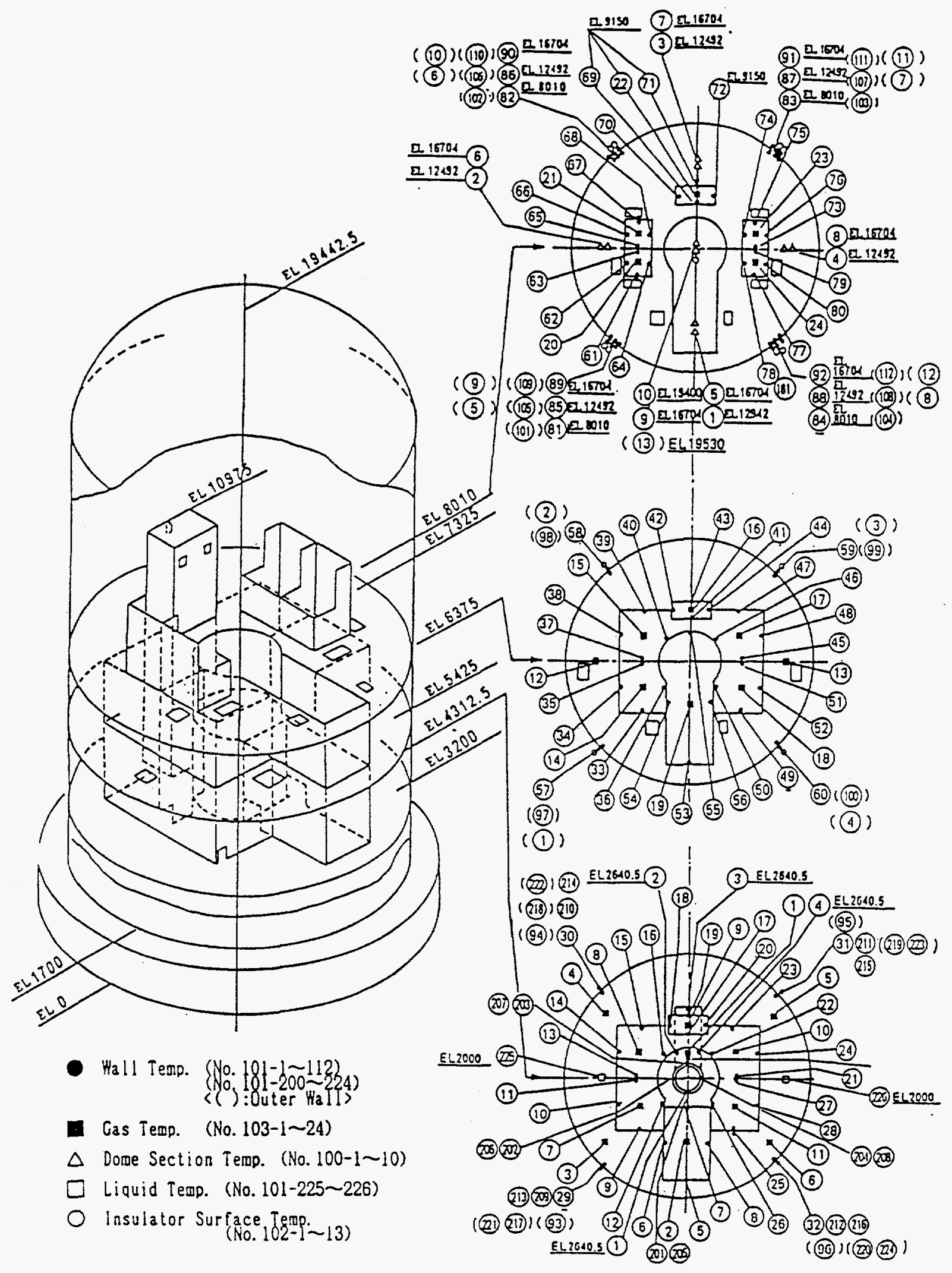

Figure 1.5. Location of the temperature measurement points in the NUPEC facility [1]. 


\subsection{SOLUTION METHOD}

CONTAIN has models to predict the thermal-hydraulic conditions inside a containment, such as in the event of an accident in a nuclear power plant. A detailed description of CONTAIN's architecture and models is beyond the scope of this report but can be found in Reference 3 . This chapter briefly describes the key models in the analyses of the NUPEC tests.

Owing to CONTAIN's lumped-parameter formulation, momentum is not treated in the computational cells but rather the conservation of momentum equation is solved for the flow paths. Because of this formulation, quantities inside the computational cell are assumed to be well mixed. A first-order implicit method is used to solve the inertial flow model for intercell flow. The integration time step is selected automatically by the code but cannot exceed a userspecified maximum time step, which was 1 second for this calculation. The inertial flow model takes into account the inertia of the fluid and the flow losses at cell junctions when calculating flows due to pressure differences between cells. A flow loss coefficient equal to one was assumed for all junctions. The equations for the conservation of mass and energy and the equation of state are solved for each computational cell.

CONTAIN Versions $1.12 \mathrm{~W}$ and $1.12 \mathrm{XBG}$ were assessed using the data from tests $\mathrm{M}-4-3, \mathrm{M}-$ 5-5, M-7-1, M-8-1, and M-8-2. Test M-7-1 was designated as the International Standard Problem 35 (ISP-35). Test M-7-1 calculation was initially performed without any knowledge of the results followed by subsequent open calculations. The flow solver in CONTAIN $1.12 \mathrm{~W}$, which is the current default flow solver, connects the ends of the flow paths to cell centers. The flow path density is assumed to be the average of the upstream and downstream cells. This flow solver will be referred to as the default flow solver throughout this report. The default flow solver tends to overpredict the rate and extent of mixing. The other flow solver assessed, which will be referred to as the hybrid flow solver (1.12 XBG), interpolates between the average-density formulation and a formulation which assumes the flow path density is equal to the upstream cell density.

The calculational procedure for the spray model is for CONTAIN to first determine the number of droplets introduced into a cell time step using a user-supplied initial average droplet diameter and spray mass flux rate. The equations for heat and mass transfer to the drop are solved for the entire fall of a single droplet and then multiplied by the total number of drops. The diameter of the water spray droplets can change as a result of condensation or evaporation. The water spray heat and mass transfer models account for the total heat flux between the drop and the atmosphere. The total heat flux includes the convective heat transport across the boundary layer and the heat transported by the mass flux. The convective heat flux is calculated by using the temperature difference between a drop and the bulk gas temperature and a heat transfer coefficient based on a Nusselt correlation for forced convection around a spherical drop. The heat transported by mass flux is calculated by using the mass flux and the difference in specific enthalpies between the bulk atmosphere vapor and the liquid water in the drop. The mass flux is proportional to the difference in partial pressure of water vapor between the drop and the atmosphere. The mass transfer coefficient is determined using the heat-mass transfer analogy. The effects on the atmosphere are assumed to be instantaneous. The spray model does not include the hydrodynamic drag on the atmospheric gases created by the drops. The spray drops accumulate in a pool at the bottom of each computational cell and 
the passage of the spray drops from one compartment to another is not automatic. Except for the dome, sprays in a compartment are fed by water from the pool in the immediate compartment above.

The spray model does not account for any effects from the impact of the spray drops on the containment wall or internal structures. These effects, such as evaporation and condensation, can be included using the film tracking model. This model allows a water film to flow down a series of structures and the heat and mass transfer to or from the film to be approximated. Depending on whether the film flow is laminar or turbulent based on the film Reynolds number, the film thickness and velocity are determined using one-dimensional steady-state film flow equations assuming no shear at the film-atmosphere interface. The outflow from one structure during one time step is applied as a constant inflow for the recipient structure during the next time step. Heat and mass transfer between the film and the atmosphere are accounted for as well as sensible heat from the incoming water.

Liquid water from condensate or the sprays is handled in one of three ways. In the current analysis, the "cell overflow" keyword is used to divert condensate runoff from structures in each cell in the facility to a cell in the bottom of the containment that contains a pool. For cells that contain pools, any water in excess of a pool depth of $5 \mathrm{~cm}$ is eventually transferred to the water storage tank automatically by the engineered systems "overflow" keyword. Every cell that has sprays also has a pool. When spray impingement is included, the liquid water on the containment shell is accounted for with the film tracking model. The water flows down the entire shell from the dome to the rooms at the bottom of the facility, where it is eventually diverted to a cell's pool.

Convection, radiation, and mass transfer are accounted for in the heat and mass transfer between the atmosphere and the structures. A one-dimensional finite-difference representation of the conduction heat transfer equations within the structures is used to account for the transient response of the containment wall and internal structures.

The convective heat flux between the atmosphere and a surface is determined by an appropriate heat transfer coefficient and the difference between the bulk atmosphere temperature and the atmosphere-liquid film interface temperature. The heat transfer coefficient is determined from a Nusselt number correlation for either laminar natural convection, turbulent natural convection, or forced convection.

Radiant heat transfer between the atmosphere and the structures, the atmosphere and the water pool, and the pool and the structures is accounted for in a simple radiant heat transfer model. The radiation model also accounts for the optical properties of the atmosphere, such as the total gas mixture emissivity and absorptivity, that are affected by steam and other nontransparent gases.

Mass flux caused by evaporation or condensation of water vapor is determined by the mass transfer coefficient and the difference in the water vapor partial pressures between the bulk gas and the water on the structural surface or the water droplets in the atmosphere. CONTAIN's aerosol model must be activated for liquid water, however, before steam condensation can occur in the atmosphere. This is accomplished by specifying an initial median particle diameter and particle distribution. The mass transfer coefficient is based on Nusselt number 
correlations and the heat-mass transfer analogy. The heat transfer caused by evaporation or condensation is calculated using the mass flux and the difference in specific enthalpies of the water vapor at the film interface and the bulk gas.

Conduction within structures is modeled using a fully implicit finite-difference representation of the heat conduction equations. Structures can be modeled as one-dimensional slabs, halfcylinders, or hemispheres. Composite structures, such as insulation covering the containment metal wall, may be specified and the noding within the structure may be arbitrarily spaced. The lower part of the cell can be composed of a water pool, steel plates, insulation, or other materials. The heat transfer model in CONTAIN for the lower cell materials allows one of these materials to be nodalized for one-dimensional heat conduction. The other materials, such as the pool, are assumed to have a uniform temperature. In the analysis of this experiment, the lower part of the computational cells with water sprays was modeled as a pool overlying a metal floor, except for the bottom floor. The water was insulated from the steel floor. In this case, the lower part of the computational cell was modeled as three overlying layers: the water pool on top, the metal floor below, and the insulation on the bottom. In all cases, the lower materials were assumed to have a uniform temperature. The boundary conditions for internal structures and the inside of the containment wall are determined by the heat and mass transfer to the atmosphere. Several different boundary conditions are available for the external wall exposed to the environment, such as an adiabatic surface, constant temperature surface, or a constant heat transfer coefficient, among others. For the analysis of this experiment, a constant heat transfer coefficient was specified for the surface of the exterior insulation to account for the heat transfer between the outside of the containment wall and the environment. Since the facility was a domed cylinder, a Nusselt number correlation for flow across a cylinder was used to estimate the heat transfer coefficient. Correlations for other geometries, such as for a vertical wall, could also have been used. However, as will be shown from sensitivity studies discussed in Section 4.2.1, the external heat transfer coefficient makes a small contribution to the total thermal resistance of the containment shell. Thus variations in the value of the external heat transfer coefficient based on different correlations are not critical. 


\subsection{RESULTS}

The results of the CONTAIN assessment of the five NUPEC tests, M-4-3, M-5-5, M-7-1, M$8-1$, and $M-8-2$, are presented in this section. Calculations were performed using two different versions of CONTAIN and two different nodalization schemes. The results for each of the four variables of interest (gas and wall temperatures, helium concentration, and gas pressure) in each of the 25 compartments for the four different calculations of each test were too voluminous to include in this report. As a result, the "best estimate" prediction for each test is reported in this section and selected comparisons of the predictions using different flow solvers and nodalization schemes are given in Section 4. The selection of the "best" prediction for each test was subjective.

A procedure was recently introduced to remove the subjectivity when assessing thermal hydraulic system codes [4]. As part of the assessment of test M-7-1 (ISP-35), a methodology based on the fast Fourier transform (FFT) was applied for the first time to containment thermal hydraulics. The amplitude and frequency of the differences in the code predictions in the frequency domain were displayed for each variable in each compartment and reduced to a single value for the entire calculation. Although it was beyond the scope of this work to apply this methodology to the current assessment, it is recommended that such an approach be evaluated for future CONTAIN assessment activities. This methodology allows the user to quantify the improvement in a prediction associated with different modeling approaches or the "best" prediction using different code versions or nodalization schemes.

The helium concentration, gas temperature and pressure, and wall temperature were predicted for each room in the facility and compared with the data. Because of the large number of rooms in the facility and because there was little change in the variables in the azimuthal direction, the results for helium concentrations and gas temperatures of three vertical columns of rooms are presented and are representative of the results for the inner, middle, and outer rooms in the facility.

There are some general comments that are applicable to all of the experiments analyzed. These are discussed in the rest of this section and pertain to experimental conditions or data acquisition.

Saturated steam at $165^{\circ} \mathrm{C}$ was produced in a boiler $24.5 \mathrm{~m}$ from the containment. The steam was injected into a steam generator foundation compartment in the lower part of the containment. The temperature of the injected steam was approximately $110^{\circ} \mathrm{C}$. Based on heat loss calculations for the flow of steam through the $24.5-\mathrm{m}$ pipe, the NUPEC organization estimated that the steam injected into the containment was saturated. Except for a limited number of calculations for sensitivity studies, the injected steam was assumed to be saturated in the calculations.

Because of the gas sampling technique, the predicted results were normalized to the volume percentage of helium at 1 atmosphere and $0^{\circ} \mathrm{C}$ in dry air to compare with the data. Actual volume percentages of helium on a wet basis were less, owing to the steam. The source compartment (Cell 8) wall temperature and the temperature of the inner surface of the containment wall in the lower general compartment (Cell 4) were measured at an elevation of $4.312 \mathrm{~m}$. The 
containment wall temperatures of the upper general compartment (Cell 12), lower region of the dome (Cell 33), and the ceiling of the dome (Cell 25) were measured at elevations of 6.375 $\mathrm{m}, 8.010 \mathrm{~m}$, and $16.704 \mathrm{~m}$, respectively. Compartment 1 was the lowest room in the facility and filled with water during the experiment. Helium concentration and gas temperature measurements in Compartment 1 were affected by water that accumulates in this room. A sudden change in these variables in Compartment 1 during the test indicated that the measurements were affected by the accumulation of water. Comparisons between the prediction and data for this room should not be made after this time.

\subsection{CONTAIN Assessment of NUPEC Test M-4-3}

The gas pressure at the beginning of test M-4-3 was approximately $101 \mathrm{kPa}$ and the structure and gas temperatures were at room temperature (approximately $27^{\circ} \mathrm{C}$ to $32^{\circ} \mathrm{C}$ ). At the beginning of the experiment, helium and steam were coinjected into the steam generator foundation (D Loop) compartment (Cell 8). Water sprays were not operated during this experiment. The helium and steam mass flow rates were constant at $0.027 \mathrm{~kg} / \mathrm{s}$ and $0.33 \mathrm{~kg} / \mathrm{s}$, respectively, during the 30-minute injection period. It was assumed that helium and saturated steam were injected into the containment at $20^{\circ} \mathrm{C}$ and $110^{\circ} \mathrm{C}$, respectively.

The models discussed in Section 2 were used in the calculations for test M-4-3 except for those models pertaining to water sprays. The results using different flow solvers and nodalization schemes were nearly identical so that the selection of the "best" prediction was somewhat arbitrary. Since the calculation using the XBG version and the 28 -node scheme predicted the concentration and temperature gradients slightly better in some rooms, the results of this calculation will be presented in this section.

The results for the best-estimate predictions of the helium concentrations and their comparison with the data are shown in Figures 3.1-3.3. Figure 3.1 shows the results for the steam generator foundation room (Cell 8), which is the source compartment, and all of the rooms directly above it. Figure 3.2 shows the results for a vertical column of outer rooms: the lower general compartment (Cell 4) and the rooms directly above it. Figure 3.3 shows results for a number of rooms in the center of the containment, including the pressurizer compartment (Cell 16).

In general, the trends of the predicted results agreed with the data. Typically, the difference between the final predicted and measured concentrations was less than $12 \%$ although the discrepancies were larger in the source room (Compartment 8 ) and the steam generator rooms above it during the injection phase. The final predicted concentration in the dome was approximately $4 \%$ lower than the measured value. Except for Compartments 1, 16, and 22, the helium was fairly well mixed throughout the containment which was due, in part, to the low elevation of the release point and the relatively open geometry of the facility. It seems reasonable that the pressurizer room (Compartment 22) and the dead-end room connected to it (Compartment 16) would have low helium concentrations. The small openings to these rooms are located high in the dome and there was no means of strong mixing, such as water sprays, at that location. The code predicted the helium concentrations in these compartments reasonably well. 
Low helium concentrations were also measured in the in-core chase (Compartment 1), which is a reasonably complicated geometry: two vertical sections of the room are connected by a horizontal section, as shown in Figure 2.2. One of the vertical sections was an annular region and had small square connections $(0.241 \mathrm{~m}$ on a side) at an elevation of $4.53 \mathrm{~m}$ to the source room (steam generator foundation, Compartment 8 ) as well as the other steam generator foundation rooms. The elevation of the horizontal room was $2.097 \mathrm{~m}$ and was below the operating deck and the source room, which were at $3.200 \mathrm{~m}$. The horizontal section protruded into the water storage tank room below the operating deck. The helium gas sample tube and the thermocouple in Compartment 1 were located in the horizontal section at an elevation of approximately $2.64 \mathrm{~m}$. As shown in Figure 3.6, the gas temperature at this location was

approximately $30^{\circ} \mathrm{C}$ and was similar to the water temperature. There are two possible reasons for the low helium concentration measurements in the horizontal section of the in-core chase room. The horizontal section was below the source and typically mixing does not occur below the source. Also, the openings into the in-core chase were approximately $1.3 \mathrm{~m}$ above the top of the horizontal section. Its reasonable to assume that it would be easier for the gases coming from the source compartment to flow into other steam generator compartments at the same elevation rather than to push the cooler, denser gases in the horizontal section through the vents in the other vertical section.

The results for the best-estimate predictions of the gas temperatures and their comparison with the data are shown in Figures 3.4-3.6. The results are for the same set of rooms used to illustrate the helium results in Figures 3.1-3.3. In general, CONTAIN predicted the correct trends for the temperature histories as well as the vertical temperature gradients. The difference between predicted and measured final gas temperatures was typically less than $2 \%$ on an absolute basis although it was as large as $17 \%$ based on the change in gas temperature. The only significant deviation was the overprediction of the gas temperature in the in-core chase (Compartment 1). In this case, the gas temperature measured in Compartment 1 was significantly lower than the temperatures measured in other rooms on the same floor.

The results for the wall temperatures and their comparison with the data are shown in Figure 3.7. The predictions showed the general trends of the data but did not show as large a vertical temperature gradient along the outer wall. For example, a difference of $26^{\circ} \mathrm{C}$ was measured in the final temperature along the containment wall between the ceiling of the dome (Compartment 25 ) and the lower general room (Compartment 6 ). The predicted difference was only $13^{\circ} \mathrm{C}$. The difference between the predicted and measured final wall temperatures was less than $3 \%$ on an absolute basis although the difference based on the change in wall temperature was much larger. In the worst case, for example, the predicted change in the wall temperature of Cell 6 was approximately $60 \%$ greater than the measured change. These large discrepancies on a relative basis were due, in part, to the relatively small changes measured in the wall temperatures.

The results for gas pressure in the dome and its comparison with the data are shown in Figure 3.8. The pressure was slightly overpredicted although the general trends were correct. On an absolute basis, the final pressure was approximately $4 \%$ greater than the data. On a relative basis, the predicted change in pressure was approximately $10 \%$ greater than the measured change. 


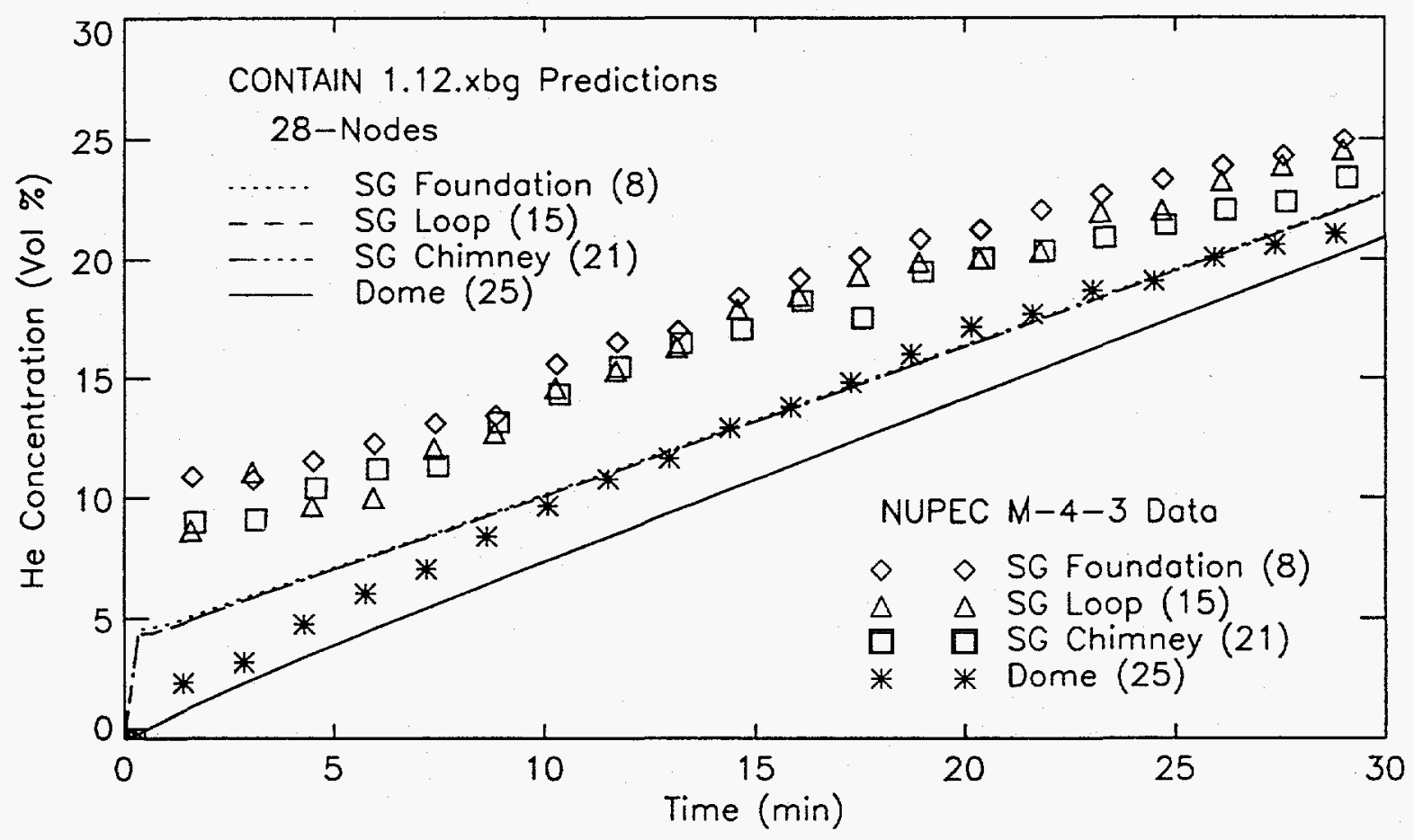

Figure 3.1. Comparison between the CONTAIN predictions and data of the NUPEC Test M-43 helium concentrations for Compartments 8, 15, 21, and 25.

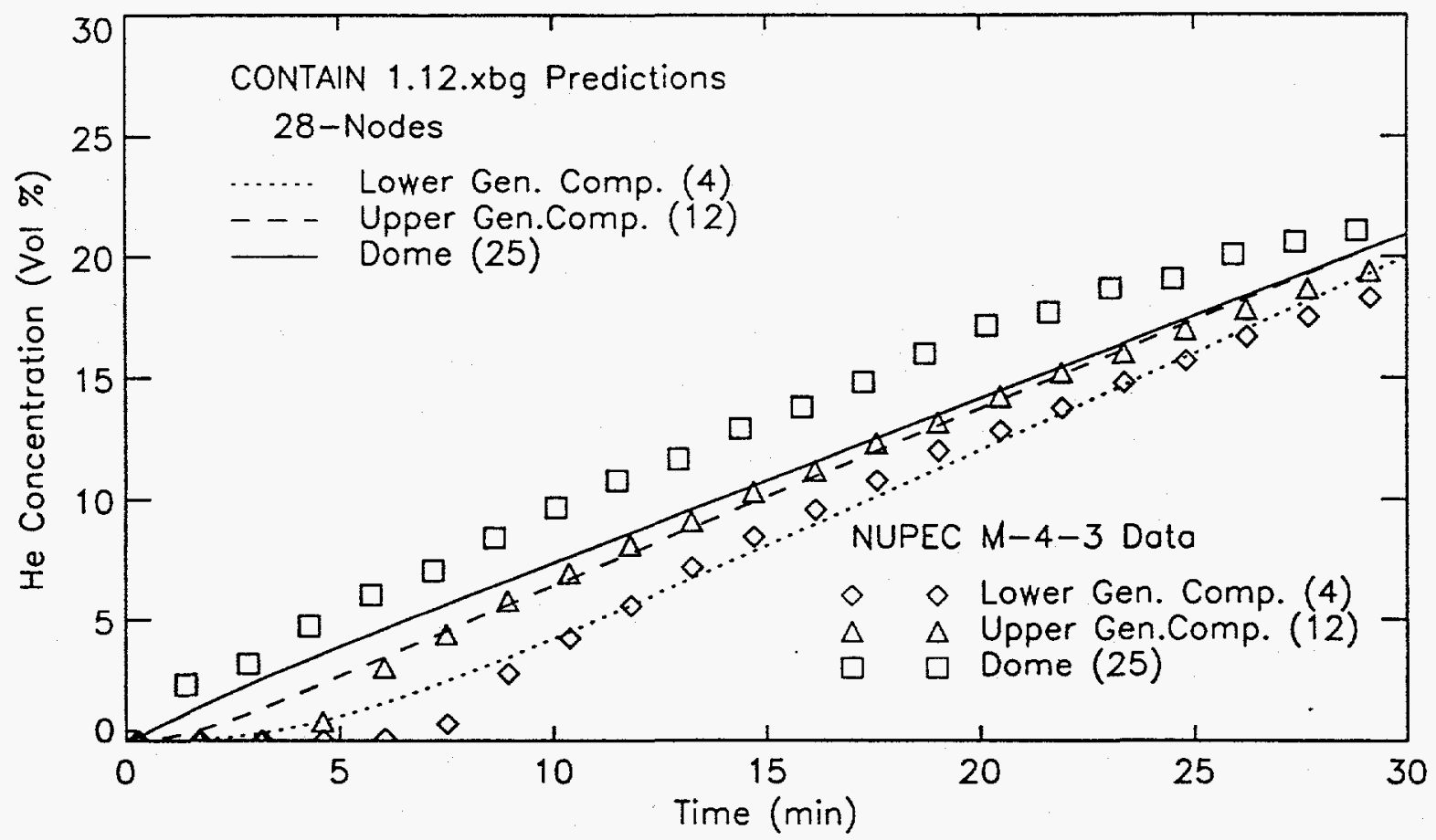

Figure 3.2. Comparison between the CONTAIN predictions and data of the NUPEC Test M-43 helium concentrations for Compartments 4,12 , and 25 . 


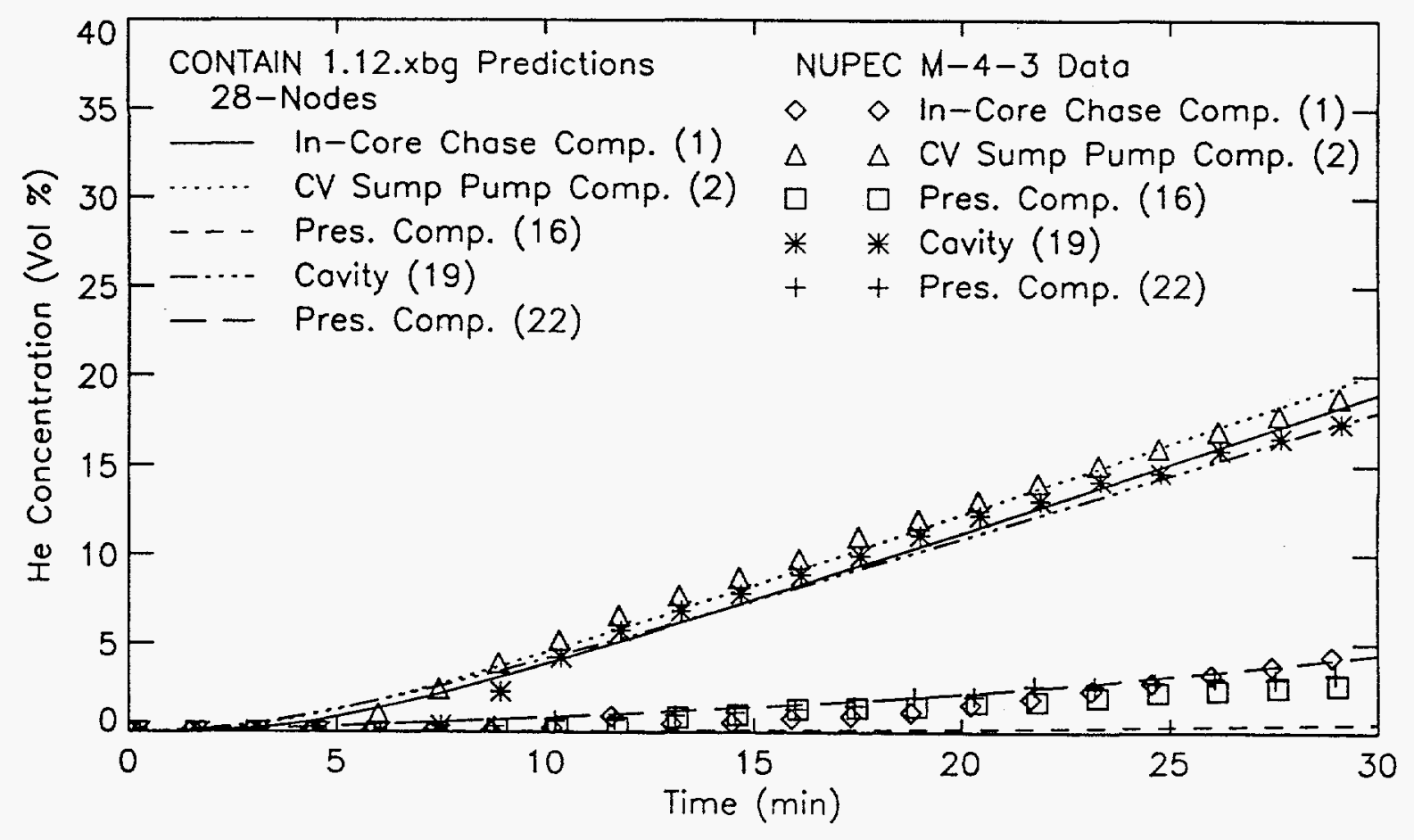

Figure 3.3. Comparison between the CONTAIN predictions and data of the NUPEC Test M-43 helium concentrations for Compartments 1,2, 16, 19, and 22.

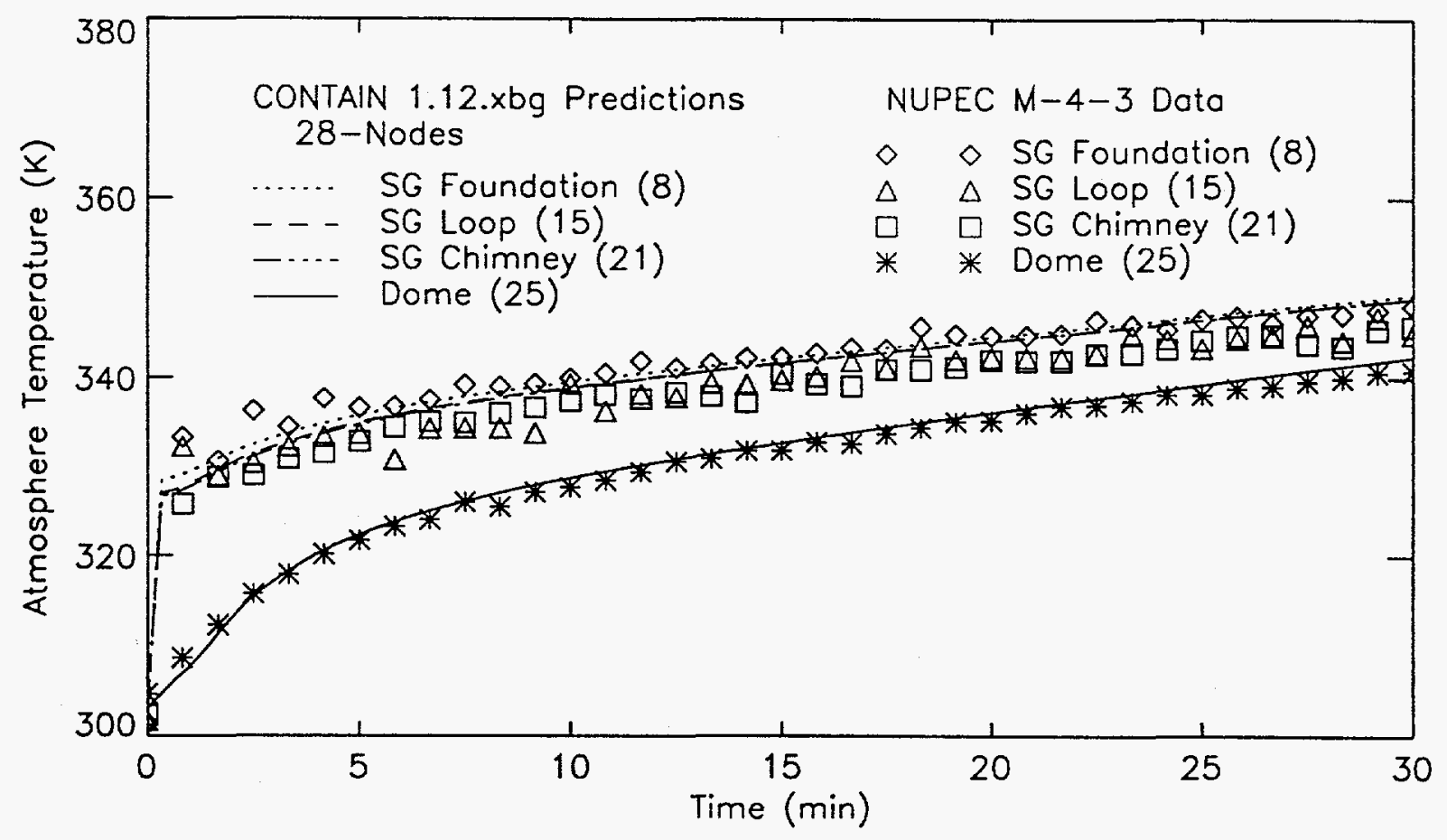

Figure 3.4. Comparison between the CONTAIN predictions and data of the NUPEC Test M-43 gas temperatures for Compartments $8,15,21$, and 25 . 


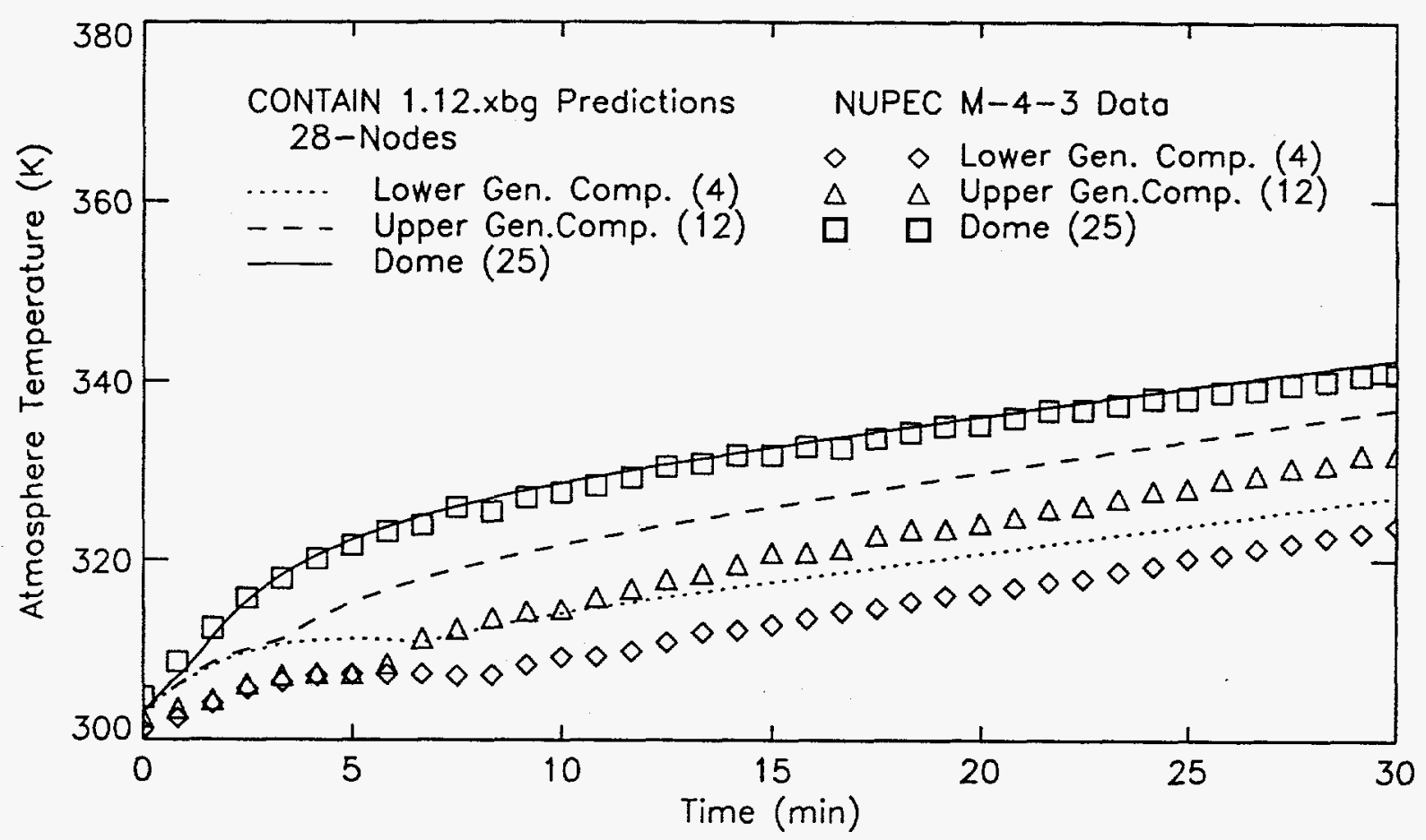

Figure 3.5. Comparison between the CONTAIN predictions and data of the NUPEC Test M-43 gas temperatures for Compartments 4, 12, and 25 .

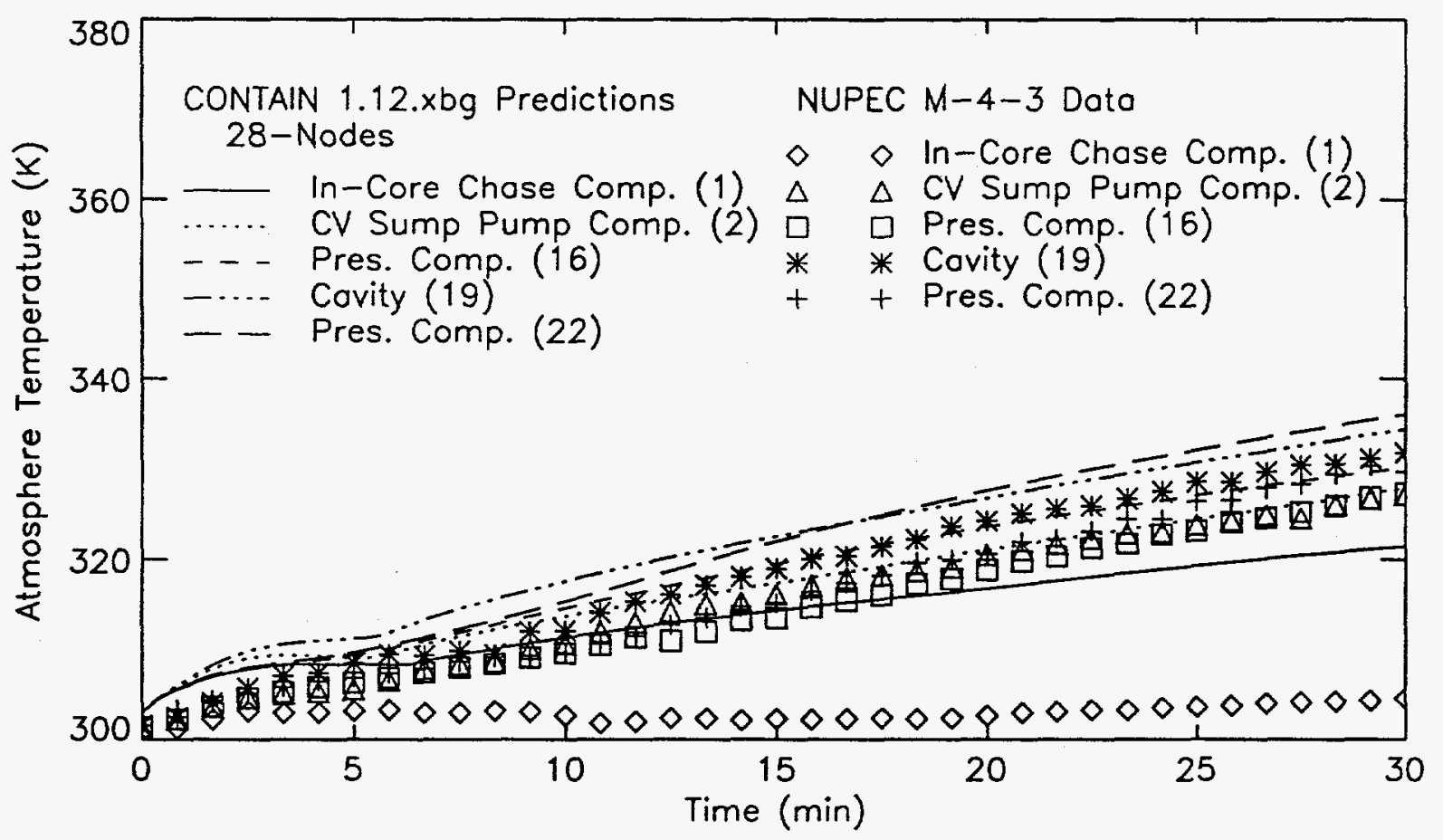

Figure 3.6. Comparison between the CONTAIN predictions and data of the NUPEC Test M-43 gas temperatures for Compartments 1,2,16, 19, and 22 . 


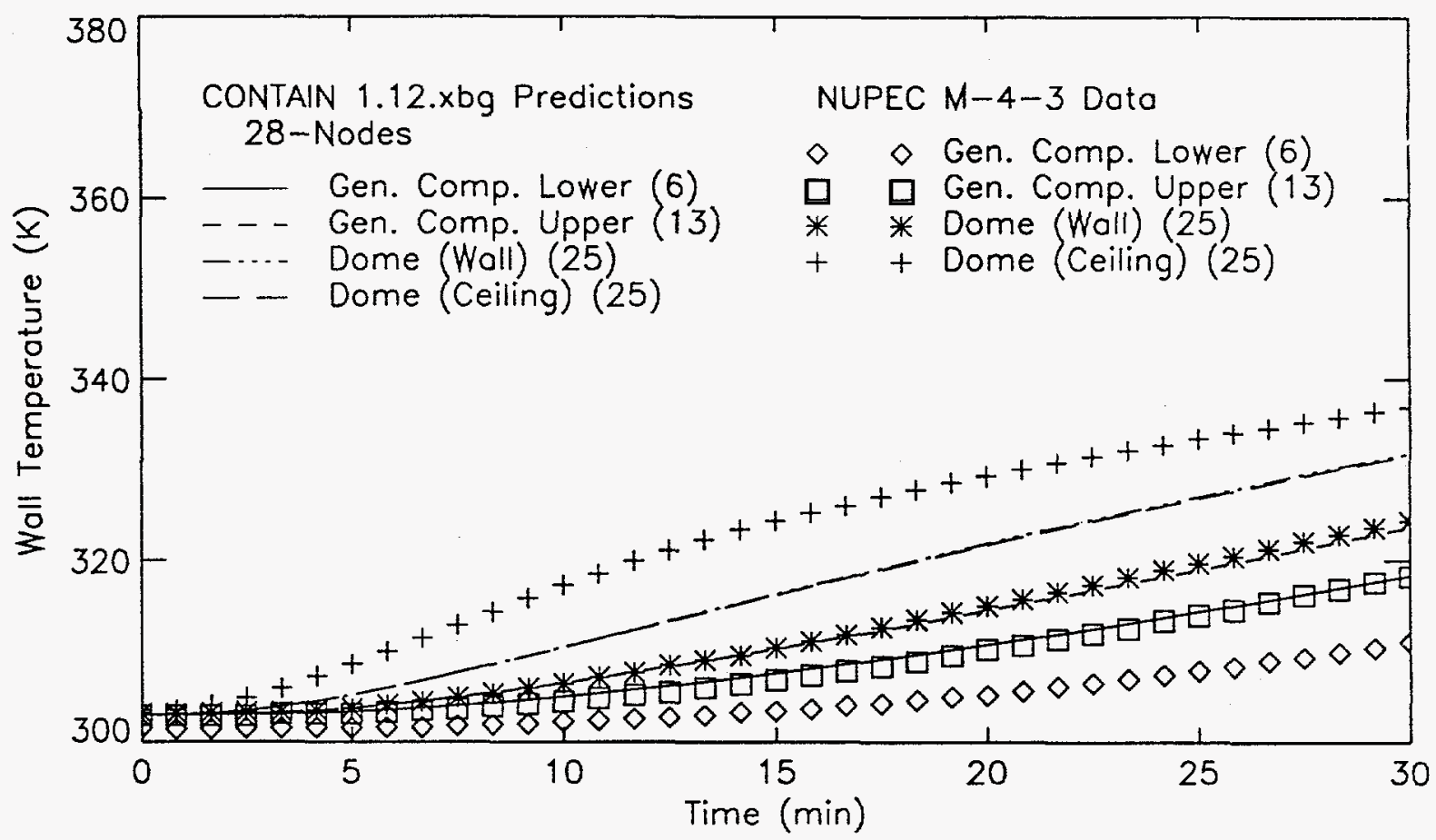

Figure 3.7. Comparison between the CONTAIN predictions and data of the NUPEC Test M-43 wall temperatures for Compartments 6,13 , and 25.

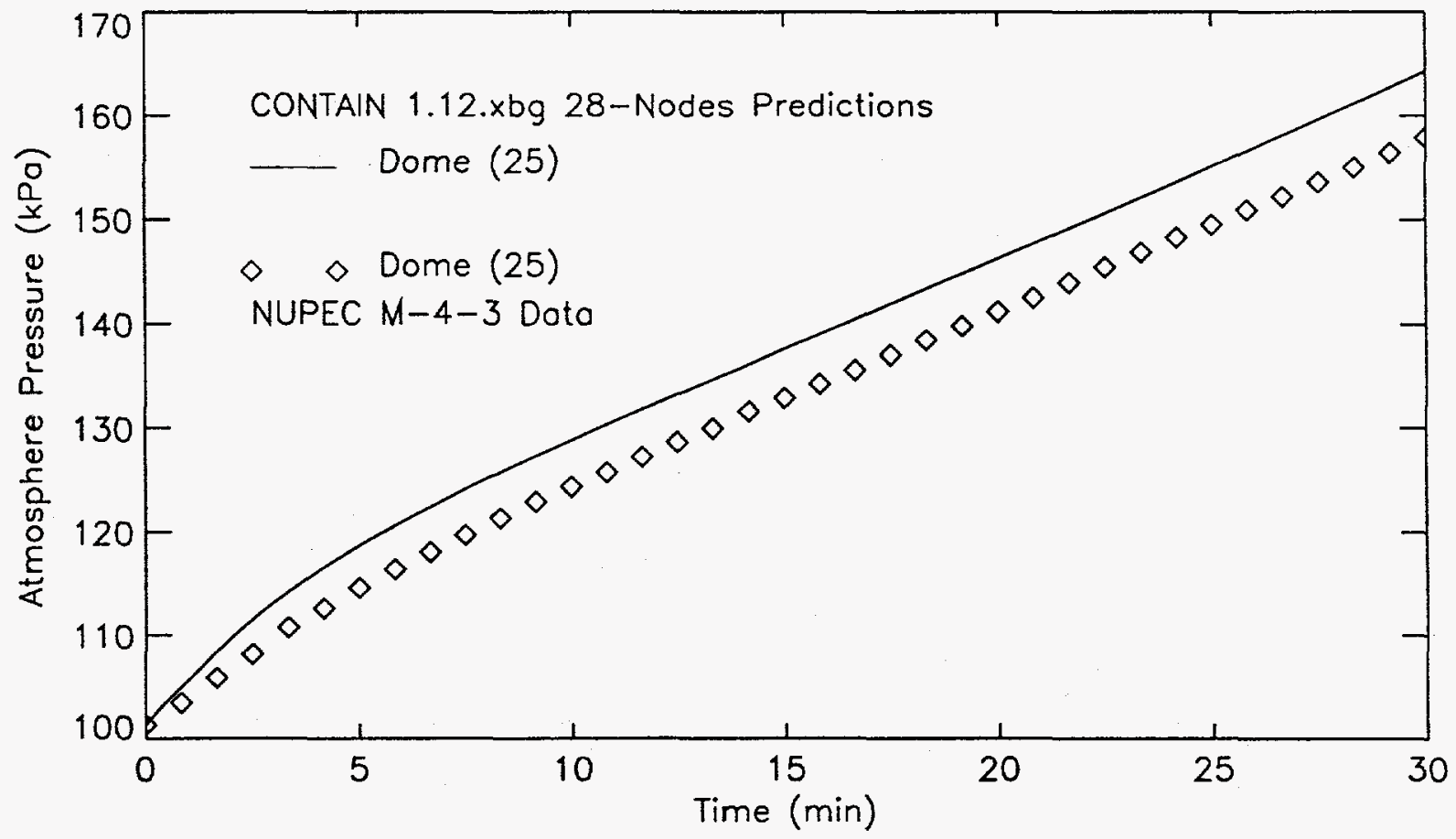

Figure 3.8. Comparison between the CONTAIN prediction and data of the NUPEC Test M-43 gas pressure for Compartment 25. 


\subsection{CONTAIN Assessment of NUPEC Test M-5-5}

The gas pressure at the beginning of test M-5-5 was approximately $101 \mathrm{kPa}$ and the structure and gas temperatures were approximately $7^{\circ} \mathrm{C}$ to $17^{\circ} \mathrm{C}$. At the beginning of the experiment, helium was injected into the steam generator foundation (D Loop) compartment (Cell 8) while water sprays were injected into the hemisphere region of the dome (Cell 25). The helium and spray water were injected at a constant mass flow rate of $0.027 \mathrm{~kg} / \mathrm{s}$ and $19.4 \mathrm{~kg} / \mathrm{s}$, respectively, during the 30-minute injection period. It was assumed that both the helium and water sprays were injected into the containment at $19^{\circ} \mathrm{C}$. The spray water was injected through 21 hollow-cone nozzles located in the hemispherical region of the dome. The average droplet diameter was assumed to be $0.75 \mathrm{~mm}$.

The models discussed in Section 2 were used in the calculations for test M-5-5. In the calculations, sprays were considered in the dome (Compartment 25) only. Because the test was nearly isothermal, the effect of increased forced convection produced by the water sprays on the heat transfer coefficients was not modeled. Only the 28-node scheme was used, but with both code versions. The results for test M-5-5 using different flow solvers were nearly identical so that the selection of the "best" prediction was somewhat arbitrary. Since the calculation using the XBG version predicted the concentration and temperature gradients slightly better in some rooms, the results of this calculation will be presented in this section.

The results for the best-estimate predictions of the helium concentrations and their comparison with the data are shown in Figures 3.9-3.11. Figure 3.9 shows the results for the steam generator foundation room (Cell 8), which is the source compartment, and all of the rooms directly above it. Figure 3.10 shows results for a vertical column of outer rooms: the lower general compartment (Cell 4) and the rooms directly above it. Figure 3.11 shows results for a number of rooms in the center of the containment.

In general, the trends of the predicted results agreed with the data. With the exception of three of the central rooms, the difference between the final predicted and measured concentrations was less than $28 \%$ and typically much better. For example, the final predicted concentration in the dome was nearly equal to the measured value. However, CONTAIN poorly predicted the helium concentration in three of the rooms in the center of the containment (Compartments 1 , 16, and 22). Except for Compartment 1, the helium was fairly well mixed throughout the containment which was due, in part, to the mixing by water sprays, the low elevation of the release point, and the relatively open geometry of the facility. The measured helium concentrations in the pressurizer compartments (Compartments 16 and 22) were significantly higher in test M-5-5 than in test M-4-3 due to the enhanced mixing from the water sprays. However, CONTAIN does not model the hydrodynamics of this enhanced mixing so that the predicted results were nearly equal to those for test M-4-3. As in test M-4-3, low helium concentrations were measured in the in-core chase (Compartment 1). CONTAIN substantially overpredicted the measured helium concentration in this room. As discussed in Section 3.1, it is not clear why the discrepancy between the predicted and measured helium concentrations was so large for this room.

The results for the best-estimate predictions of the gas temperatures and their comparison with the data are shown in Figures 3.12-3.14. The gas temperature results are shown for the same set of rooms used to illustrate the helium results in Figures 3.9-3.11. Because the test was 
nearly isothermal, differences between the measured and predicted gas temperatures will not be emphasized for this test. This is especially true on a relative basis, which has less meaning since the changes in the temperature were so small. At the time these calculations were performed, detailed information on the individual room temperatures was not available. In general, the predicted final temperatures are within $2^{\circ} \mathrm{C}$ of the measured value. Similar statements can be made about the wall temperatures. The results for the wall temperatures and their comparison with the data are shown in Figure 3.15. It is likely that the slight increase in the measured wall temperatures was not predicted because the enhanced heat transfer from the spraydriven convection loops was not modeled.

The results for the gas pressure in the dome and its comparison with the data are shown in Figure 3.16. The predicted pressure was in nearly perfect agreement with the measured values. Because the test was nearly isothermai, the pressure increase was due to the addition of the noncondensible gas. Because of the good agreement for this test, deviations between the predicted and measured pressures in other tests are most likely due to the inability to model the heat transfer processes correctly. 


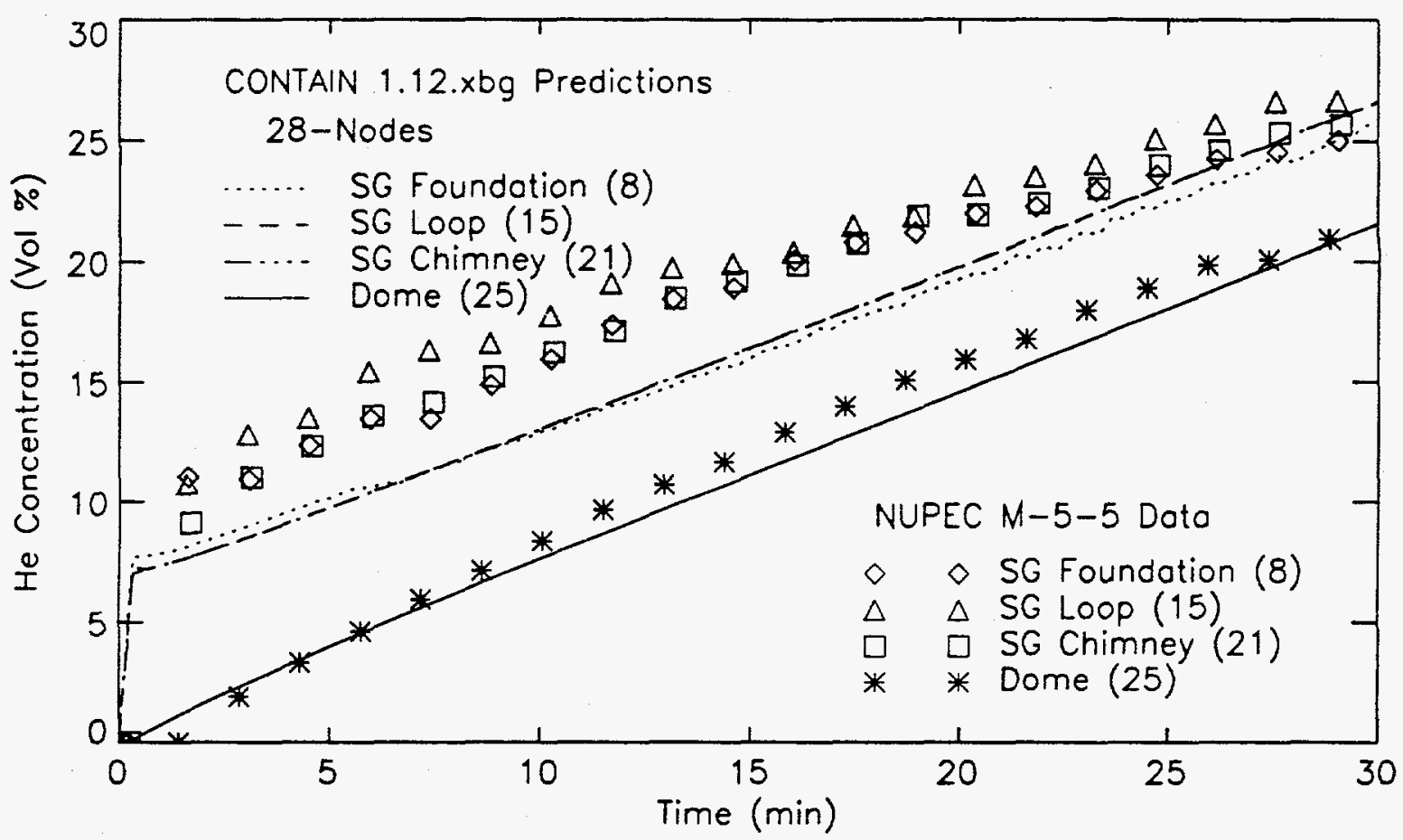

Figure 3.9. Comparison between the CONTAIN predictions and data of the NUPEC Test M-55 helium concentrations for Compartments $8,15,21$, and 25 .

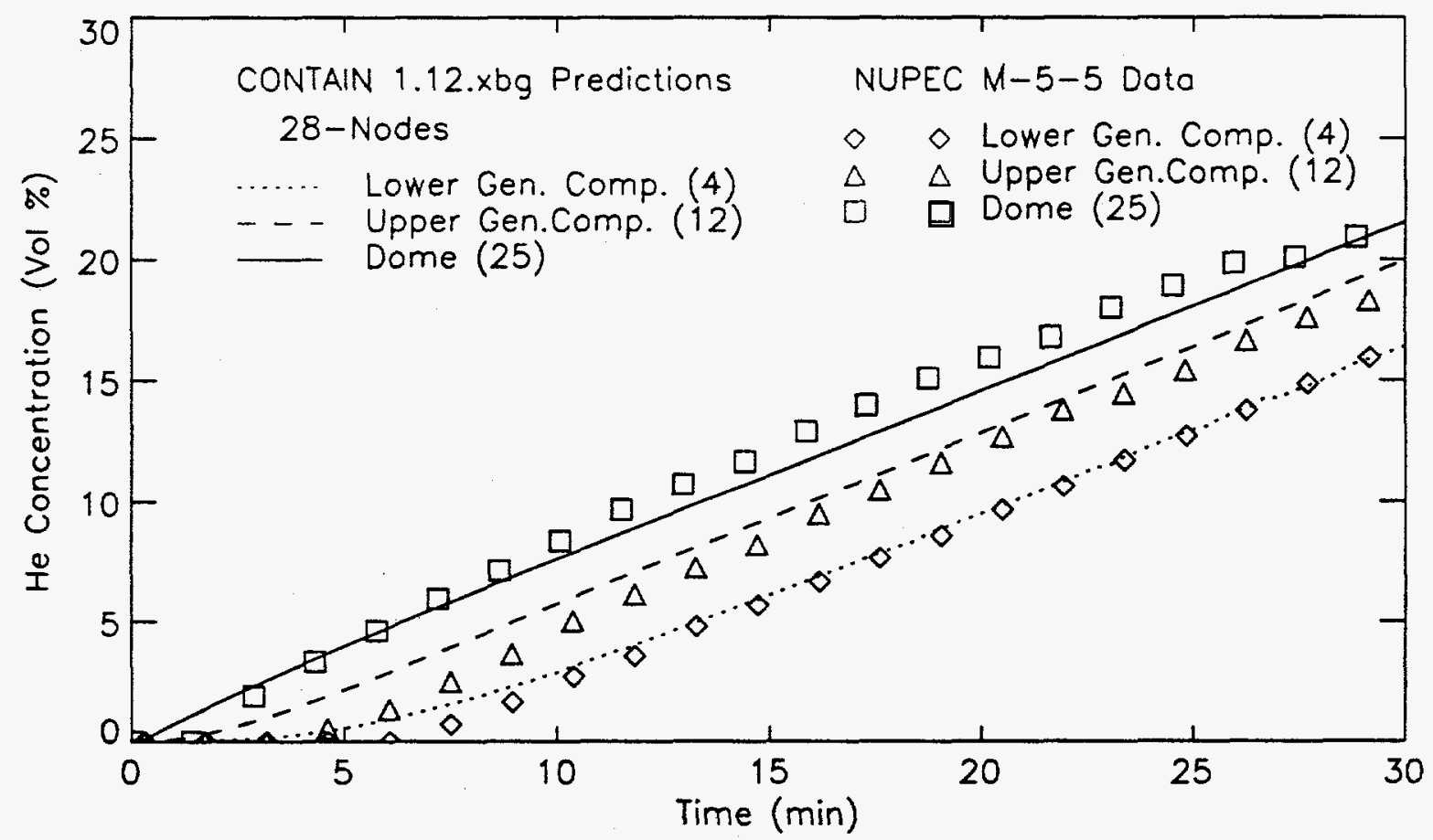

Figure 3.10.Comparison between the CONTAIN predictions and data of the NUPEC Test M5-5 helium concentrations for Compartments 4, 12, and 25. 


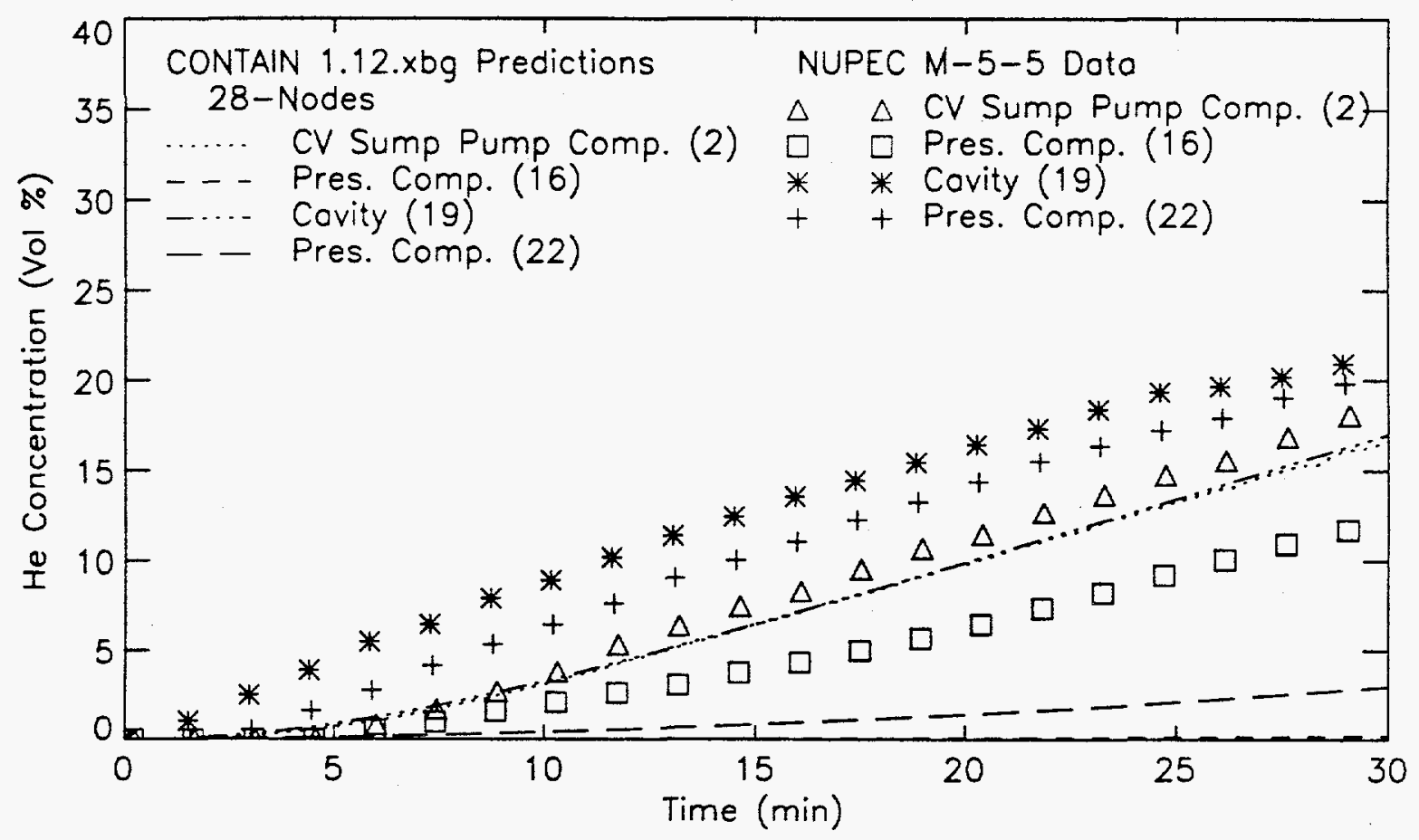

Figure 3.11.Comparison between the CONTAIN predictions and data of the NUPEC Test M5-5 helium concentrations for Compartments 2, 16, 19, and 22.

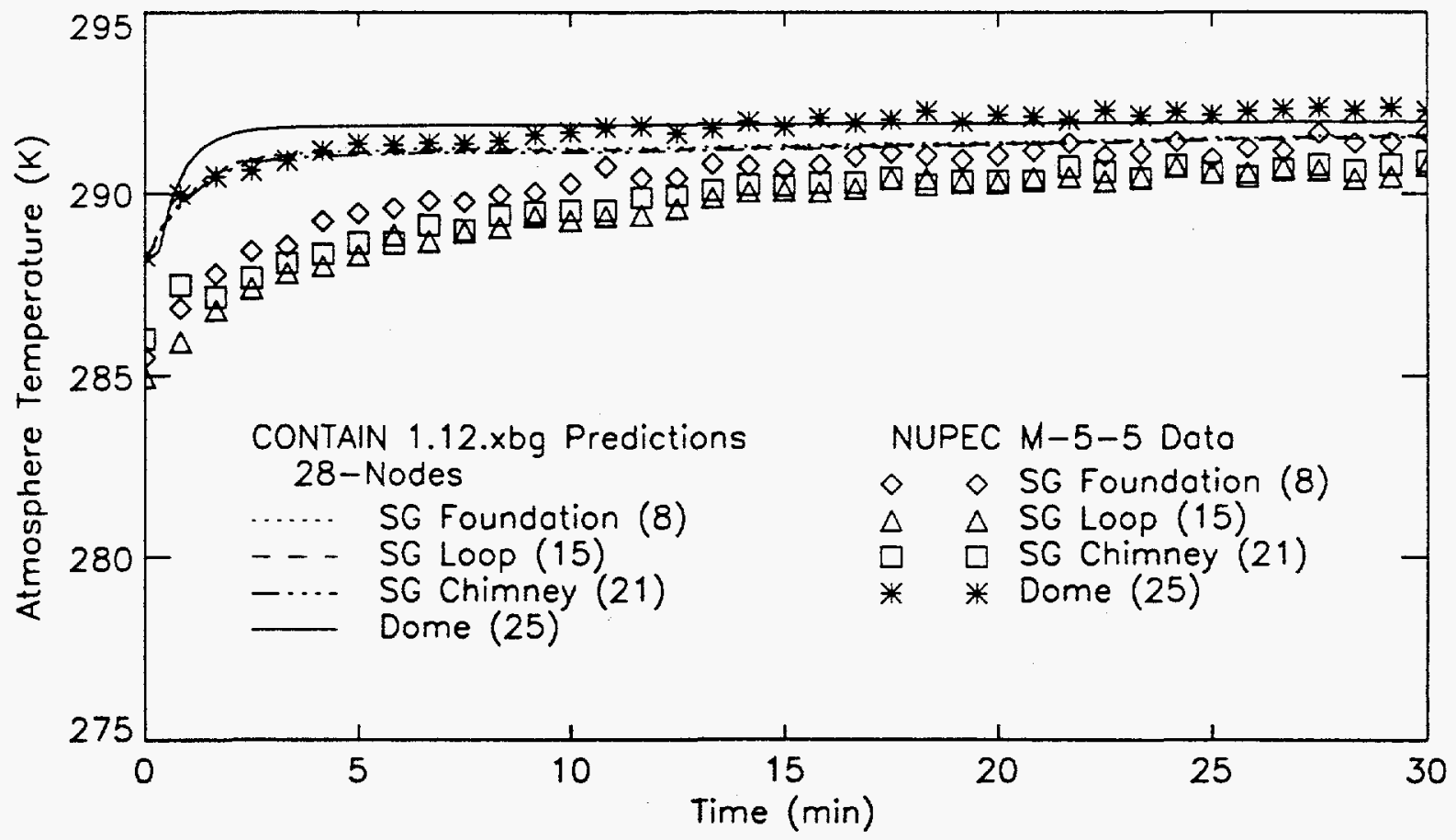

Figure 3.12.Comparison between the CONTAIN predictions and data of the NUPEC Test M5-5 gas temperatures for Compartments $8,15,21$, and 25. 


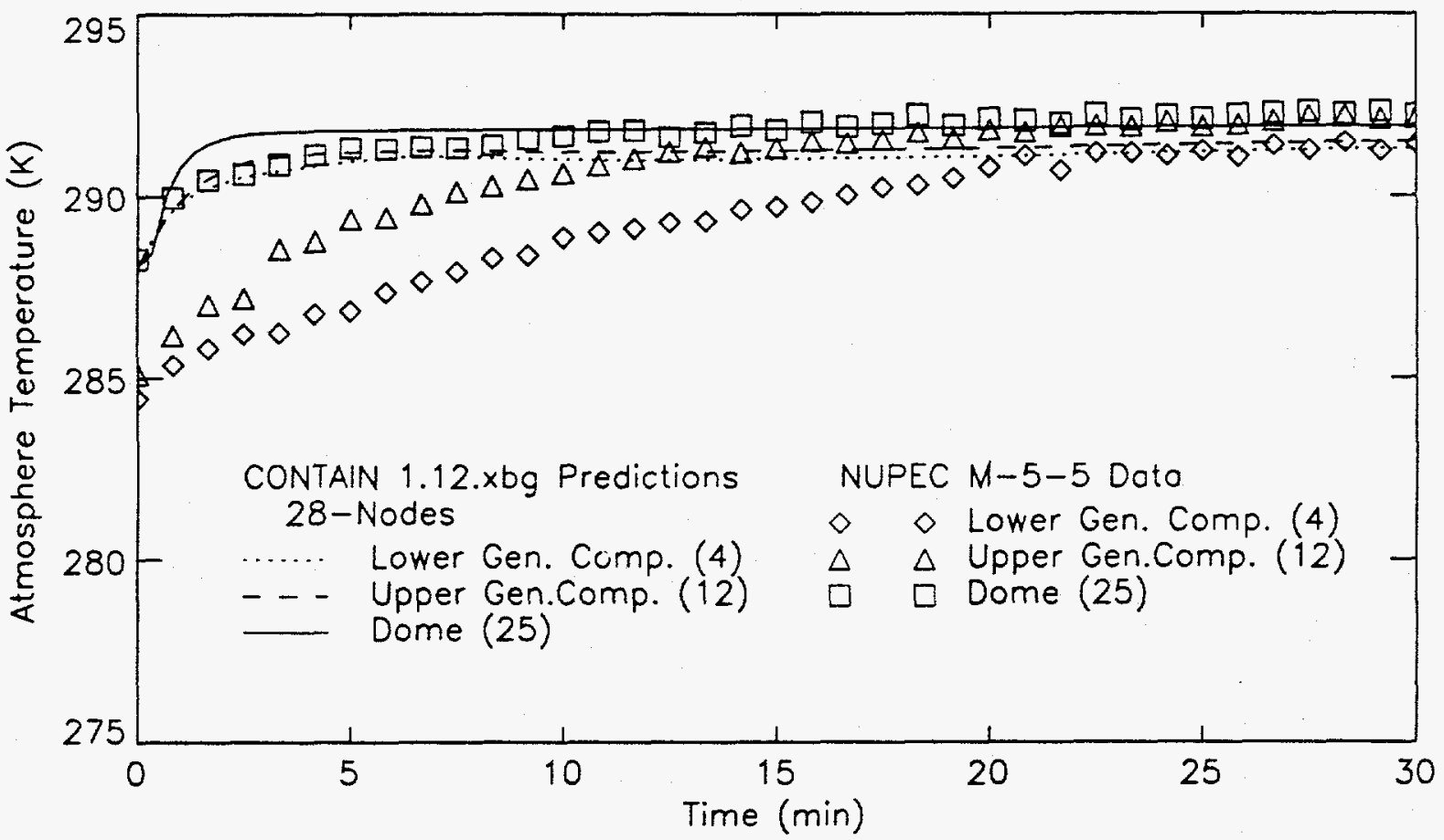

Figure 3.13.Comparison between the CONTAIN predictions and data of the NUPEC Test M5-5 gas temperatures for Compartments 4,12 , and 25.

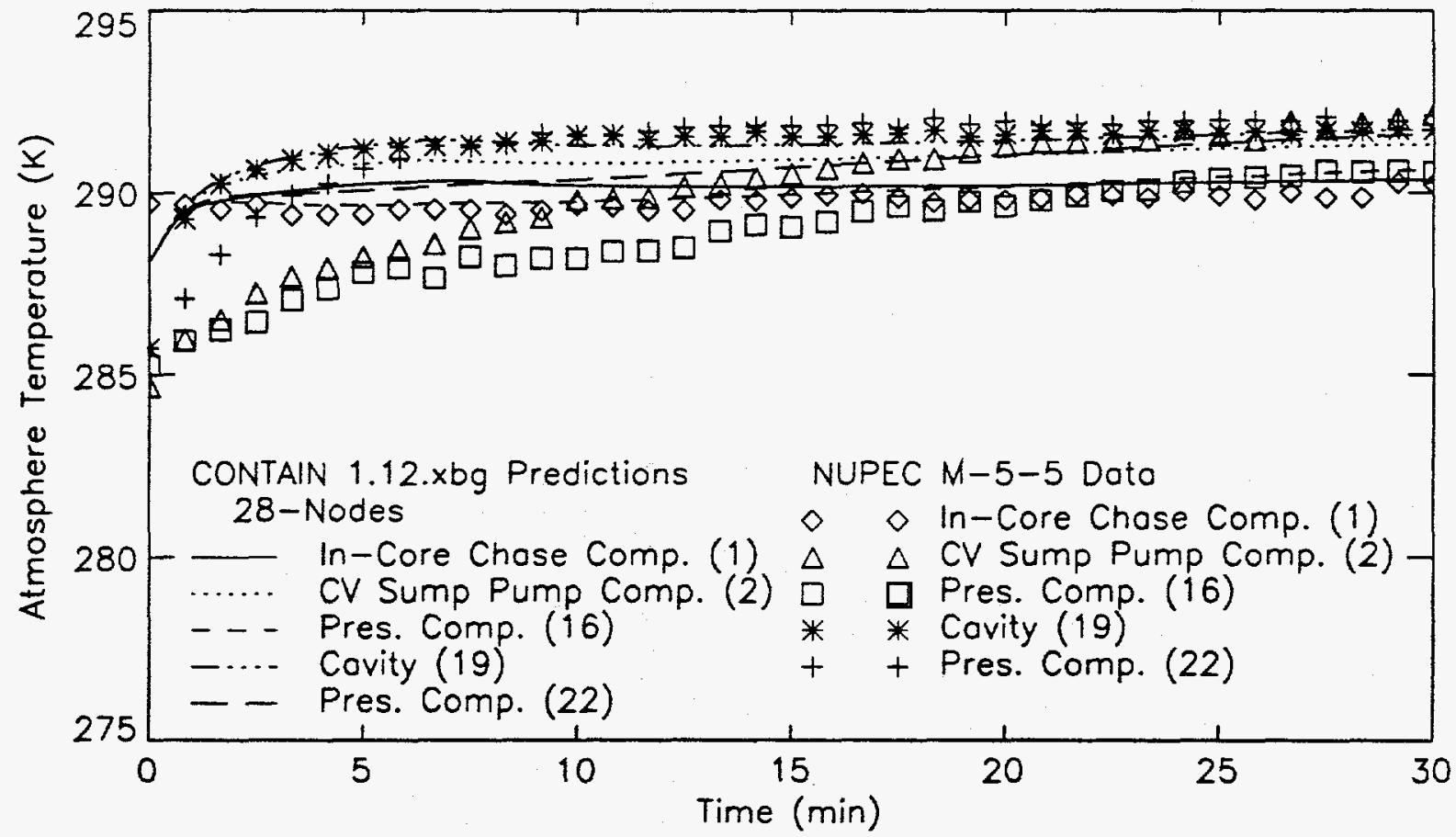

Figure 3.14.Comparison between the CONTAIN predictions and data of the NUPEC Test M5-5 gas temperatures for Compartments $1,2,16,19$, and 22 . 


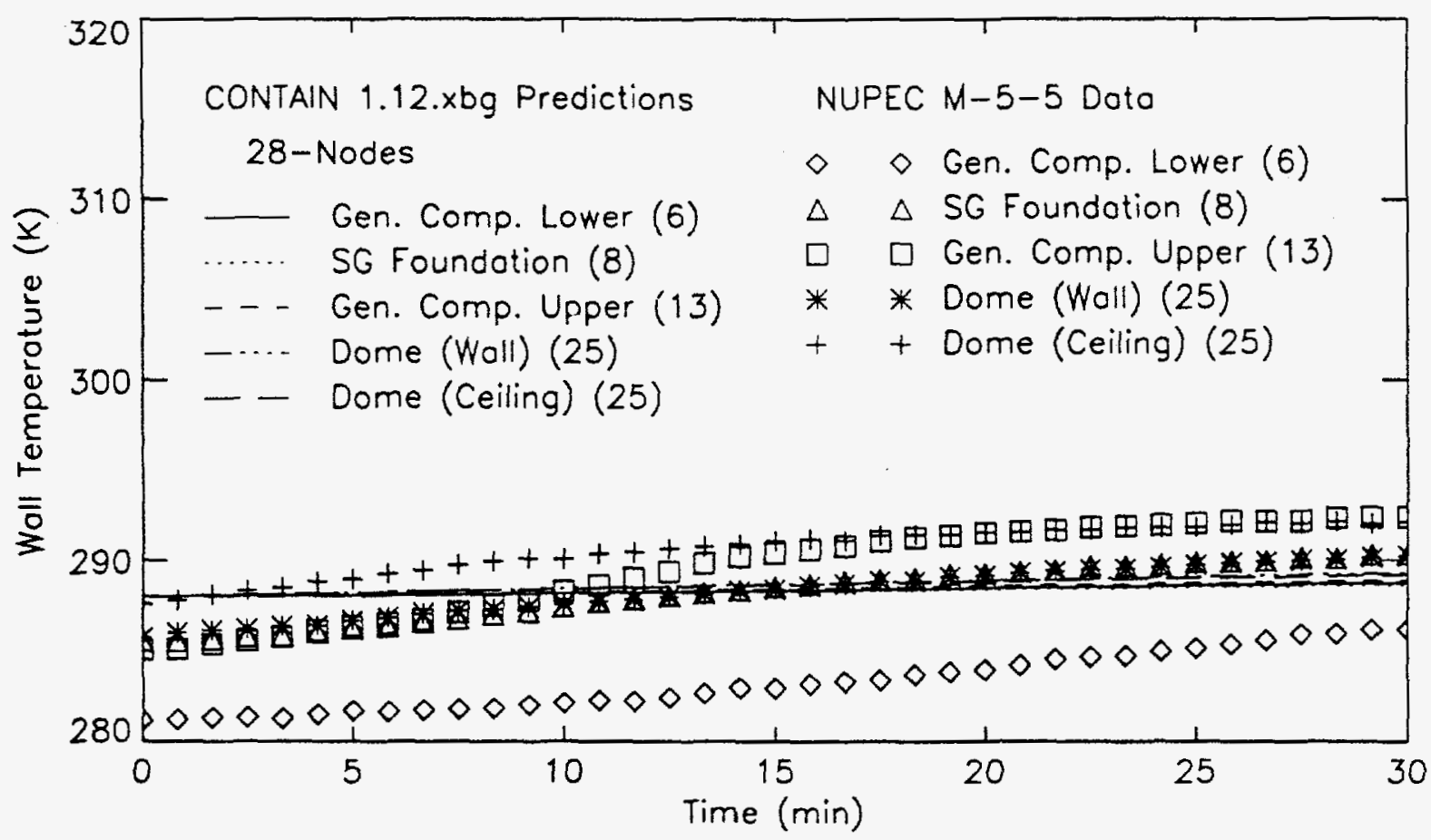

Figure 3.15.Comparison between the CONTAIN predictions and data of the NUPEC Test M5-5 wall temperatures for Compartments 6,13 , and 25.

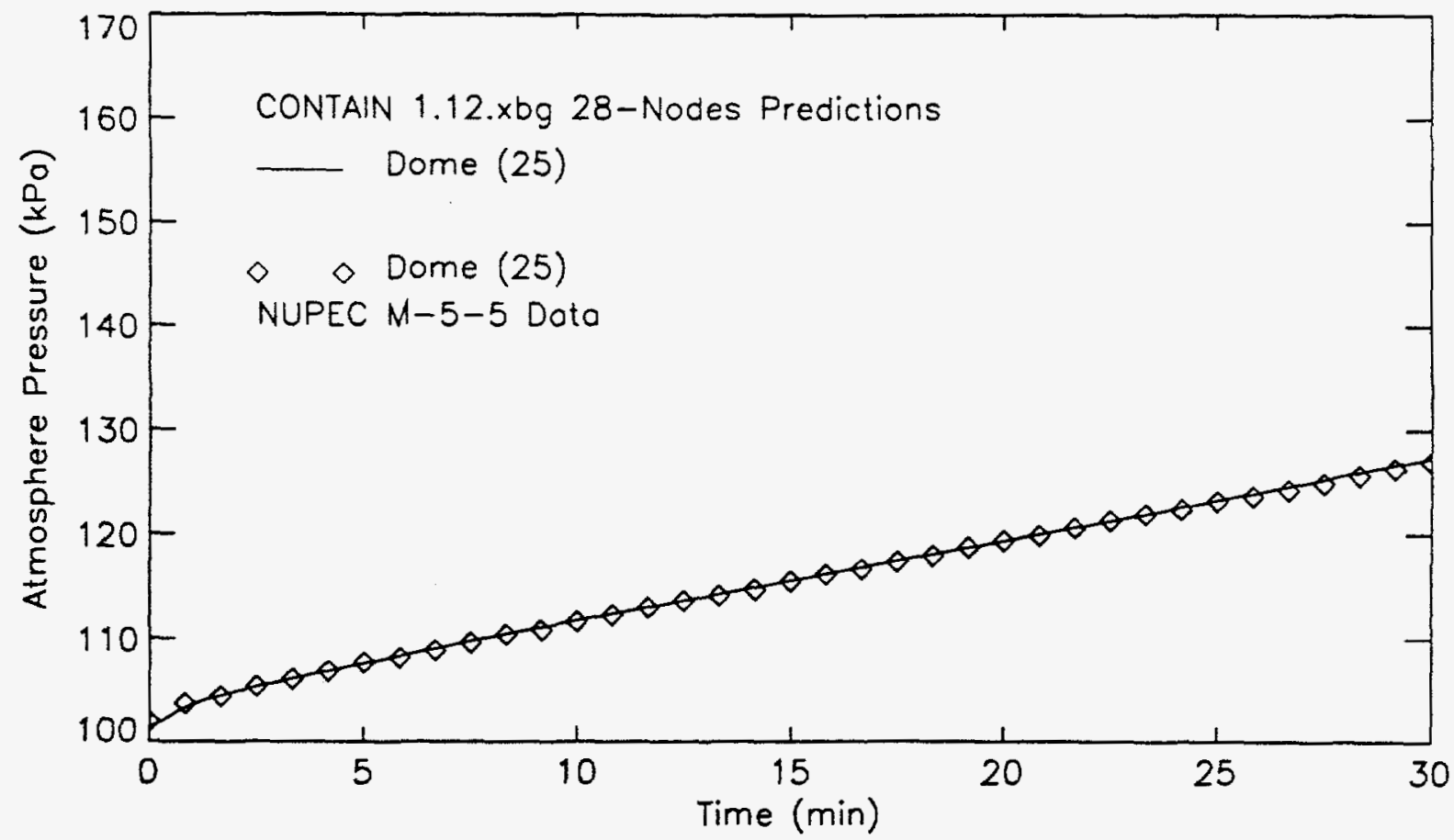

Figure 3.16.Comparison between the CONTAIN prediction and data of the NUPEC Test M-55 gas pressure for Compartment 25 . 


\subsection{CONTAIN Assessment of NUPEC Test M-7-1}

The containment was preheated by injecting steam into the steam generator foundation compartment $\mathrm{D}$ loop (Cell 8) for 210 minutes before the start of the test. The steam was injected at approximately $110^{\circ} \mathrm{C}$ and a flow rate of $0.10 \mathrm{~kg} / \mathrm{s}$ for the first 188 minutes, and then $0.08 \mathrm{~kg} / \mathrm{s}$ for the next 15 minutes. The test was started 7 minutes later.

The data for gas pressure in the dome (Cell 25) and gas temperatures in the containment volume sump pump room (Cell 2), the cavity (Cell 19), and the dome (Cell 25) during the preheat phase are shown as the symbols in Figures 3.17 and 3.18, respectively. The peak pressure was $143.3 \mathrm{kPa}$ and the peak gas temperatures ranged from $63^{\circ} \mathrm{C}$ at the bottom of the containment to $68^{\circ} \mathrm{C}$ at the top.

CONTAIN was used to predict the thermal hydraulics for the preheat phase. The best-estimate prediction for the gas pressure is shown as the thick continuous line in Figure 3.17. This prediction was made using the 35-cell nodalization scheme. Material properties and source conditions specified by the NUPEC organization were used in the calculation. The predicted peak pressure of $151.1 \mathrm{kPa}$ was $7.8 \mathrm{kPa}$, or $5.4 \%$, greater than the measured peak pressure. The uncertainty in the pressure measurement was $\pm 3 \mathrm{kPa}$ based on a $3 \sigma$ confidence level [1]. The change in pressure from the beginning of the preheat phase to the time at peak pressure was predicted to be $51.1 \mathrm{kPa}$, or $18 \%$, greater than the measured value of $43.3 \mathrm{kPa}$. Possible reasons for this discrepancy are discussed in Section 4.2.1. The best-estimate predictions of the gas temperatures are shown in Figure 3.18. Predicted peak gas temperatures were approximately $5^{\circ} \mathrm{C}$, or $1.5 \%$, greater than the measured peak gas temperatures. The uncertainty in the temperature measurement was $\pm 0.6^{\circ} \mathrm{C}$ based on a $3 \sigma$ confidence level [1]. The change between the initial gas temperature and the peak value was predicted to be approximately $11 \%$ greater than the actual change in gas temperatures.

Test M-7-1 began at the end of the preheat phase. The gas pressure at the beginning of the test was $139.7 \mathrm{kPa}$ and the structure and gas temperatures were approximately $65^{\circ} \mathrm{C}$ to $70^{\circ} \mathrm{C}$. At the beginning of the experiment, helium and steam were coinjected into the steam generator foundation (D Loop) compartment (Cell 8) while water sprays were injected into the hemisphere region of the dome (Cell 25). The helium mass flow rate was increased linearly from $0.0 \mathrm{~kg} / \mathrm{s}$ to $0.03 \mathrm{~kg} / \mathrm{s}$ for the first 15 minutes of the experiment and then was decreased linearly to $0.0 \mathrm{~kg} / \mathrm{s}$ during the next 15 minutes. The steam mass flow rate was decreased linearly from $0.08 \mathrm{~kg} / \mathrm{s}$ to $0.03 \mathrm{~kg} / \mathrm{s}$ during the same 30 -minute period. It was assumed that helium and saturated steam were injected into the containment at $14^{\circ} \mathrm{C}$ and $110^{\circ} \mathrm{C}$, respectively. The helium and steam were mixed in a chamber outside of the containment. Water sprays were injected at a constant mass flow rate of $19.4 \mathrm{~kg} / \mathrm{s}$ for the same 30 -minute period at a constant temperature of $40^{\circ} \mathrm{C}$. The spray water was injected through 21 hollow-cone nozzles located in the hemispherical region of the dome. The average droplet diameter was $0.75 \mathrm{~mm}$.

The models discussed in Section 2 were used in the calculation for test M-7-1. Results for the 35 -node scheme were generally better than the 28-node scheme. The results for test M-7-1 using different flow solvers, however, were nearly identical for the 35-node scheme so that the selection of the "best" prediction was somewhat arbitrary. Since the calculation using the W version predicted slightly better results, those results will be presented. Furthermore, test M-7- 
1 was also the ISP-35 and the results using the W version of CONTAIN were submitted for this exercise [1].

An analysis and numerical simulation of water sprays in an unobstructed confined geometry showed that a large air convection loop formed in the containment [2]. The numerical calculation using the CONCHAS-SPRAY code simulated the operation of water sprays in a nuclear power plant, and the spray drop distribution in the simulation was similar to that of the water sprays used in the NUPEC facility. The CONCHAS-SPRAY code calculation showed that a large air vortex formed as a result of the hydrodynamic drag created by the drops falling through the air. The air flowed down the center and up the walls of the containment. This air current concentrated the spray drops into the center of the containment so that the water drops did not hit the walls. These results are shown in Figure 3.19. Heat transfer between the containment wall and the gas was aided by the increased forced convection from the air current. The magnitude of the spray-induced air current velocity can be estimated using the simple equation $u=\sqrt{2 g h}$ where $u$ is a representative air velocity, $g$ is the acceleration due to gravity, and $h$ is the average spray head height above the floor [2]. This equation was obtained by equating the power added to the air current by the drag force to the power removed as the air current initially accelerated the drops [2]. Using this equation and a mass flow rate, weighted, average spray head height of approximately $10 \mathrm{~m}$ for the NUPEC facility, the representative air current velocity was estimated to be $14 \mathrm{~m} / \mathrm{s}$. It was estimated that the water drops fell at a terminal velocity of approximately $3-4 \mathrm{~m} / \mathrm{s}$ relative to the air current. Although the free-fall velocity of the drops is not required for the CONTAIN spray model, this information is given to show the significance of the spray-driven air current.

The procedure used to model test M-7-1 with CONTAIN was to nodalize the NUPEC facility with a central core and annular region of cells using the 35-cell nodalization scheme. The dome was subdivided into seven cells. The upper hemispherical region of the dome was one computational cell and the lower cylindrical part of the dome was divided into three annular compartments and three inner compartments in the center of the containment. Water sprays were injected into the upper hemispherical region of the dome (Cell 25) and each subsequent central cell in the dome (Cells 30,32, and 34, respectively). The spray water in each subsequent lower cell was supplied with water from the pool in the cell immediately above it. The spray mass flow rate was assumed to be equal to the injected rate, in spite of the reduction in cross-sectional area from Cell 25 to Cell 30, because it was assumed that the air current concentrated the water drops in the center of the containment. No water was assumed to impinge on the containment wall. Spray water was introduced into all of the lower compartments with direct vertical connections to Cell 34 and all subsequent compartments below it. The spray mass flux was scaled according to the reduction in area between two vertically connected rooms. Any spray that did not fall into the lower rooms was collected in a pool and eventually drained into the water storage area under the bottom floor. In all cases, the spray mass flux was assumed to be uniform over the cross-sectional area. The outer rooms in the facility (Cells 3$6,12-13,29,31$, and 33) did not receive any spray water. Since CONTAIN cannot model the hydrodynamic drag between the drops and the air, the hydrodynamics of the large air current was not modeled in any of the tests. However, the enhanced heat transfer due to this air current was accounted for by imposing a $14 \mathrm{~m} / \mathrm{s}$ air velocity in the heat transfer correlations for 
the containment wall and all structures inside the containment. A best-estimate calculation was made using this procedure.

The results for the best-estimate predictions of the helium concentrations and their comparison with the data are shown in Figures 3.20-3.22. Figure 3.20 shows the results for the steam generator foundation room (Cell 8), and all of the rooms directly above it. Figure 3.21 shows results for a vertical column of outer rooms: the lower general compartment (Cell 4) and the rooms directly above it. Figure 3.22 shows results for a number of rooms in the center of the containment, including the source room (Compartments 22 and 35) and the pressurizer compartment (Cell 16), which is a dead-end compartment.

In general, the trends of the predicted results agreed with the data. Typically the difference between the predicted and measured concentrations was less than $15 \%$ and, as shown in Figures 3.20-3.22, was generally much better than that. The helium concentrations in one column of steam generator rooms (Cells 10,17, and 23) were overpredicted by a factor of 2 at one point during the transient due to a predicted branching flow from the source compartment that did not actually exist. However, the predicted final concentrations in these rooms were within $10 \%$ of the data. The results for Cells 10, 17, and 23 are not illustrated in Figures 3.20-3.22 but are cited to illustrate an exception to the error estimates. The predicted concentration in the dome was in nearly perfect agreement with the data. The helium was fairly well mixed throughout the containment, which was primarily a result of the water sprays, but was also due to the low elevation of the release point and the relatively open geometry of the facility. Even the pressurizer compartments, Cells 22 and 16, had helium concentrations of $11.9 \%$ and $11.3 \%$, respectively, which were similar to those of the rest of the containment. Cell 16 results were predicted reasonably well using the 35 -node representation, in which the pressurizer compartment (Cell 22) was subdivided, but the results were not predicted well using the 28node representation, in which Cell 22 was not subdivided. In fact, using the 28-node representation, the final helium concentrations were approximately $1 \%$ and nearly $0 \%$ in Cell 22 and Cell 16, respectively. This compared with approximately $12.3 \%$ and $12.0 \%$ for these two cells using the 35-node representation. This example illustrates the large effect that different nodalization schemes can have on predicted mixing behavior of a light gas, such as helium or hydrogen, in local regions and has important implications when using lumped-parameter codes to design hydrogen control schemes for containments.

The results for the best-estimate predictions of the gas temperatures and their comparison with the data are shown in Figures 3.23-3.25. The gas temperature results are shown for the same set of rooms used to illustrate the helium results in Figures 3.20-3.22. The difference between the predicted and measured final gas temperatures was less than $4 \%$ on an absolute basis although the discrepancy was much larger based on the change in gas temperature. Because the water spray temperature was only $30^{\circ} \mathrm{C}$ less than the initial gas temperature, the drop in gas temperature during the 30 -minute period the sprays were operating was relatively small at only about $18-23^{\circ} \mathrm{C}$. In the outer rooms, especially, the predicted change in temperature was only about one third of the actual change. In the experiment, it would be expected that the large air current driven by the sprays would force cooler air from the center of the containment up through the outside rooms. This was not predicted by CONTAIN since the code does not model the hydrodynamic drag of the water droplets on the air and CONTAIN overpredicted 
the gas temperature in the outer rooms. Likewise, the rate at which the temperature dropped in the dome would have been slower if the energy in the outer rooms could have been convected upward into the dome in the predictions. This might explain why CONTAIN overpredicted the rate of temperature decrease in the dome early in the experiment. A calculation that used a gas velocity of $14 \mathrm{~m} / \mathrm{s}$ to simulate this forced flow through the horizontal flow paths from the middle to the outer rooms yielded better agreement between the dome gas temperature and the data.

The results for the wall temperatures and their comparison with the data are shown in Figure 3.26. The predictions were reasonably good except for the outer compartments below the dome. The wall temperatures in the lower outer compartments, such as Cells 6 and 13, were overpredicted. Based on numerical calculations [2], it is expected that a spray-driven air convection loop would circulate cooler air through these rooms and cool the walls. However, since CONTAIN did not model this effect, the wall temperatures in these rooms were overpredicted. In terms of absolute wall temperatures, the difference between the predicted and measured values was typically less than $5 \%$ although the difference based on the change in wall temperature was much larger. In the worst case, for example, the predicted change in the wall temperature of Cell 4 was only one fourth of the measured change. The wall temperature in the outer compartments, however, was the most difficult to predict. In contrast, the predicted changes in the containment wall temperatures of the dome were within $3-15 \%$ of the measured values at the end of the test.

The predicted gas pressure in the dome and its comparison with the data are shown in Figure 3.27. The general trend was predicted. Initially the pressure dropped as the gas was cooled by the water sprays. Eventually the continuous addition of the noncondensible gas (helium) caused the pressure to increase again. Similar to the prediction for the gas temperatures, the rate at which the pressure dropped was overpredicted early in the experiment. On an absolute basis, the final pressure was approximately $2 \%$ greater than the data. On a relative basis, however, the predicted drop in pressure was only $72 \%$ of the measured change. The final predicted pressure was $3 \mathrm{kPa}$ greater than the measured pressure, which was within the experimental uncertainty of approximately $\pm 3 \mathrm{kPa}$. 


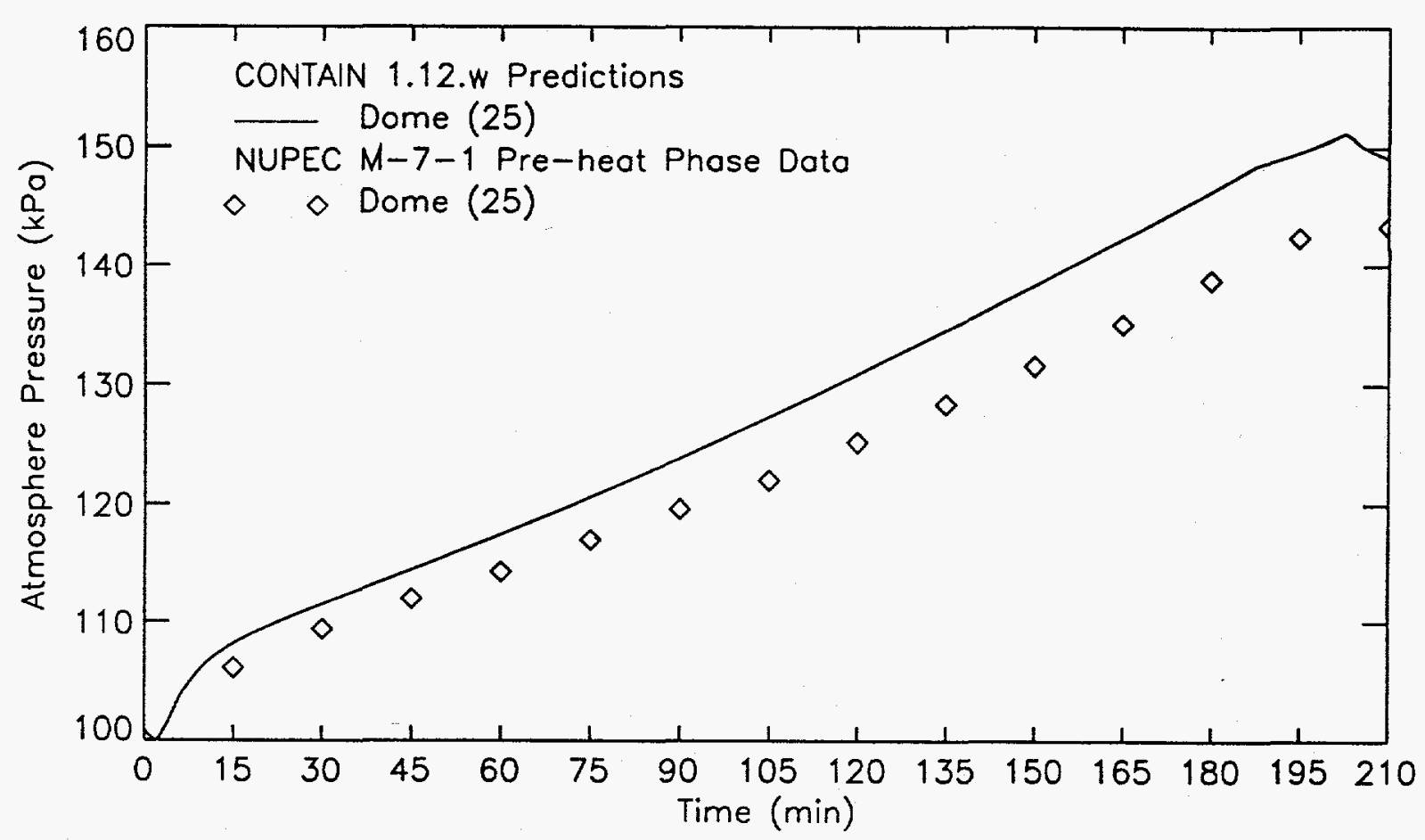

Figure 3.17.Comparison between the CONTAIN predictions and data of the preheat phase of NUPEC Test M-7-1 gas pressure for Compartment 25.

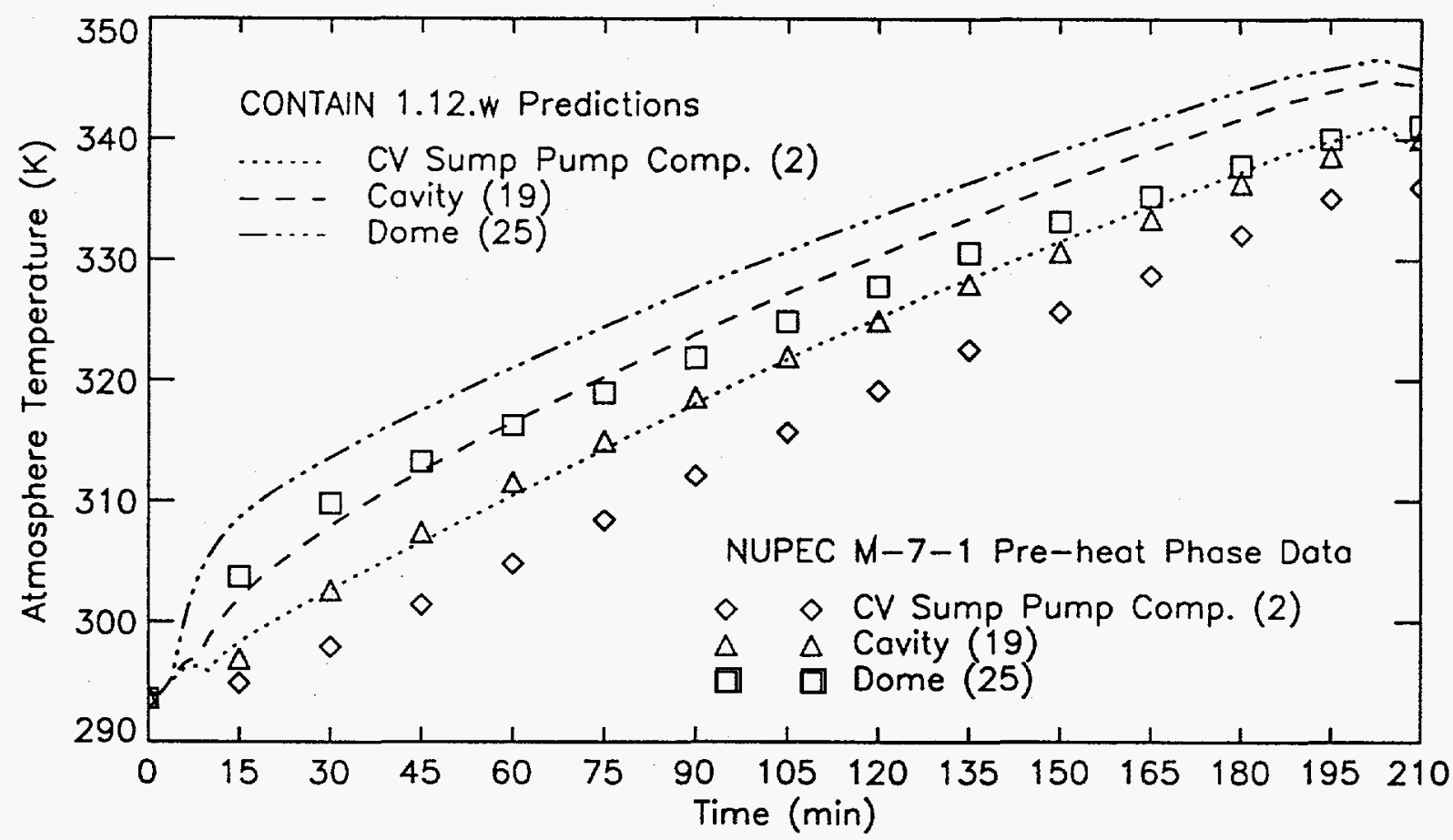

Figure 3.18.Comparison between the CONTAIN predictions and data of the preheat phase of NUPEC Test M-7-1 gas temperatures for Compartments 2, 19, and 25. 

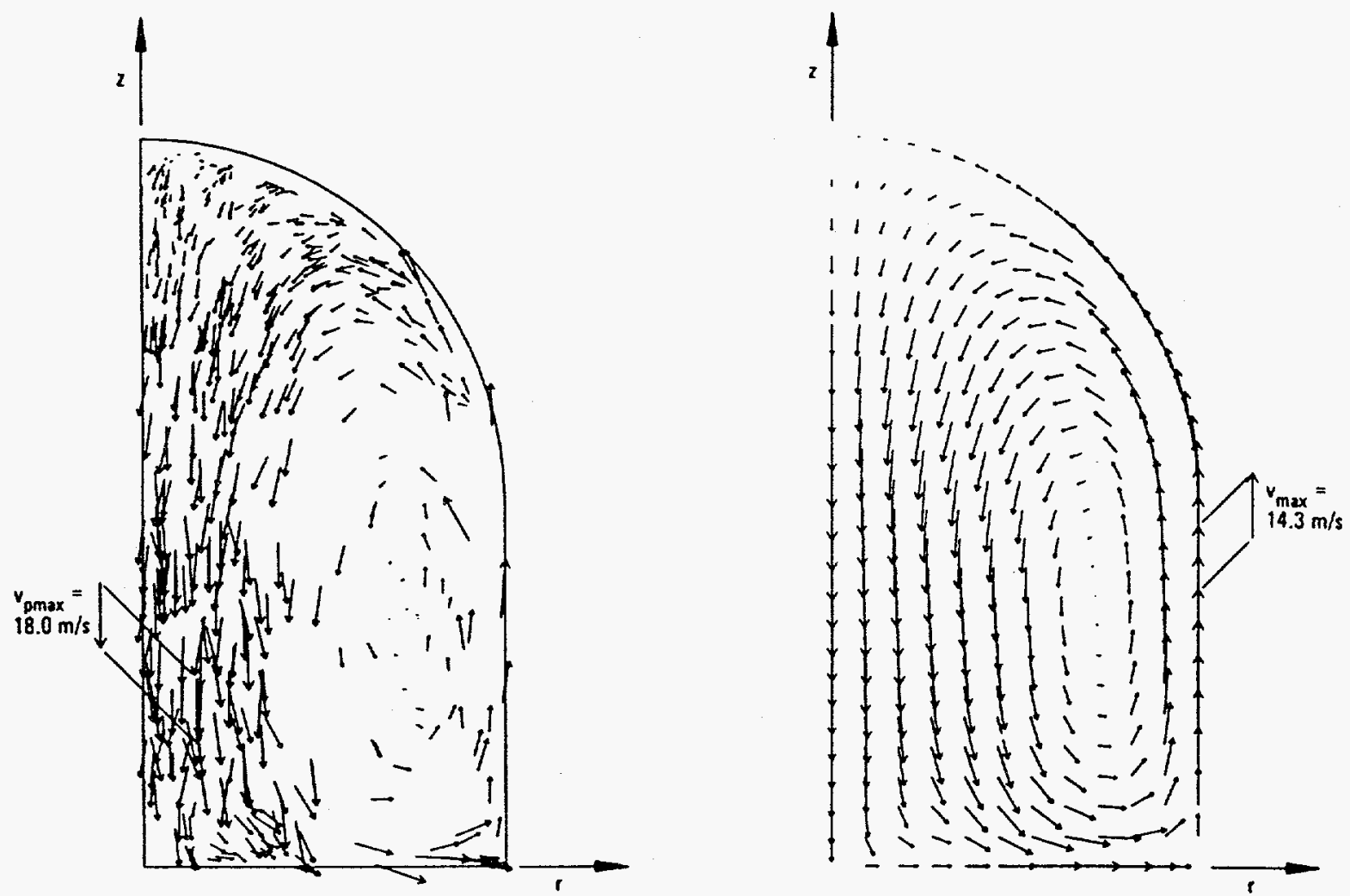

Figure 3.19.Numerical simulation of the water droplet and air velocity patterns for water sprays in an unobstructed containment [2].

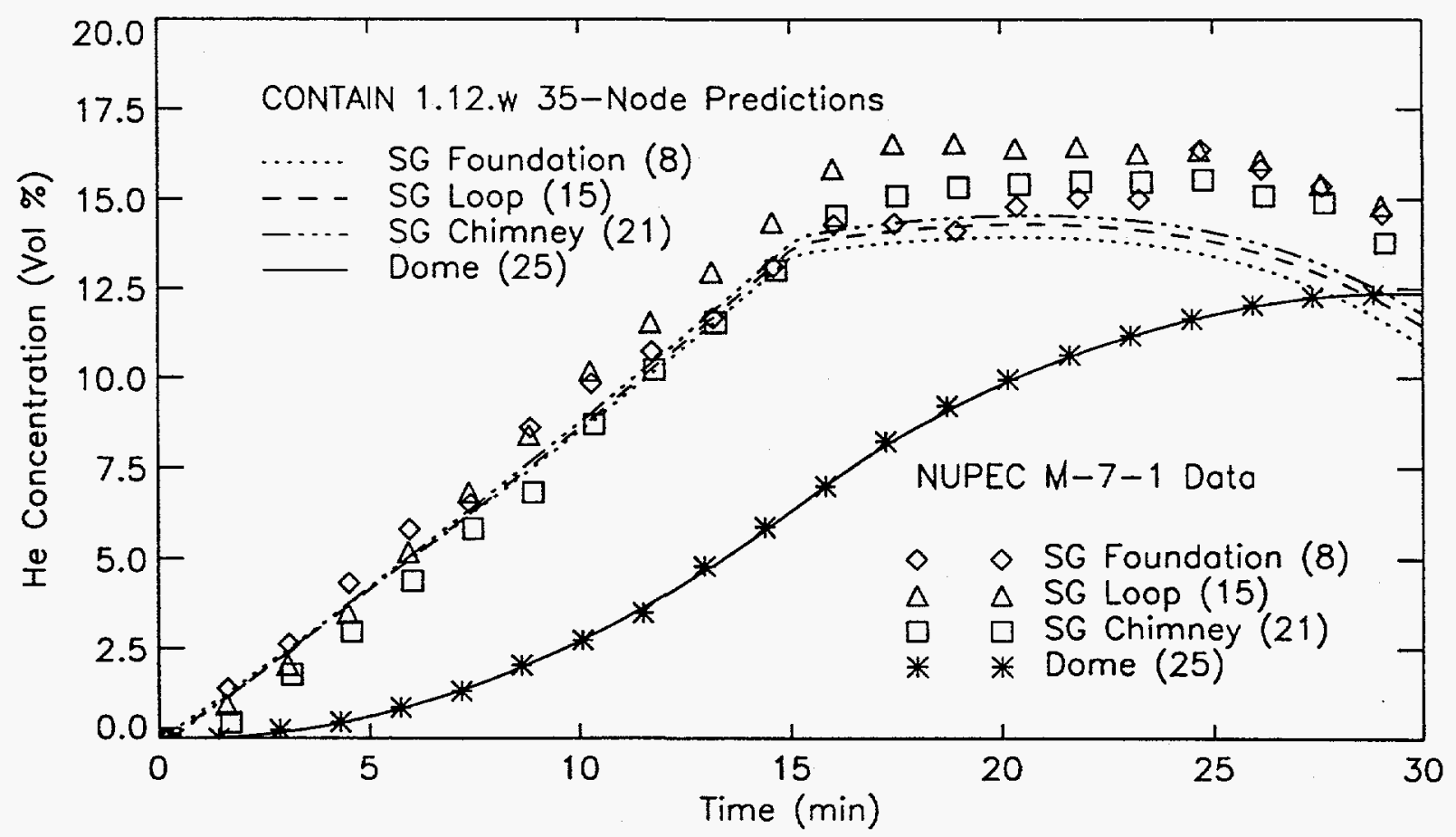

Figure 3.20.Comparison between the CONTAIN predictions and data of the NUPEC Test M7-1 helium concentrations for Compartments $8,15,21$, and 25. 


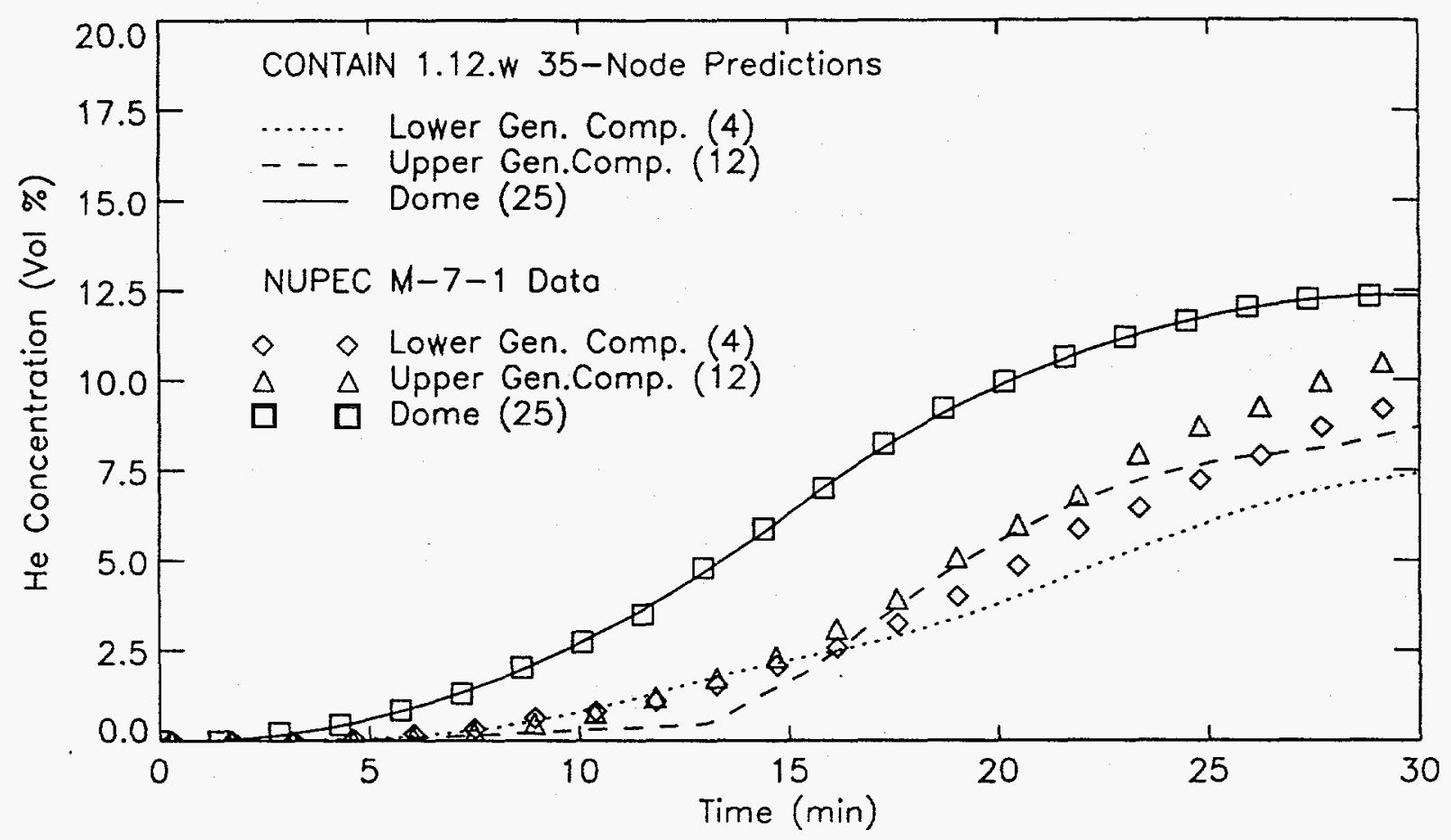

Figure 3.21. Comparison between the CONTAIN predictions and data of the NUPEC Test M7-1 helium concentrations for Compartments 4,12 , and 25 .

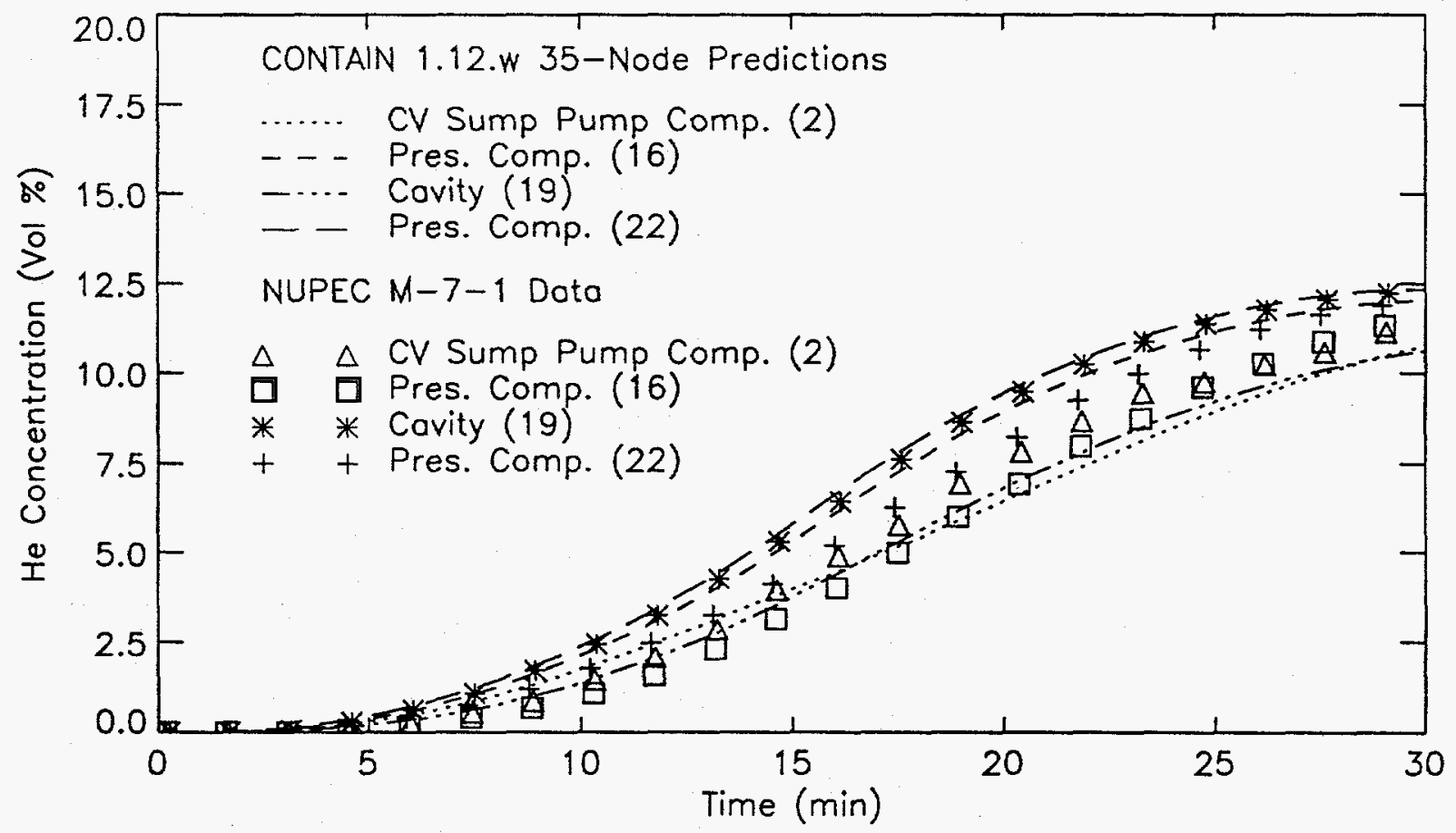

Figure 3.22. Comparison between the CONTAIN predictions and data of the NUPEC Test M7-1 helium concentrations for Compartments 2, 16, 19, and 22. 


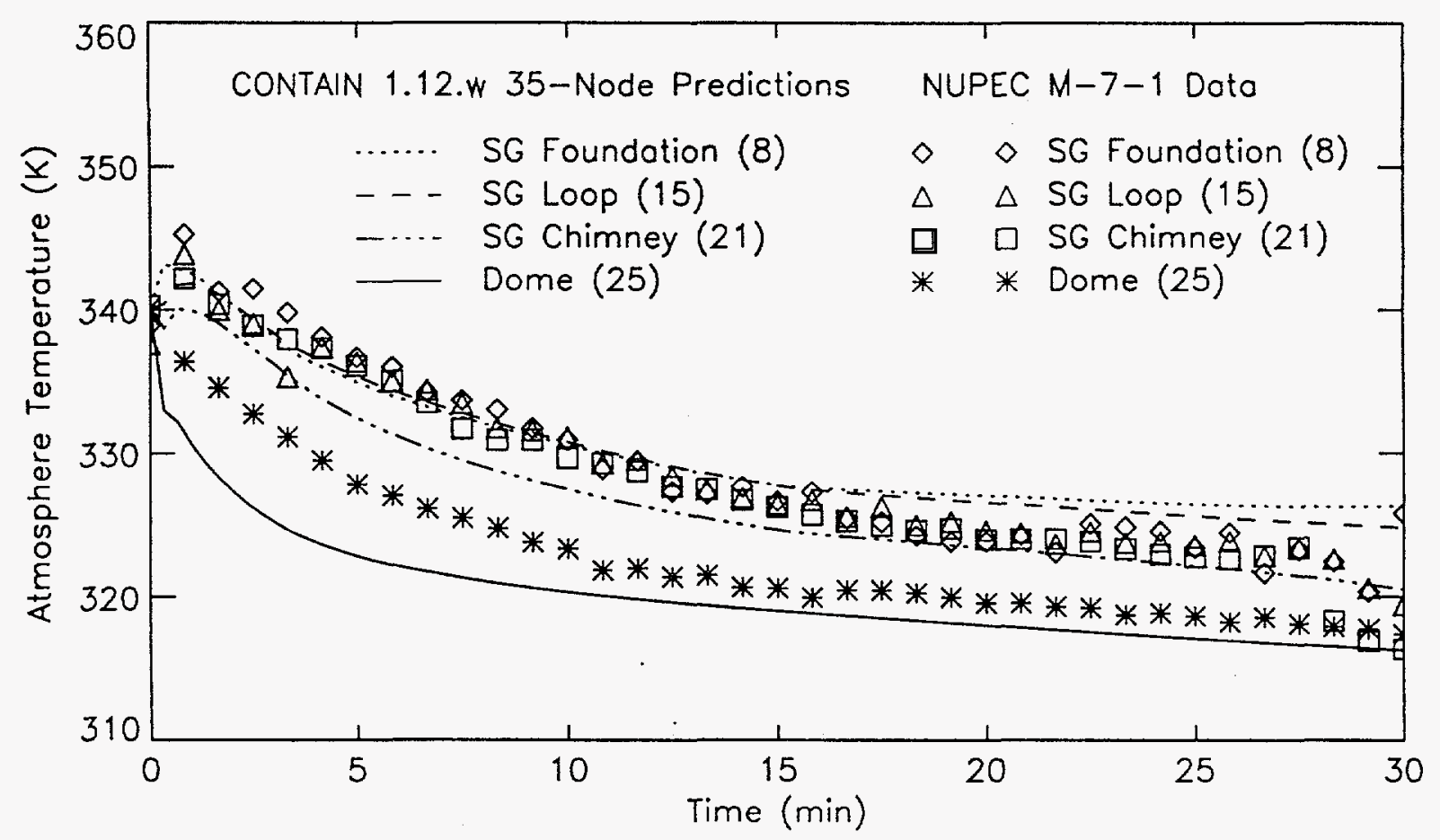

Figure 3.23.Comparison between the CONTAIN predictions and data of the NUPEC Test M7-1 gas temperatures for Compartments 8, 15,21, and 25 .

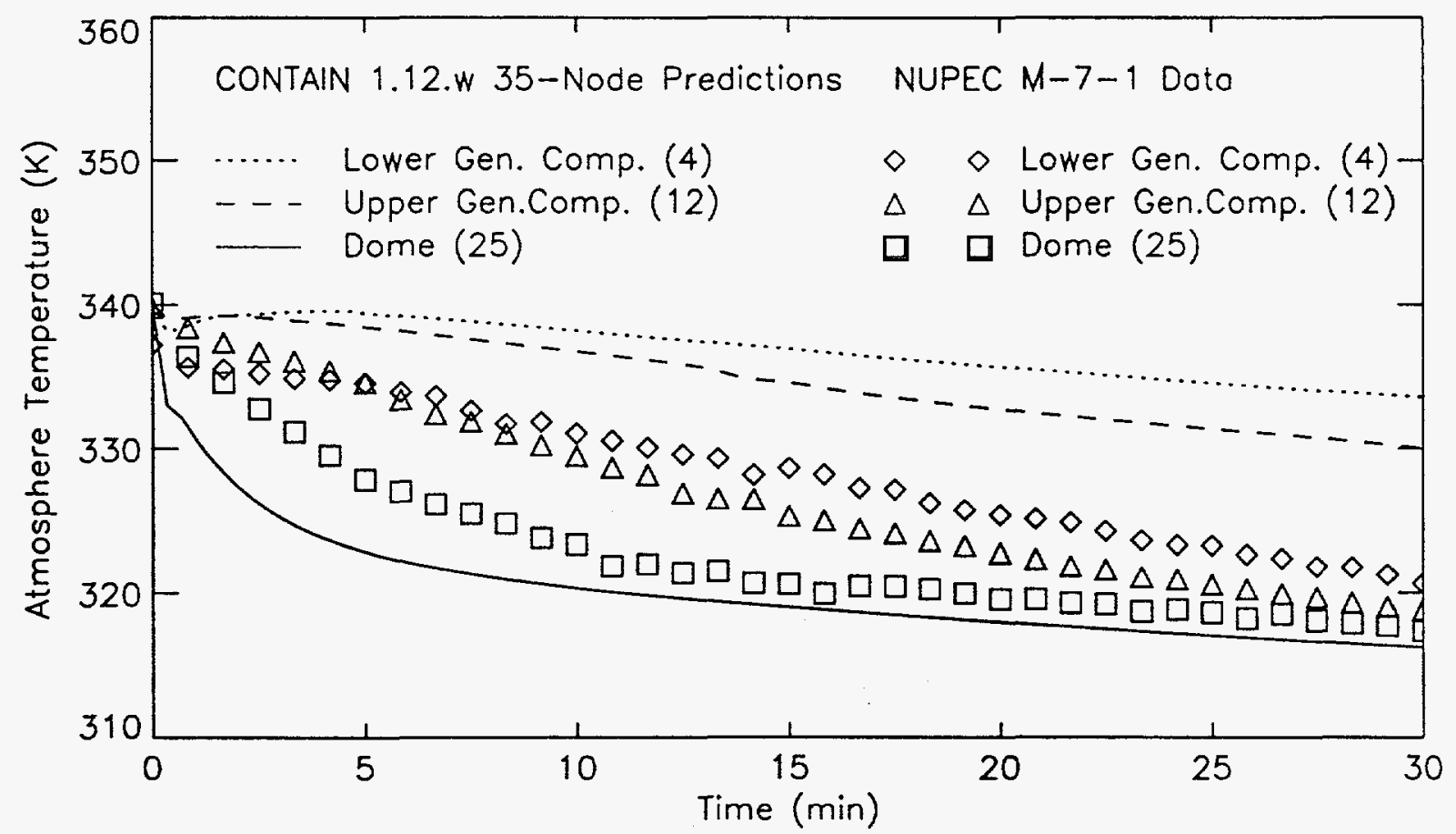

Figure 3.24.Comparison between the CONTAIN predictions and data of the NUPEC Test M7-1 gas temperatures for Compartments 4,12 , and 25 . 


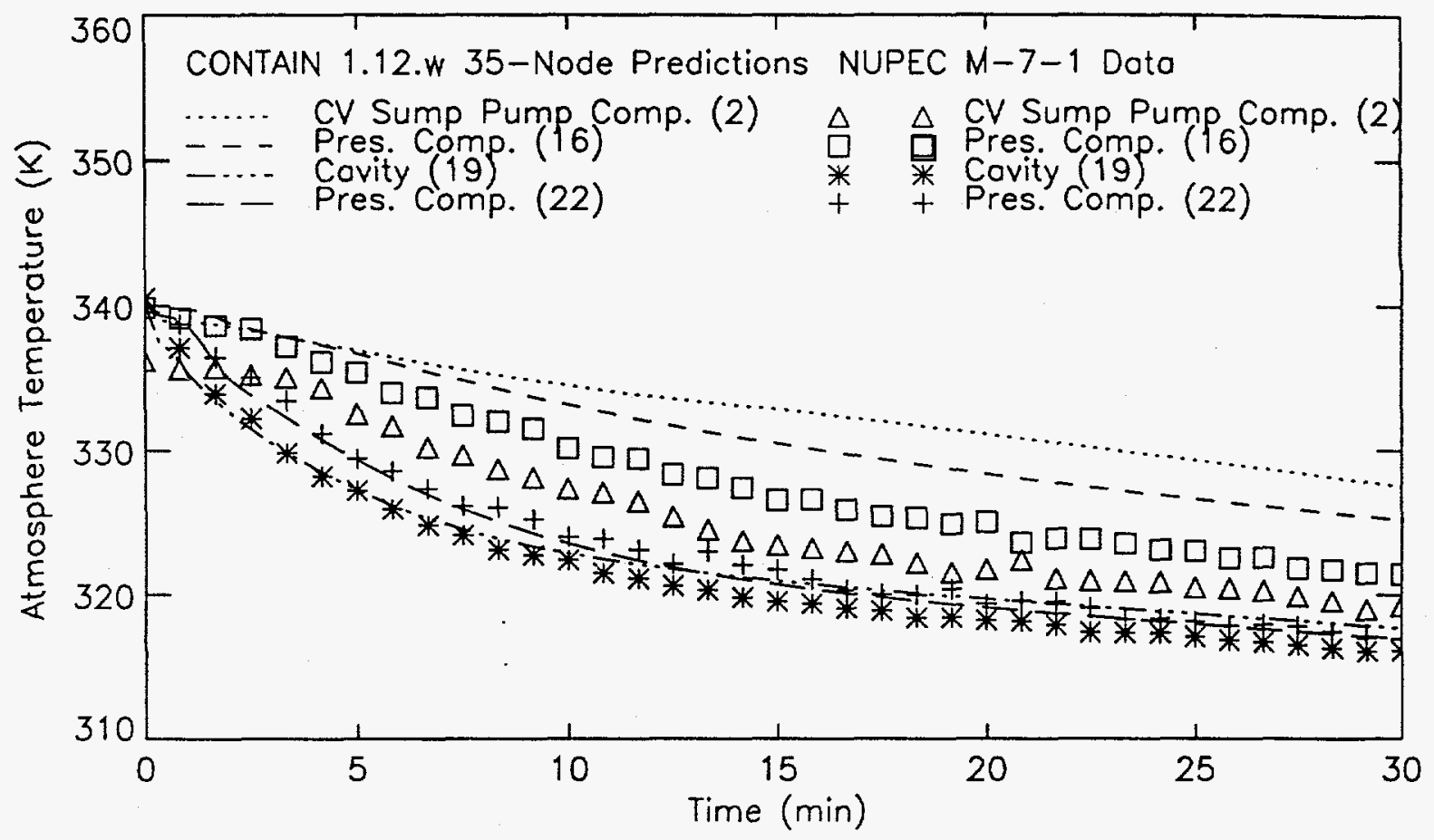

Figure 3.25.Comparison between the CONTAIN predictions and data of the NUPEC Test M7-1 gas temperatures for Compartments 2, 16, 19, and 22.

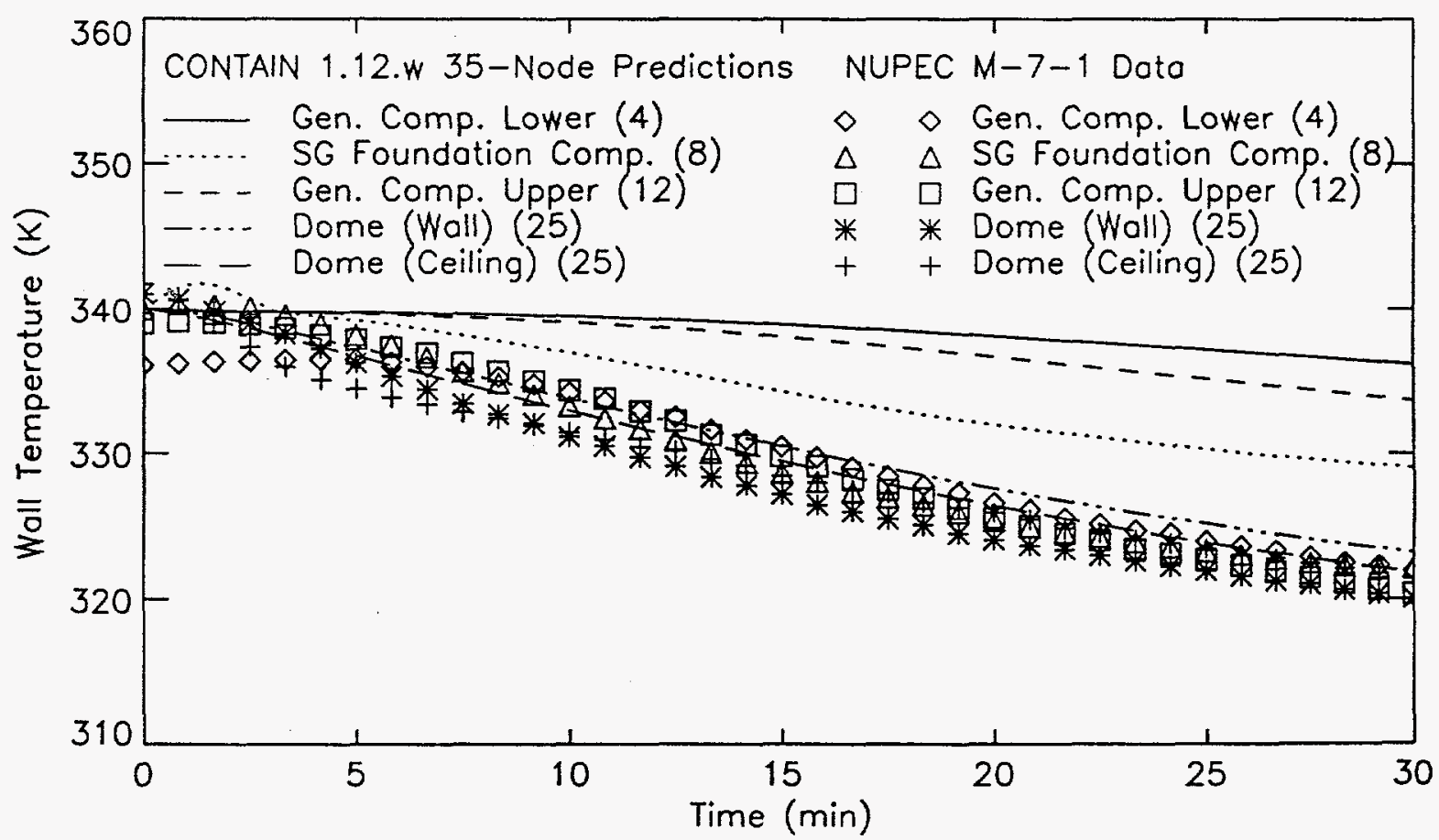

Figure 3.26.Comparison between the CONTAIN predictions and data of the NUPEC Test M7-1 wall temperatures for Compartments $4,8,12$, and 25. 


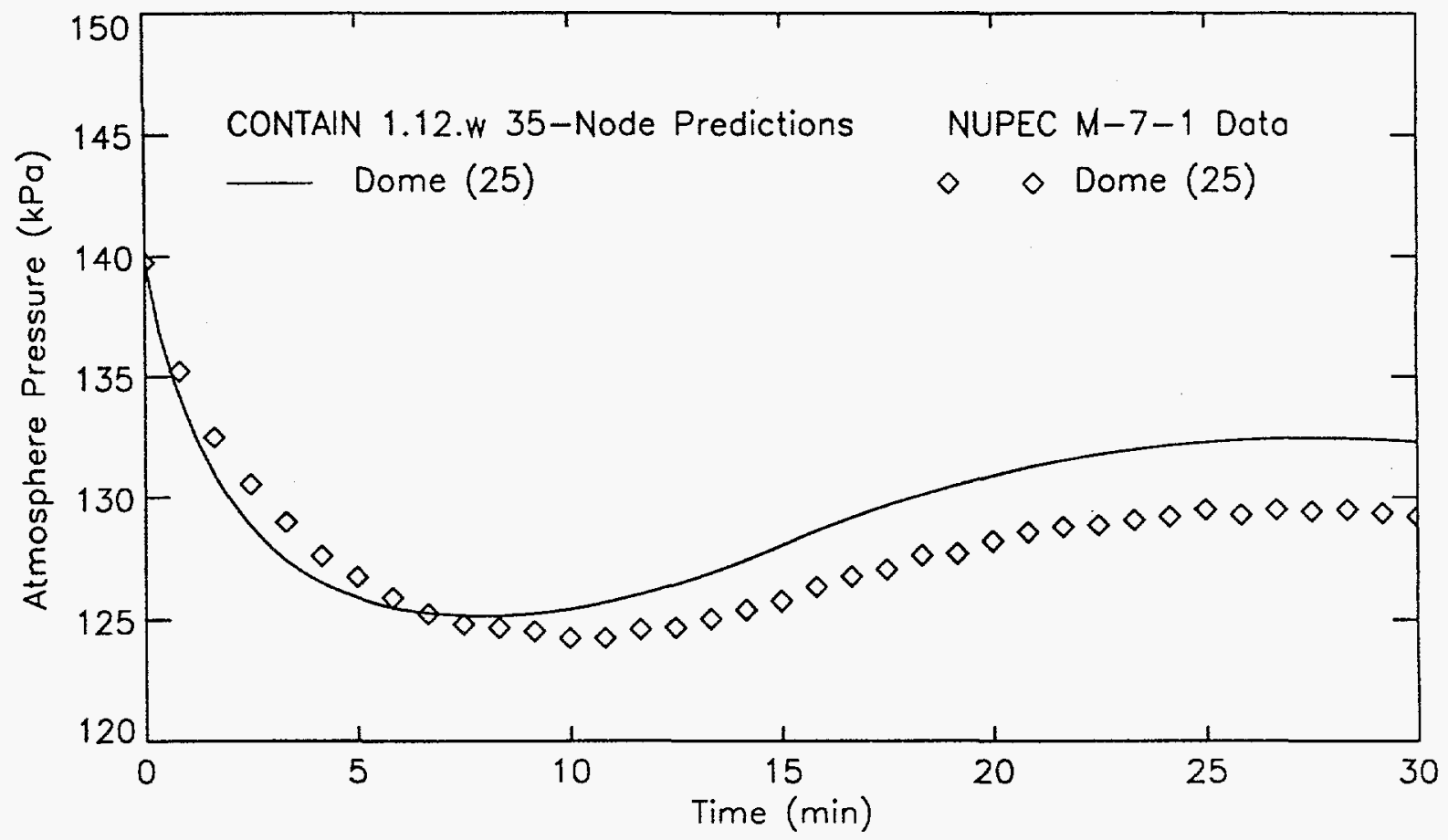

Figure 3.27.Comparison between the CONTAIN prediction and data of the NUPEC Test M-71 gas pressure for Compartment 25. 


\subsection{CONTAIN Assessment of NUPEC Test M-8-1}

The gas pressure in the facility at the beginning of test M-8-1 was approximately $101 \mathrm{kPa}$ and the structure and gas temperatures were at room temperature (approximately $7^{\circ} \mathrm{C}$ to $10^{\circ} \mathrm{C}$ ). At the beginning of the experiment, helium and steam were coinjected into the pressurizer (Cells 22 and 35). Water sprays were not operated during this experiment. The helium and steam mass flow rates were constant at $0.027 \mathrm{~kg} / \mathrm{s}$ and $0.33 \mathrm{~kg} / \mathrm{s}$, respectively, during the 30 -minute injection period. It was assumed that helium and saturated steam were injected into the containment at $10^{\circ} \mathrm{C}$ and $108^{\circ} \mathrm{C}$, respectively. The helium and steam were mixed in a chamber outside of the containment.

The models discussed in Section 2 were used in the calculations for test M-8-1 except for those models pertaining to water sprays. The results for test M-8-1 using the hybrid flow solver (XBG version) and the 35-node scheme were clearly better than the other calculations. This is because the hybrid flow solver (XBG version) has the potential to predict stratified mixtures better than the default flow solver (W version). However, as will be shown in Section 4.1 , the strengths of the hybrid flow solver cannot be capitalized on without proper nodalization.

The results for the best-estimate predictions of the helium concentrations and their comparison with the data are shown in Figures 3.28-3.30. Figure 3.28 shows the results for the steam generator foundation room (Cell 8 ) and all of the rooms directly above it. Figure 3.29 shows the results for a vertical column of outer rooms: the lower general compartment (Cell 4$)$ and the rooms directly above it. Figure 3.30 shows results for a number of rooms in the center of the containment, including the pressurizer compartment (Cell 16), which is a dead-end compartment, and the pressurizer (Cells 22 and 35), which is the source compartment.

In general, the trends of the predicted results agreed with the data. Because the helium was quite stratified, concentrations below the dome were low. Predicted helium concentrations were up to a factor of three greater in this region than measured values. However, because the absolute values of helium concentrations were so low, the magnitude of such discrepancy can be put into better perspective when actual deviations in helium concentrations are reported. For example, the predicted helium concentration in Compartment 15 at the end of the injection phase was three times larger than the measured value. Even though this discrepancy appears large on a relative basis, the actual difference between predicted and measured helium concentrations was not that large. In this case, the predicted helium concentration was $5 \%$ compared with a measured value of $1.5 \%$. The helium concentration at the end of the injection phase in the dome, which constituted $71 \%$ of the containment, was approximately $10 \%$ lower than the measured value. There were also significant deviations in the source room and the dead-end room connected to it.

The results for the best-estimate predictions of the gas temperatures and their comparison with the data are shown in Figures 3.31-3.33. The gas temperature results are shown for the same set of rooms used to illustrate the results for the helium concentrations in Figures 3.28-3.30. Except for some of the center rooms, CONTAIN predicted the temperature histories fairly well. The difference between the predicted and measured final gas temperatures was typically less than $2 \%$ on an absolute basis, although for rooms that had small temperature changes, the difference was as large as $30 \%$ on a relative basis. Significant deviations between the pre- 
dicted and measured gas temperatures occurred in the in-core chase (Compartment 1) and the pressurizer rooms (Compartments 16,22, and 35), which is similar to the difficulty in predicting the helium concentrations in these rooms. The predicted final gas temperature in the dome deviated less than $1 \%$ from the measured value on an absolute basis and CONTAIN predicted the change in gas temperature within approximately $4 \%$.

The results for the wall temperatures and their comparison with the data are shown in Figure 3.34. Because CONTAIN tended to overpredict the rate of mixing in the facility, the predicted results did not show the strong stratification that was measured. Therefore, the dome ceiling temperature was slightly underpredicted and the dome wall temperature was overpredicted. The predictions showed the general trends of the data but did not show as large a vertical temperature gradient along the outer wall. For example, a difference of $61^{\circ} \mathrm{C}$ was measured in the final temperature along the containment wall between the ceiling of the dome (Compartment 25 ) and the lower general room (Compartment 6 ). The predicted difference was $10 \%$ lower at approximately $55^{\circ} \mathrm{C}$. The difference in the predicted final wall temperatures was approximately $4 \%$ or less on an absolute basis although the difference in the change in wall temperature for some rooms was much larger. In the worst case, for example, the predicted change in the wall temperature of the dome (Compartment 33) just below the source point was over a factor of two greater than the measured change. These large differences on a relative basis are due, in part, to the relatively small changes measured in the wall temperatures.

The results for the gas pressure in the dome and its comparison with the data are shown in Figure 3.35. The pressure was slightly overpredicted although the general trends were correct. On an absolute basis, the final pressure was approximately $4 \%$ greater than the data. On a relative basis, the predicted change in pressure was approximately $12 \%$ greater than the measured change. 


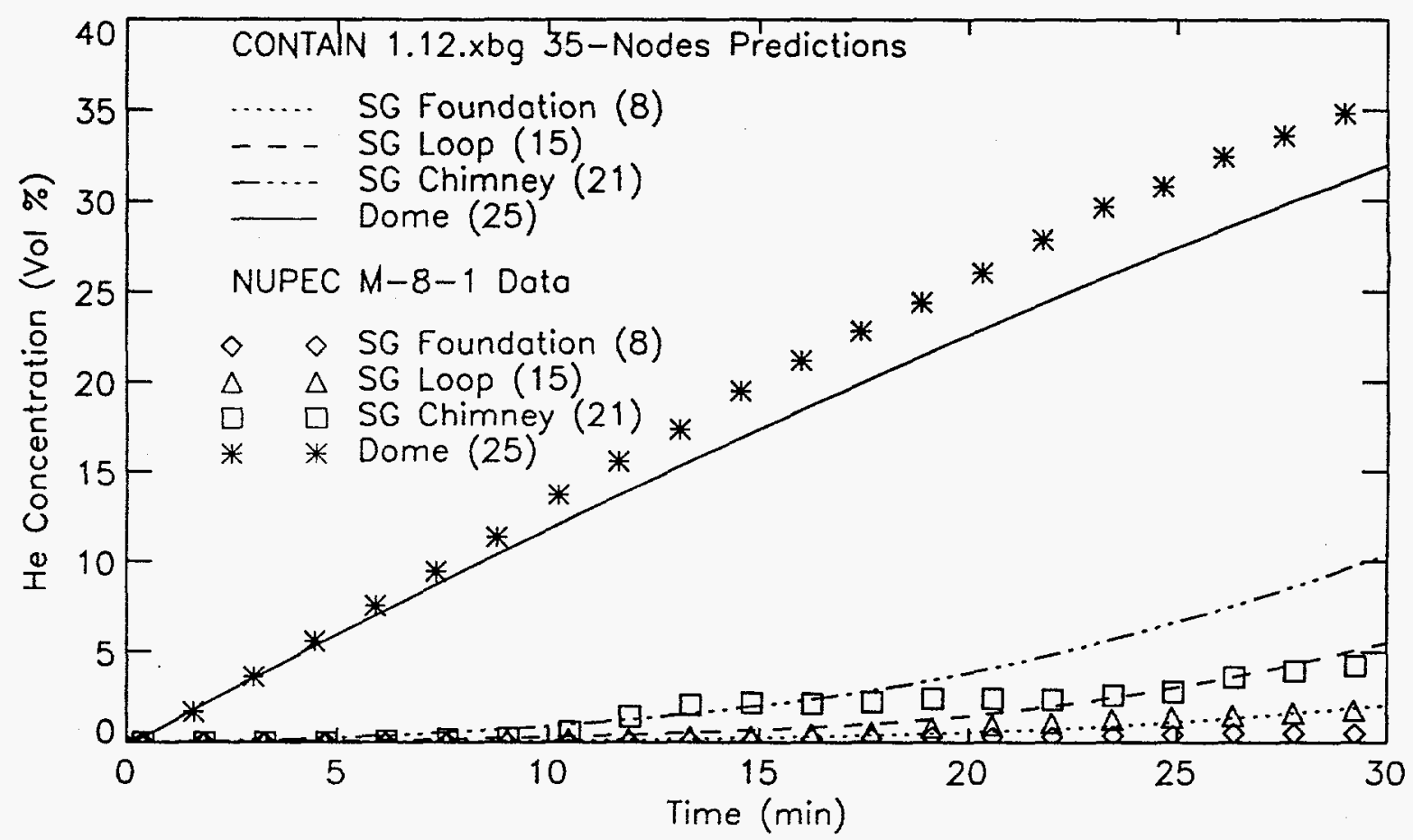

Figure 3.28. Comparison between the CONTAIN predictions and data of the NUPEC Test M8-1 helium concentrations for Compartments 8, 15, 21, and 25 .

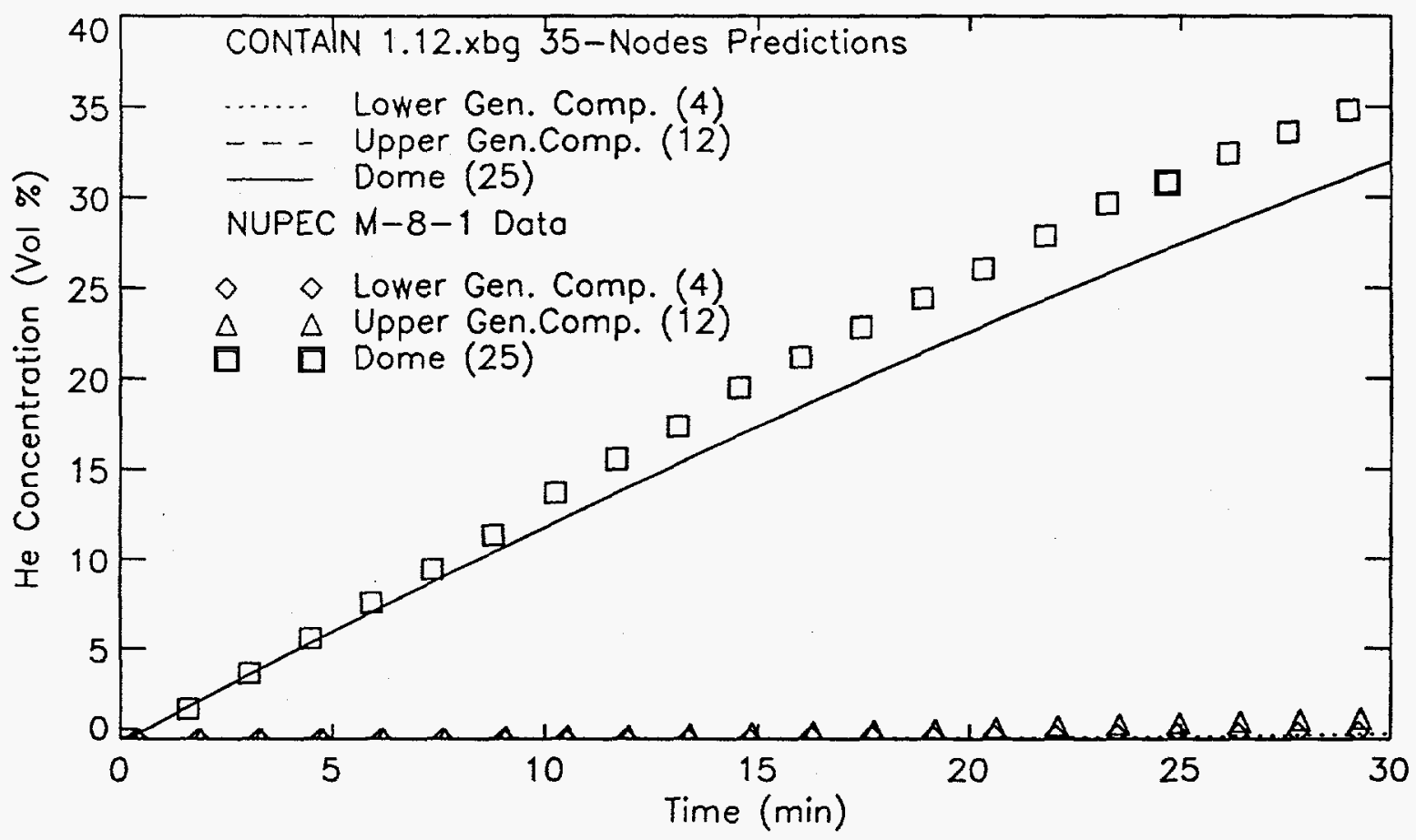

Figure 3.29. Comparison between the CONTAIN predictions and data of the NUPEC Test M8-1 helium concentrations for Compartments 4, 12, and 25. 


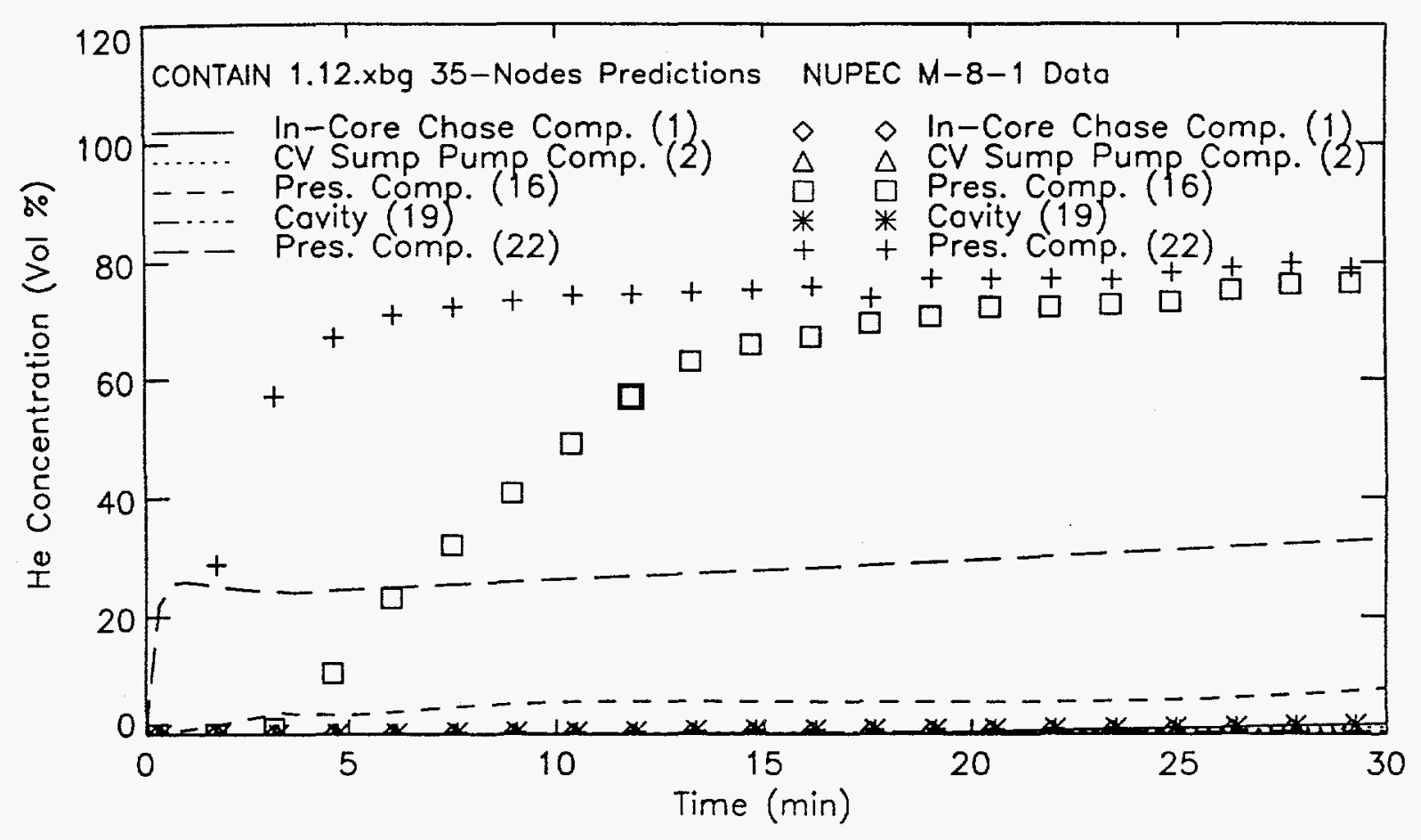

Figure 3.30.Comparison between the CONTAIN predictions and data of the NUPEC Test M8-1 helium concentrations for Compartments 1,2,16, 19, and 22 .

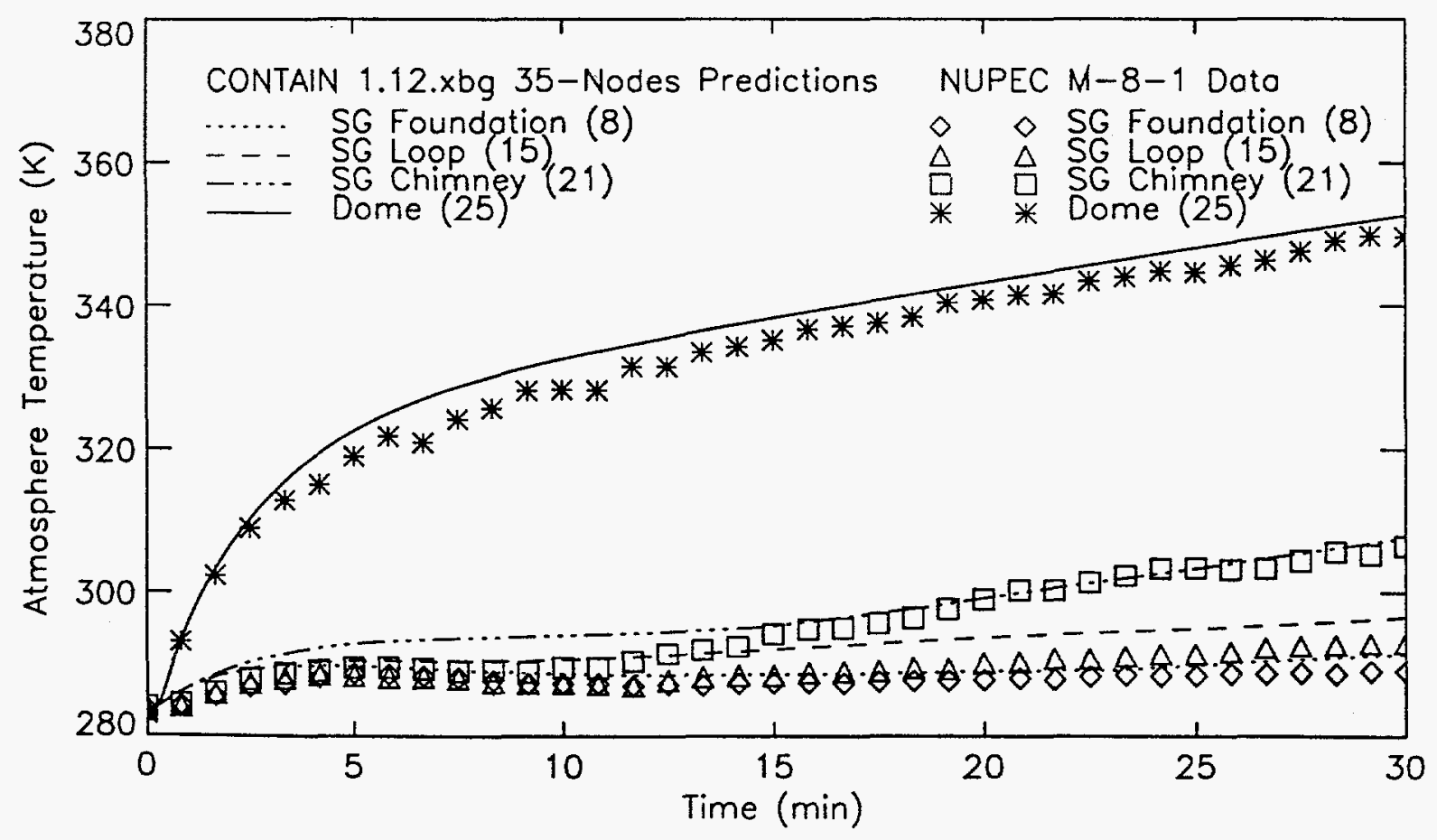

Figure 3.31.Comparison between the CONTAIN predictions and data of the NUPEC Test M8-1 gas temperatures for Compartments 8, 15, 21, and 25. 


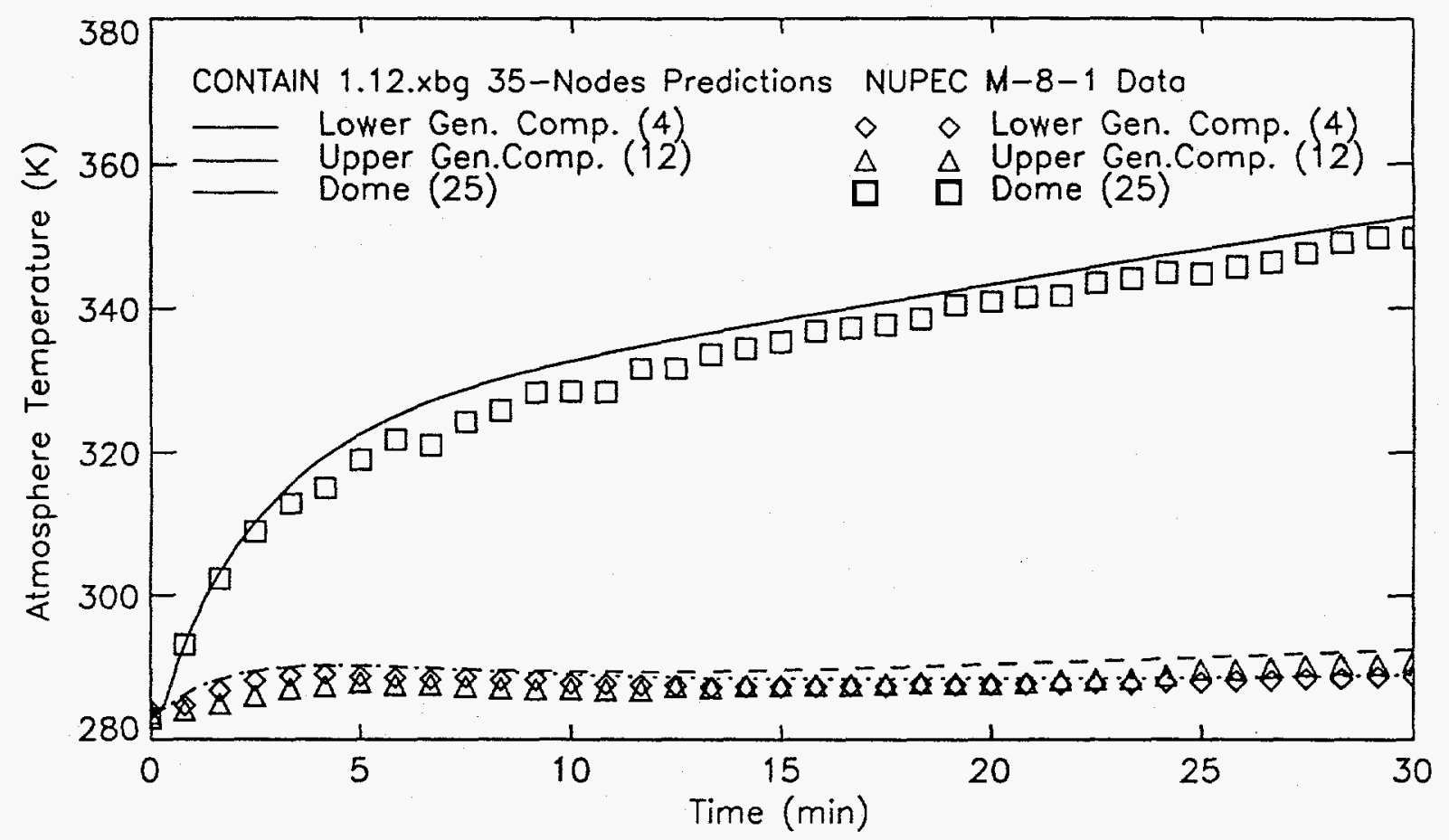

Figure 3.32. Comparison between the CONTAIN predictions and data of the NUPEC Test M8-1 gas temperatures for Compartments 4, 12, and 25.

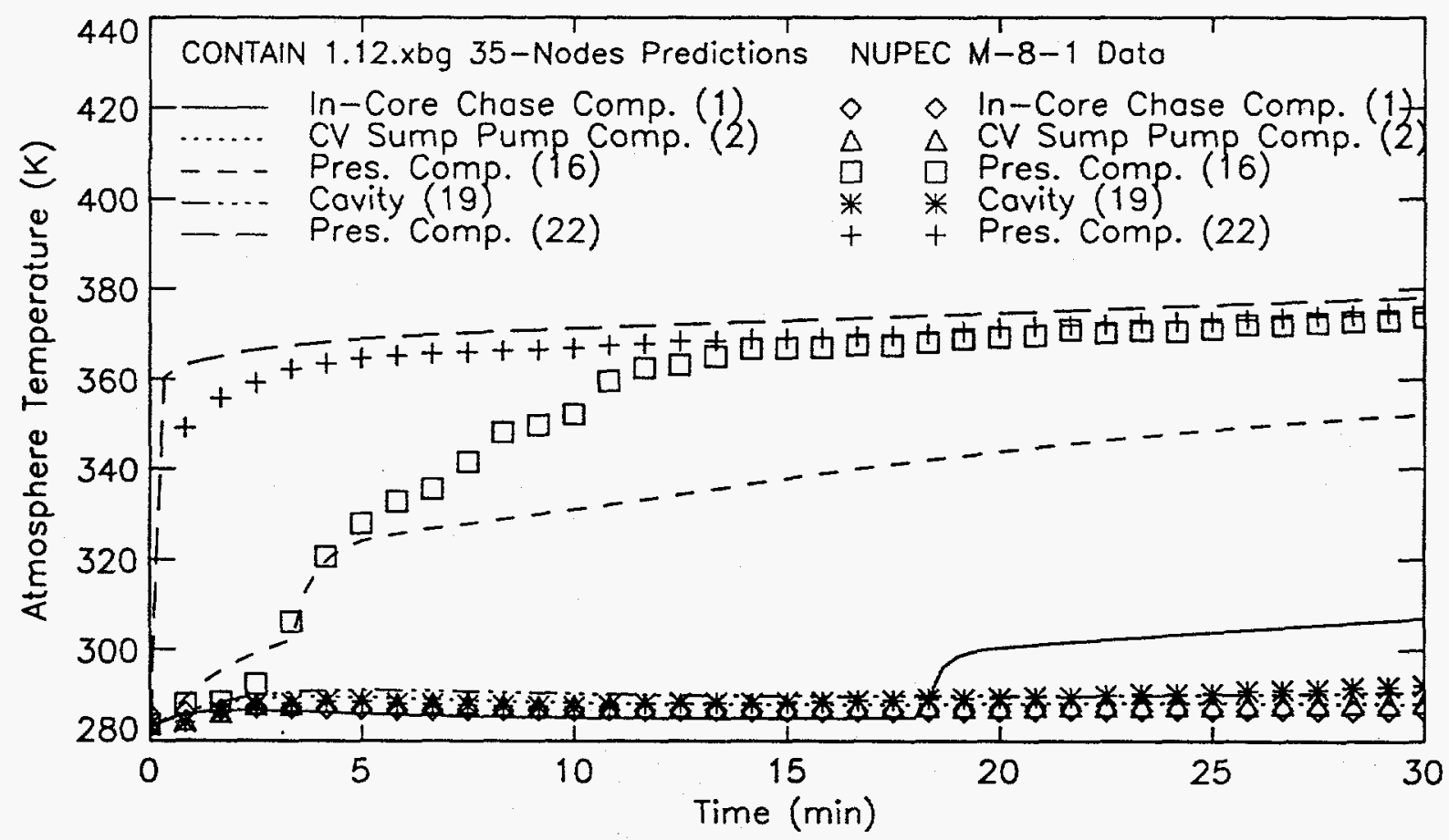

Figure 3.33.Comparison between the CONTAIN predictions and data of the NUPEC Test M8-1 gas temperatures for Compartments $1,2,16,19$, and 22 . 


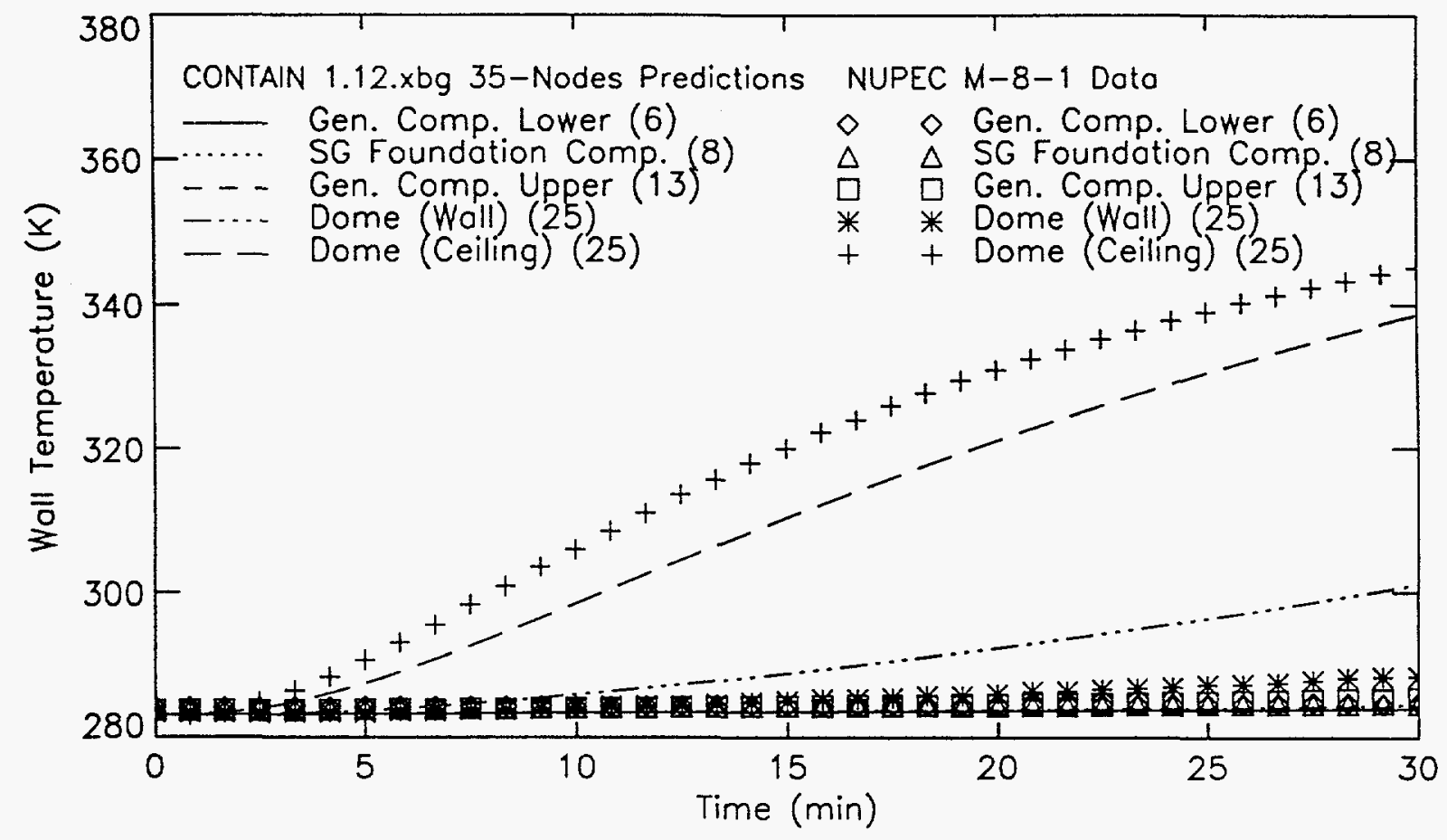

Figure 3.34.Comparison between the CONTAIN predictions and data of the NUPEC Test M8-1 wall temperatures for Compartments $6,8,13$, and 25.

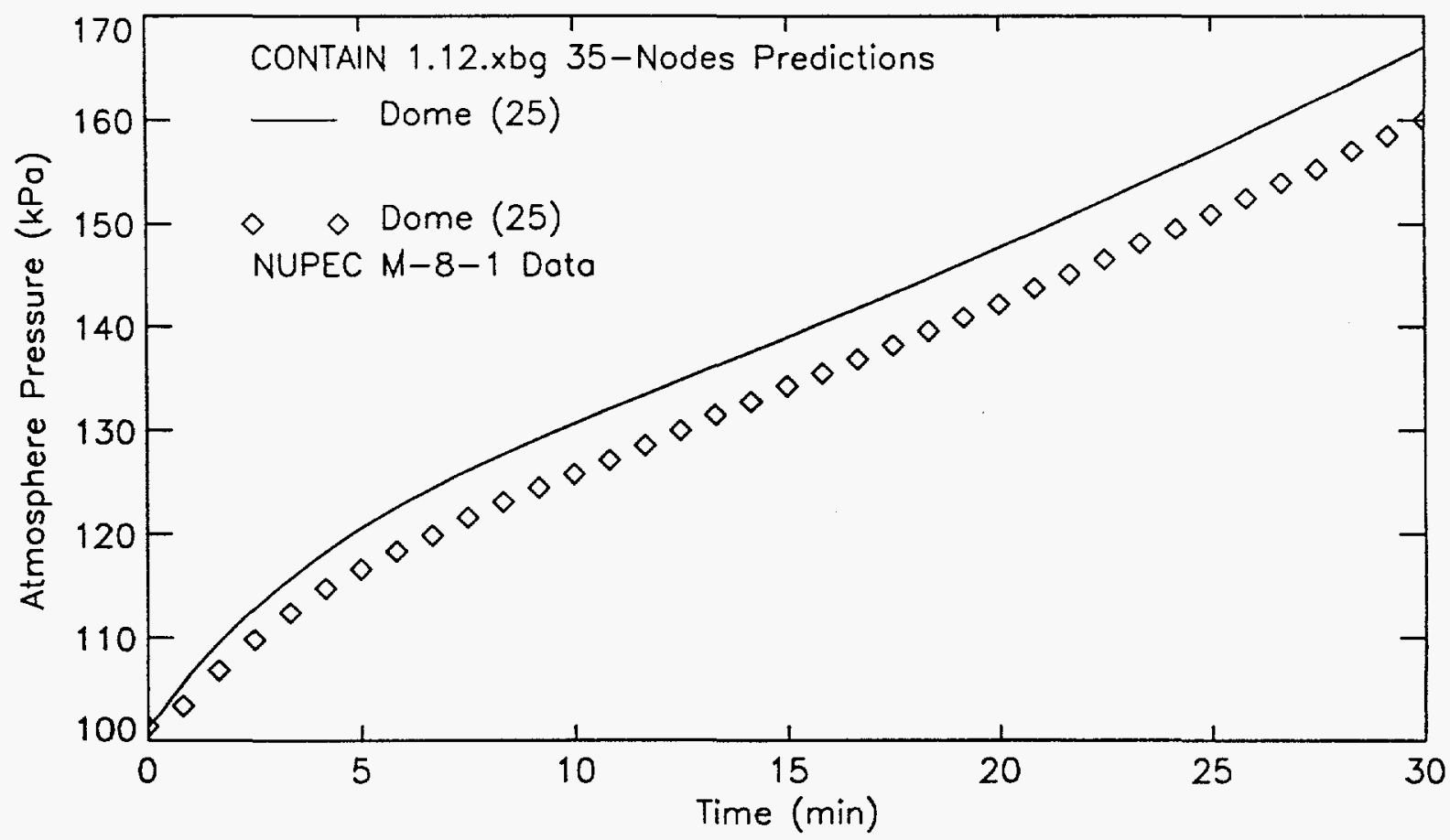

Figure 3.35.Comparison between the CONTAIN prediction and data of the NUPEC Test M-81 gas pressure for Compartment 25. 


\subsection{CONTAIN Assessment of NUPEC Test M-8-2}

The gas pressure at the beginning of test M-8-2 was $142.4 \mathrm{kPa}$ and the structure and gas temperatures were approximately $67^{\circ} \mathrm{C}$ to $72^{\circ} \mathrm{C}$. At the beginning of the experiment, helium and steam were coinjected into the pressurizer (Cells 22 and 35 ) while water sprays were injected into the hemisphere region of the dome (Cell 25). The helium mass flow rate was increased linearly from $0.0 \mathrm{~kg} / \mathrm{s}$ to $0.03 \mathrm{~kg} / \mathrm{s}$ for the first 15 minutes and then was decreased linearly to $0.0 \mathrm{~kg} / \mathrm{s}$ during the next 15 minutes. The steam mass flow rate was decreased linearly from $0.08 \mathrm{~kg} / \mathrm{s}$ to $0.03 \mathrm{~kg} / \mathrm{s}$ during the same 30 -minute period. It was assumed that helium and saturated steam were injected at $10^{\circ} \mathrm{C}$ and $104^{\circ} \mathrm{C}$, respectively. The helium and steam were mixed in a chamber outside of the containment. Water sprays were injected at a constant mass flow rate of $19.4 \mathrm{~kg} / \mathrm{s}$ for the same 30 -minute period at a constant temperature of $40^{\circ} \mathrm{C}$. The spray water was injected through 21 hollow-cone nozzles located in the hemispherical region of the dome. The average droplet diameter was assumed to be $0.75 \mathrm{~mm}$.

The models discussed in Section 2 were used in the calculations for test M-8-2. The same models and procedures used in test M-7-1 were also used in this test. Results for the 35-node scheme were generally better than those for the 28 -node scheme for the prediction of helium concentrations but not for the gas pressure. Similar results were predicted for the gas and wall temperatures using both schemes. For a given nodalization scheme, the results for test M-8-2 using different flow solvers were very similar. As a result, the selection of the "best" prediction was somewhat arbitrary. The results of the XBG version using the 35-node scheme were chosen mainly so that $M-8-2$ results could be compared with $M-8-1$. Both tests had midpoint injection of helium but M-8-2 had water sprays while M-8-1 did not. This comparison will be discussed in Section 4.1.

The results for the best-estimate predictions of the helium concentrations and their comparison with the data are shown in Figures 3.36-3.38. Figure 3.36 shows the results for the steam generator foundation room (Cell 8 ), and all of the rooms directly above it. Figure 3.37 shows the results for a vertical column of outer rooms: the lower general compartment (Cell 4) and the rooms directly above it. Figure 3.38 shows the results for a number of rooms in the center of the containment, including the source room (Compartments 22 and 35) and the pressurizer compartment (Cell 16), which is a dead-end compartment.

In general, the trend of the predicted results agreed with the data. Typically the difference between the predicted and measured final concentrations was less than $14 \%$ and was generally much better than that, as shown in Figures 3.36-3.37. The predicted final concentration in the dome was approximately $7 \%$ lower than the data. The helium was fairly well mixed throughout the containment in spite of the midpoint release location, which was due largely to the water sprays and the relatively open geometry of the facility. Significant deviations were observed in Compartments 1,16, and 22, which were difficult compartments to model in other tests. Because of the complicated shape of these rooms (as in Compartment 1) or the dead-end geometry (as in Compartment 16), any hope of improving the prediction in these rooms will probably require special attention to nodalization.

The results for the best-estimate predictions of the gas temperatures and their comparison with the data are shown in Figures 3.39-3.41. The results are shown for the same set of rooms used to illustrate the helium results in Figures 3.36-3.38. The difference in the final gas tempera- 
tures was less than $3 \%$ on an absolute basis although the difference is much larger based on the change in gas temperature. Because the water spray temperature was only $30^{\circ} \mathrm{C}$ less than the initial gas temperature, the drop in gas temperature during the 30-minute period the sprays were operating was relatively small at only about $20-25^{\circ} \mathrm{C}$. In the outer rooms, especially, the predicted change in temperature was only about one half of the actual change. In the experiment, it would be expected that the large air current driven by the sprays would force cooler air from the center of the containment up through the outside rooms. This was not predicted by CONTAIN since the code does not model the hydrodynamic drag of the water droplets on the air and CONTAIN overpredicted the gas temperature in the outer rooms. CONTAIN also overpredicted the rate of drop in temperature early in the test. This also would have been slower if the energy in the outer rooms could have been convected upwards into the dome in the predictions.

The results for the wall temperatures and their comparison with the data are shown in Figure 3.42. The predictions were reasonably good except for the outer compartments below the dome. The wall temperatures in the lower outer compartments, such as Cells 6 and 13, were overpredicted since the flow of air in these rooms was not assisted by the spray-driven convection loop in the calculation. In terms of absolute wall temperatures, the difference was typically less than $5 \%$ although the difference in the change in wall temperature was much larger. In the worst case, for example, the predicted change in the wall temperature of Cell 6 was only half of the measured change. The wall temperatures in the outer compartments, however, were the most difficult to predict. In contrast, the predicted change in the containment wall temperatures of the dome were within $10-22 \%$ of the measured values at the end of the test.

The result for the gas pressure in the dome and its comparison with the data are shown in Figure 3.43. Initially the pressure dropped as a result of the cooling of the gas by the water sprays. Eventually the continuous addition of the noncondensible gas (helium) caused the pressure to increase again. On an absolute basis, the final pressure was approximately $11 \%$ greater than the data. On a relative basis, however, the maximum predicted drop in pressure was only about half of the measured change and the final pressure was overpredicted. The generally poor prediction for the gas pressure was somewhat surprising considering the relatively good prediction of the gas temperatures. A possible explanation, however, is that since the steam is saturated, small errors in the predicted temperature of the mixture can result in large changes in the steam partial pressure and, hence, total mixture pressure. 


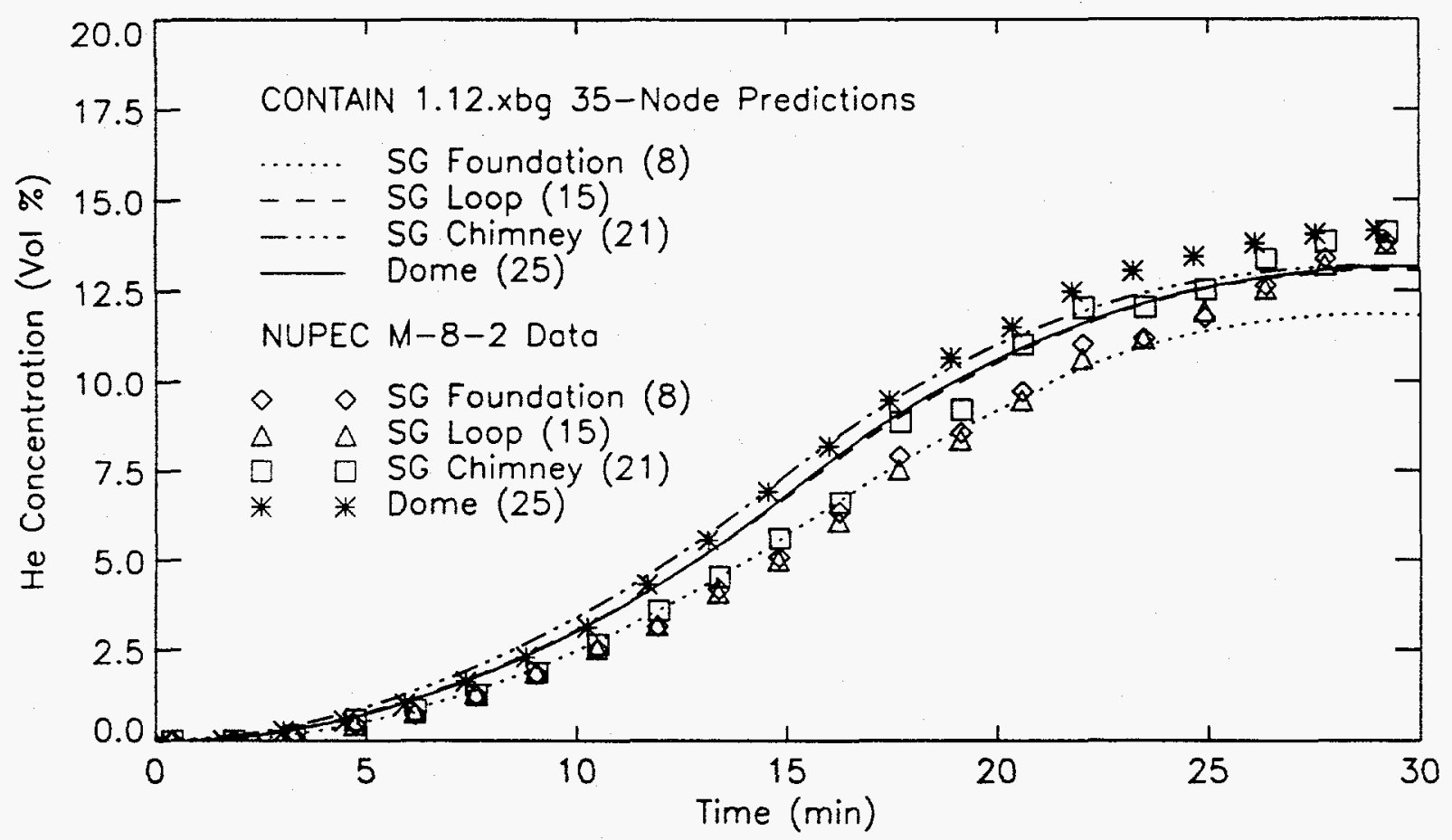

Figure 3.36. Comparison between the CONTAIN predictions and data of the NUPEC Test M8-2 helium concentrations for Compartments $8,15,21$, and 25.

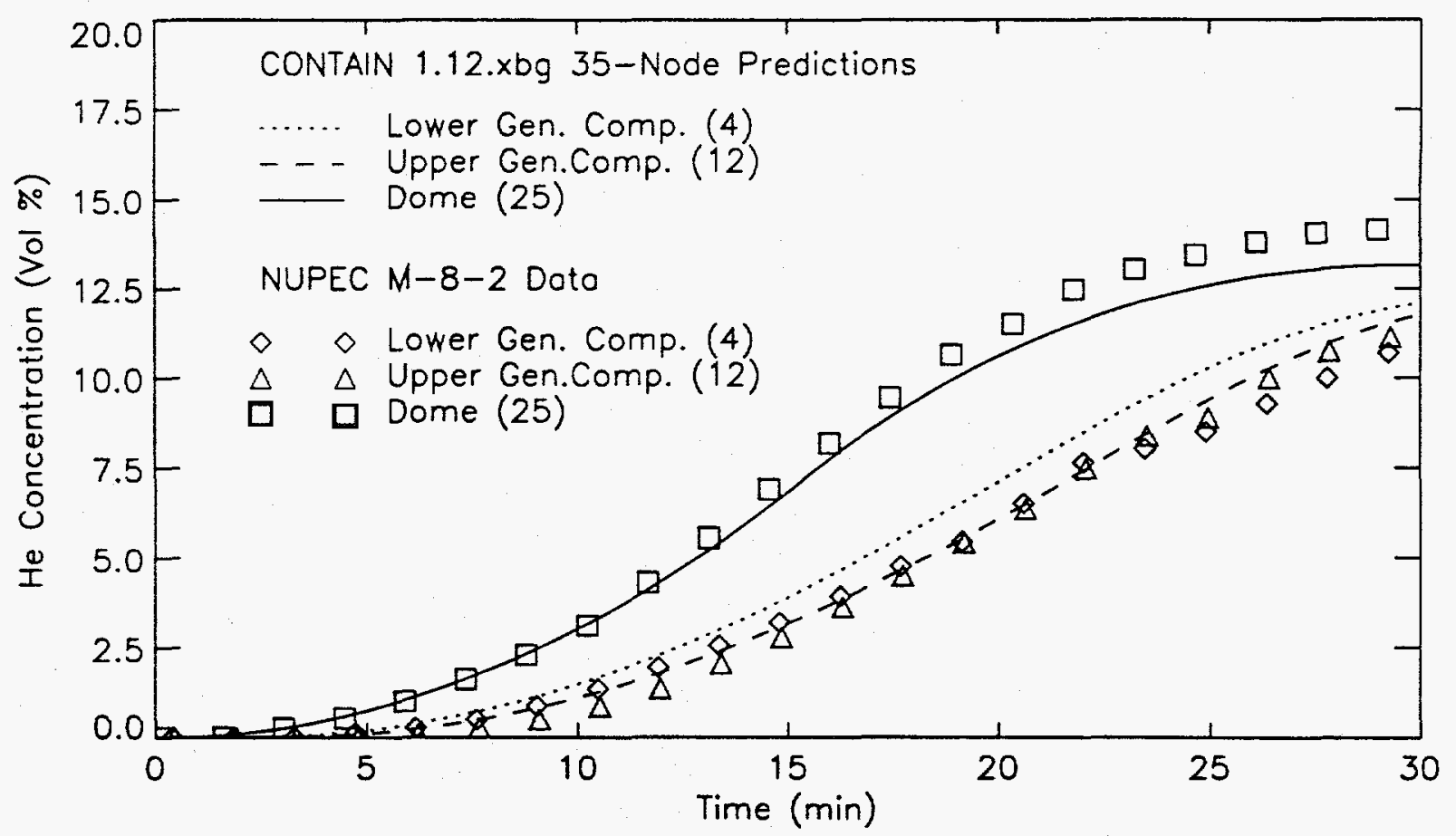

Figure 3.37. Comparison between the CONTAIN predictions and data of the NUPEC Test M8-2 helium concentrations for Compartments 4, 12, and 25. 


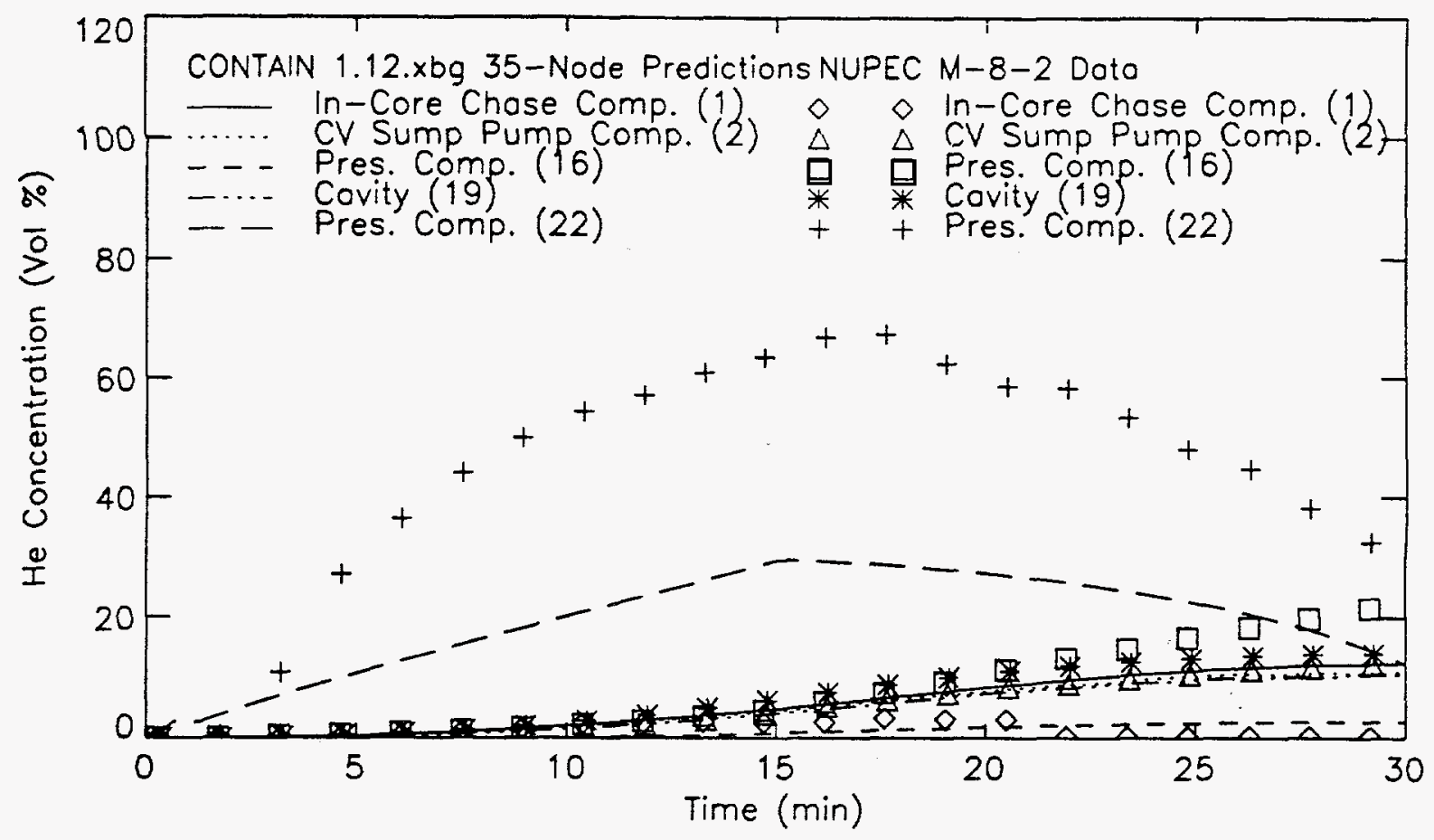

Figure 3.38.Comparison between the CONTAIN predictions and data of the NUPEC Test M8-2 helium concentrations for Compartments 1, 2, 16, 19, and 22.

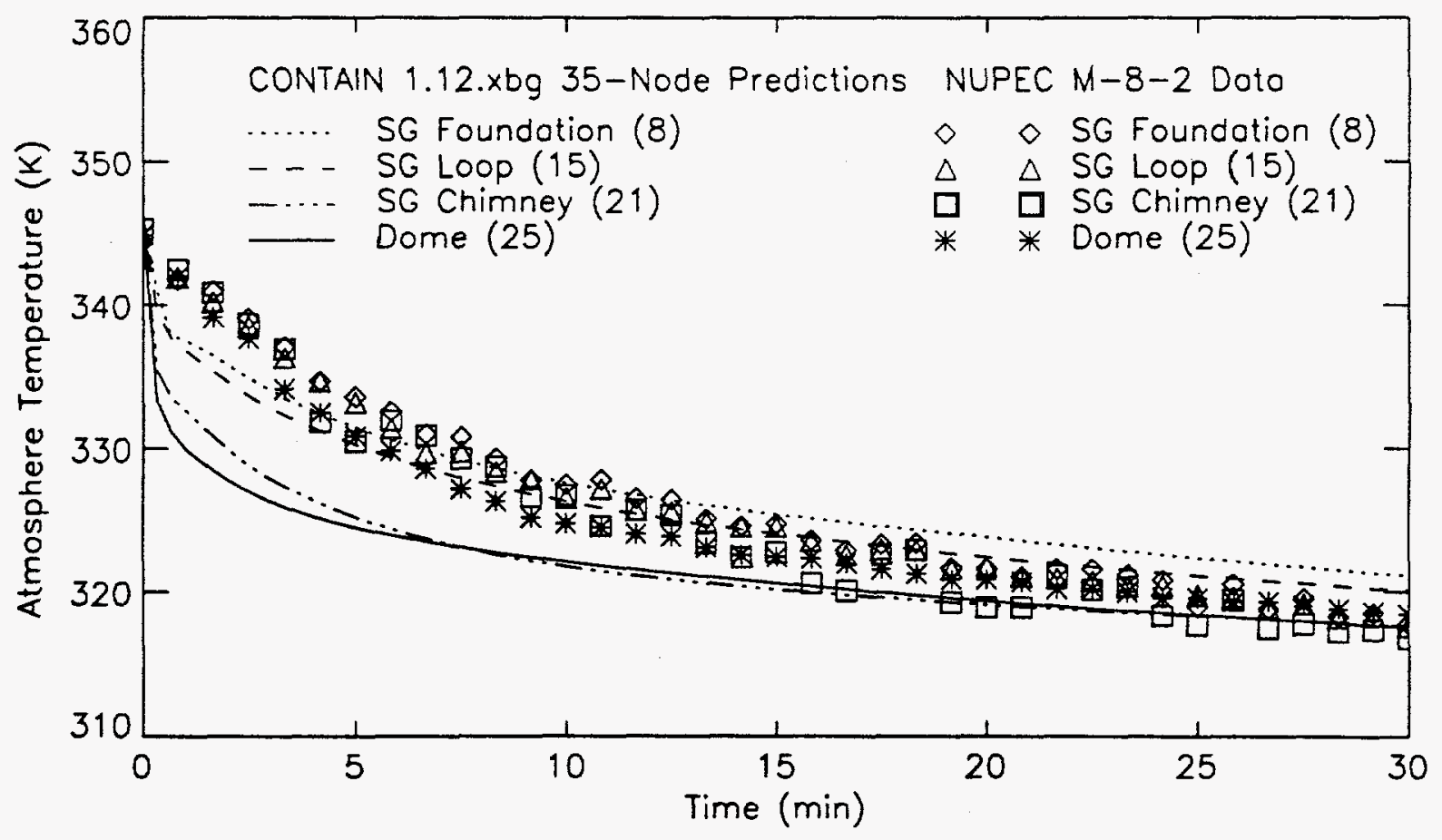

Figure 3.39.Comparison between the CONTAIN predictions and data of the NUPEC Test M8-2 gas temperatures for Compartments $8,15,21$, and 25 . 


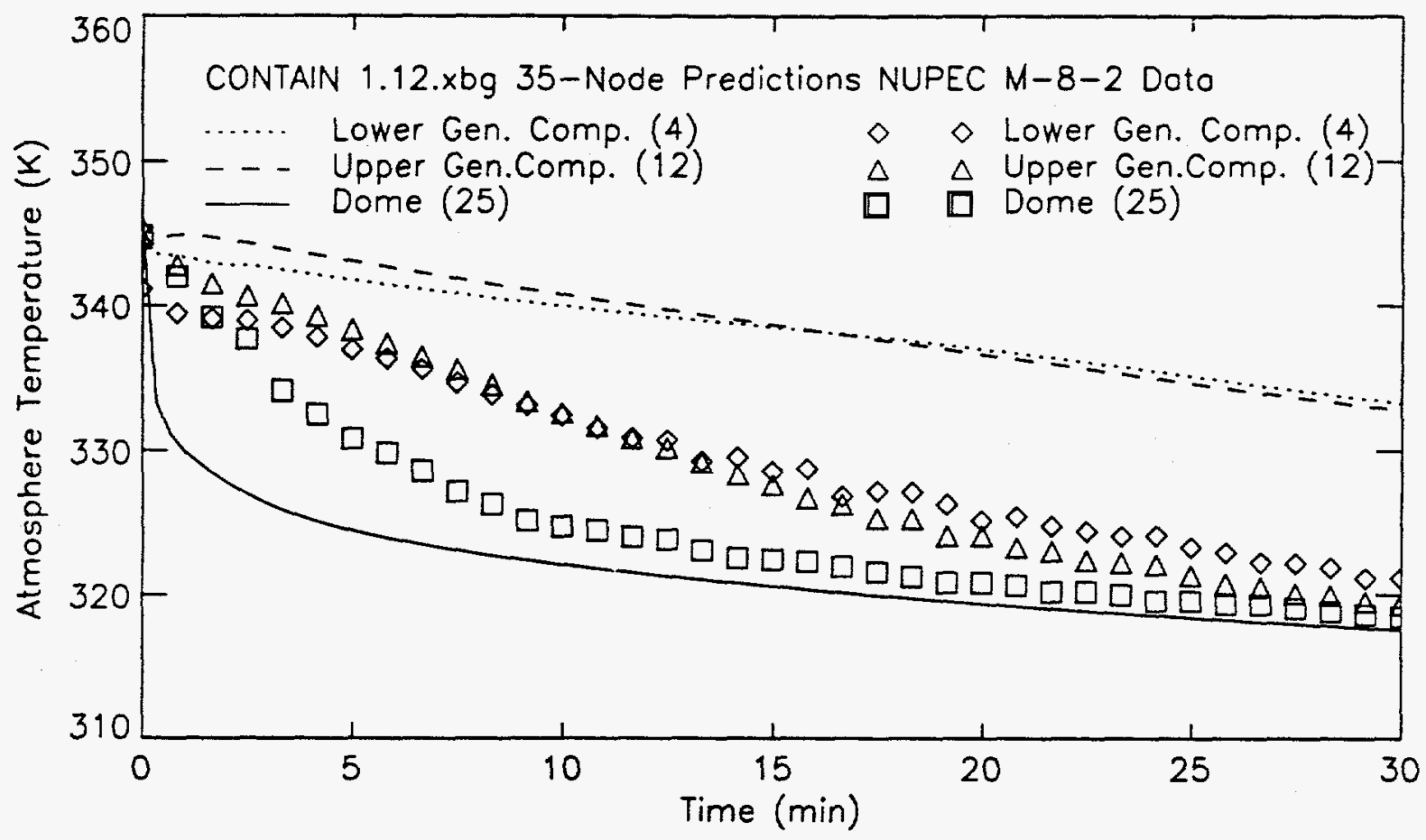

Figure 3.40.Comparison between the CONTAIN predictions and data of the NUPEC Test M8-2 gas temperatures for Compartments 4,12 , and 25 .

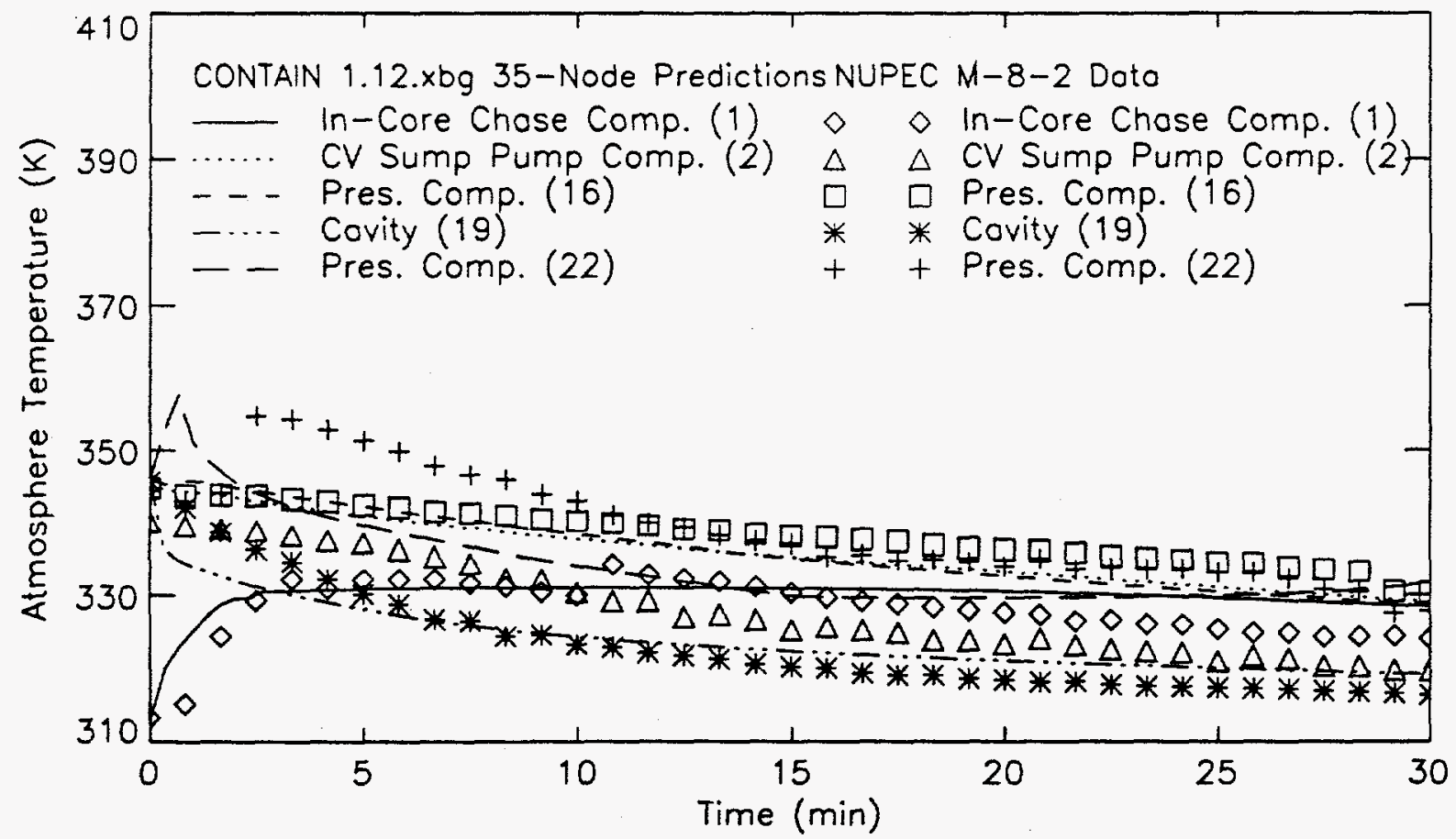

Figure 3.41.Comparison between the CONTAIN predictions and data of the NUPEC Test M8-2 gas temperatures for Compartments 1,2,16,19, and 22. 


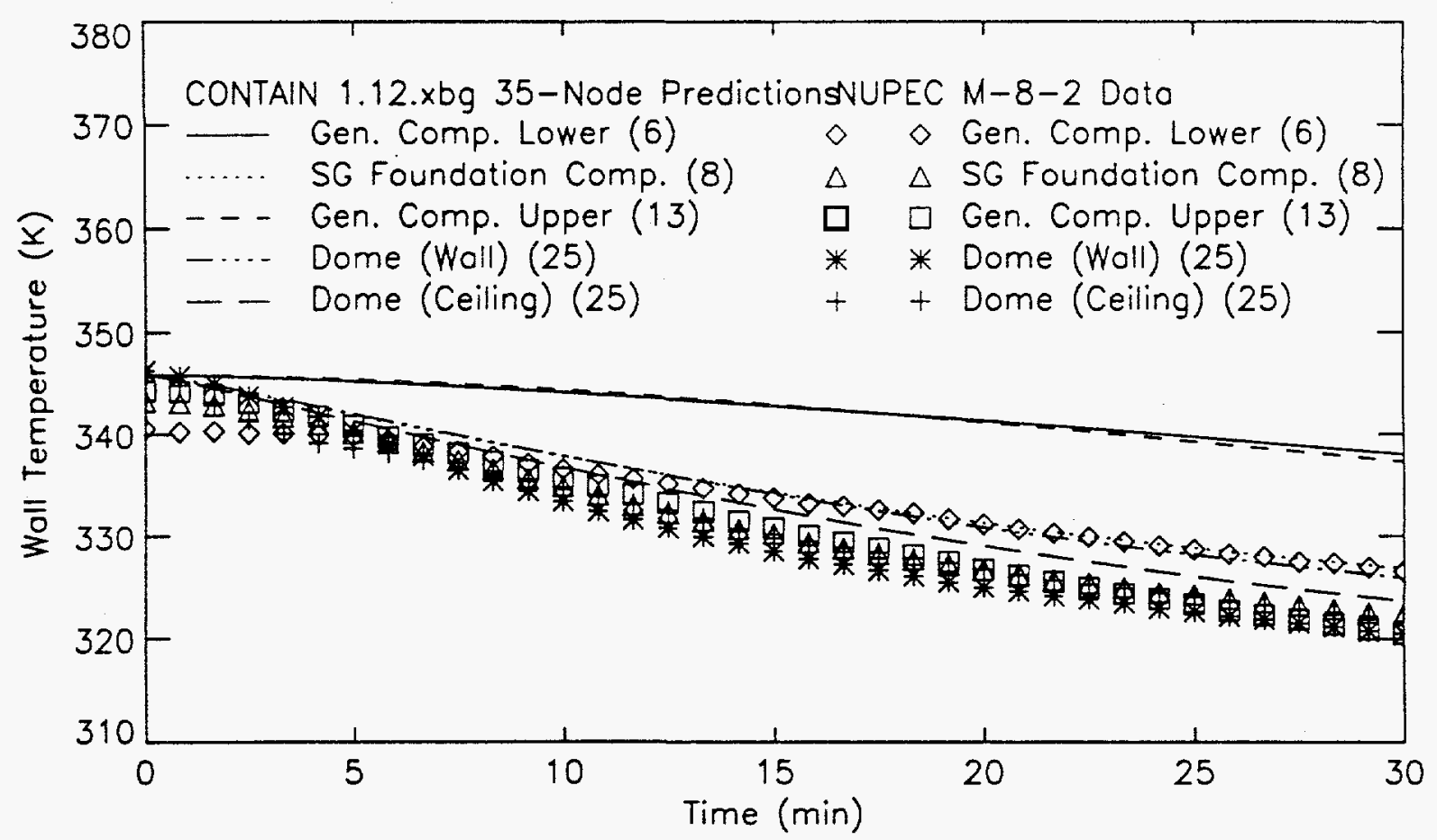

Figure 3.42.Comparison between the CONTAIN predictions and data of the NUPEC Test M8-2 wall temperatures for Compartments $6,8,13$, and 25 .

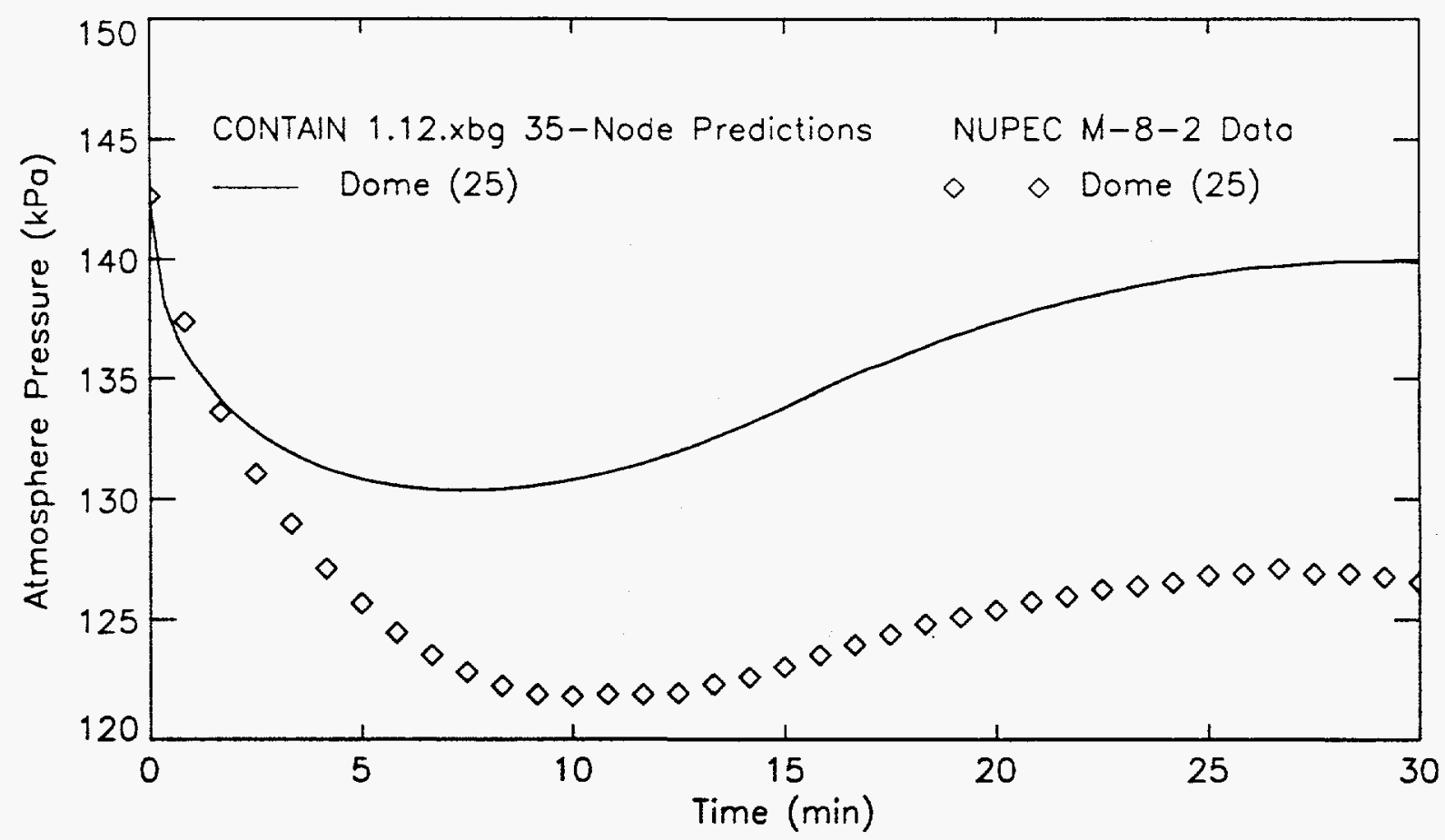

Figure 3.43.Comparison between the CONTAIN prediction and data of the NUPEC Test M-82 gas pressure for Compartment 25. 


\subsection{SENSITIVITY STUDIES}

\subsection{Flow Solvers and Nodalization Schemes}

NUPEC tests M-4-3, M-7-1, M-8-1, and M-8-2 offer an interesting opportunity to compare different flow solvers and nodalization schemes since typically only one main parameter that strongly affects the thermal hydraulics is varied when any two of these tests are compared. This allows potential strengths or weakness in the modelling approach to be isolated. Except for the release location, tests M-4-3 and M-8-1 were nearly identical, as were tests M-7-1 and M-8-2. Tests M-4-3 and M-7-1 both had low release locations while tests M-8-1 and M-8-2 had midpoint releases. The main difference between tests $M-4-3$ and $M-7-1$ was that water sprays were operated in test M-7-1 but not in test M-4-3. Other smaller differences between these two tests included different initial conditions in the facility and somewhat different flow rates for the helium and steam. However, these differences had a smaller effect on the thermal hydraulics than did the operation of water sprays or the change in elevation of the release point. The differences between tests $M-8-1$ and $M-8-2$ are similar to those of tests $M-4-3$ and M-7-1. The difference that created the biggest effect on the thermal hydraulics was that test M-8-2 had water sprays and test M-8-1 did not.

At the risk of oversimplifying the comparison among the four tests, Table 4.1 lists the differences that had the largest impact on the thermal hydraulics in the facility among these tests. It should be understood, however, that other differences existed, such as different initial conditions or different flow rates for helium and steam.

Table 4.1 Comparison of the differences that had the largest effect on the thermal hydraulics among the tests assessed by the CONTAIN code.

\begin{tabular}{lll} 
Release Location & No Sprays & Sprays \\
\hline Low & M-4-3 & M-7-1 \\
Midpoint & M-8-1 & M-8-2
\end{tabular}

When drawing conclusions from the results that are presented in the rest of this section, the following points must be kept in mind. For a given nodalization scheme, any differences in the results between different flow solvers can be attributed directly to the flow solvers' capabilities. This is because the same input deck was used for both flow solver calculations. However, different nodalization schemes used different input decks. Because these decks were constructed independently of each other, it cannot be guaranteed that the input decks were identical in every way except for the different nodalization scheme. Therefore, for a given flow solver, any conclusions drawn from results using different nodalization schemes should be drawn with more caution unless there were obvious differences in the results. The best example of this was for the M-7-1 input deck. The 28-node scheme did not include the effect of the sprays in the lower compartments or the effects of the enhanced heat transfer that was due to the spray-driven convection loops, which were included in the 35-node scheme. No such major differences existed, however, in the input decks for the other tests. 
Because of the voluminous results for the four tests, the comparison among different flow solvers and nodalization schemes will be illustrated primarily for the dome compartment. In some cases, such as in test $\mathrm{M}-8-1$, the results from additional rooms will be shown to reinforce the main points.

The results for test M-4-3 are shown in Figures 4.1-4.4. The differences in the results for the different flow solvers and nodalization schemes were not significant enough to identify any definitive trends. It is reasonable to expect that the differences would be minor, however, since the release point was low and the gases were well mixed.

The results for test M-7-1 are shown in Figures 4.5-4.8. Similar to the results for test M-4-3, the differences between the different flow solvers were not significant since the gases were well mixed by the water sprays and because of the low release point. As discussed earlier, the 28-node input deck did not include all of the features that were in the 35-node input deck. For example, it did not include the effect of the water sprays in the lower compartments or the enhanced heat transfer due to the spray-driven convection loop. The lack of enhanced heat transfer showed up most clearly in the predictions for the dome wall and, to some extent, the dome gas temperature.

The results for test M-8-1 are shown in Figures 4.9-4.12. They clearly show the superiority of the hybrid flow solver (XBG version) when used with the 35-node scheme. This is reasonable to expect since the mixture was stratified by the midpoint injection. The use of the hybrid flow solver, however, is a necessary but not sufficient condition for predicting stratified conditions. The nodalization scheme must be constructed so that sufficient mixing can occur above the source location. For example, the helium concentrations in a column of steam generator rooms of the facility are shown in Figures 4.13 and 4.14 for the predictions of the W version and XBG version, respectively, using the 28 -node scheme. While there was a slight improvement in the predicted concentration gradient with the XBG version, the strengths of this version could not be capitalized on since the gases were well mixed in the dome as a result of the single node representation. However, a significant improvement in the results was obtained when the dome was subdivided, allowing the gases to circulate in the dome. This is illustrated in Figures 4.15 and 4.16, which show the predictions for the $W$ and XBG versions, respectively, for the 35-node scheme. It should also be noted that the predictions for the helium concentration gradient using the 35-node scheme with the $W$ version were not as good as those using the 28-node scheme with this version. These results are shown in Figures 4.13 and 4.15. It is probable that the 35-node scheme allowed better mixing throughout the entire containment than the 28-node scheme when the $W$ version was used, which of course, was not desirable under stratified conditions. When the $\mathrm{W}$ version was used, this behavior was typical for both helium and gas temperature gradients for most of the rooms.

The results for test M-8-2 are shown in Figures 4.17-4.20. There were few differences between the different flow solvers for a given nodalization scheme. It would not have been unreasonable to expect predictions based on the 35-node scheme with the XBG version to have been substantially different than those of the $\mathrm{W}$ version for the same nodalization scheme, similar to the predictions for test M-8-1. The helium was well mixed in test M-8-2 because of the water sprays. However, since CONTAIN does not model the hydrodynamic 
drag of the water sprays on the air, from this perspective alone, it does not recognize any difference between tests $\mathrm{M}-8-1$ and $\mathrm{M}-8-2$. It would be reasonable to assume that CONTAIN's predicted mixing behavior for test M-8-2 would be similar to the predicted behavior for M-81 with some differences due to changes in the heat transfer. However, CONTAIN predicted that the helium in test M-8-2 was nearly as well mixed in the XBG flow solver as in the W version. Apparently the predicted natural convection induced by condensation as the gases in the center of the facility were cooled by the water sprays was sufficient to allow thorough mixing of the helium. 


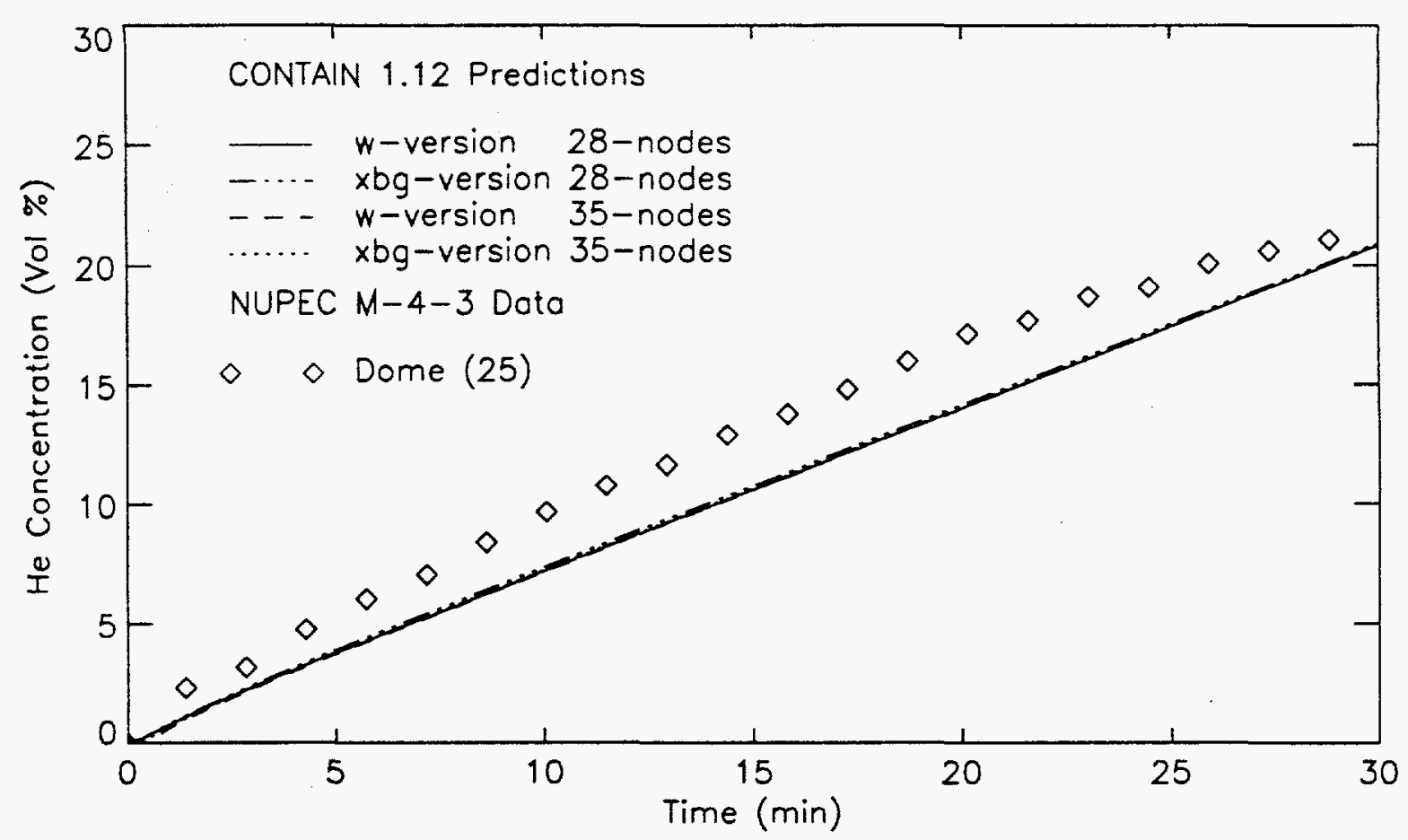

Figure 4.1. Comparison between the dome helium concentration data of NUPEC Test M-4-3 and the CONTAIN predictions using the $\mathrm{W}$ and $\mathrm{XBG}$ code versions and the 28 node and 35-node schemes.

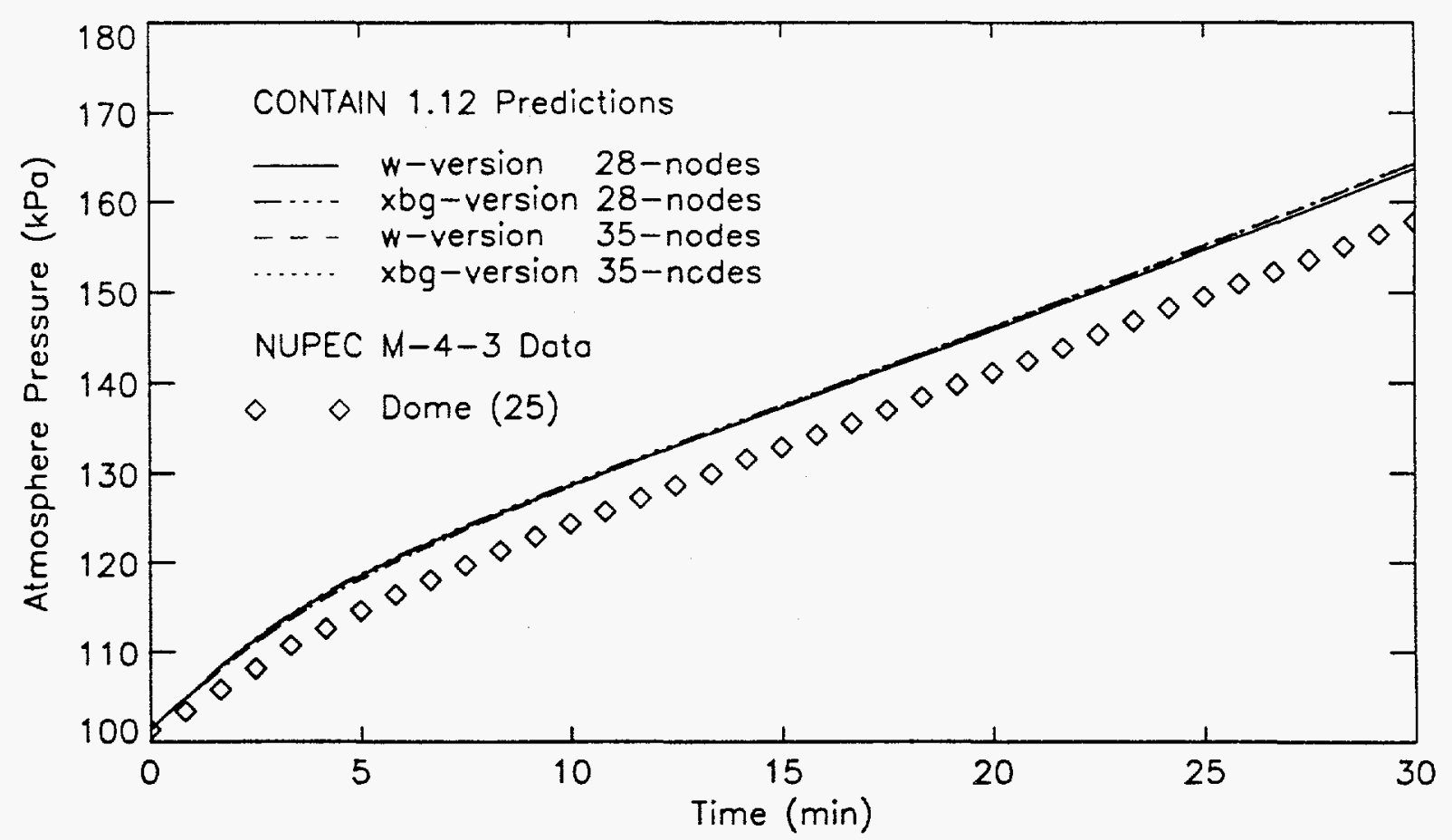

Figure 4.2. Comparison between the dome gas pressure data of NUPEC Test M-4-3 and the CONTAIN predictions using the $\mathrm{W}$ and $\mathrm{XBG}$ code versions and the 28 -node and 35-node schemes. 


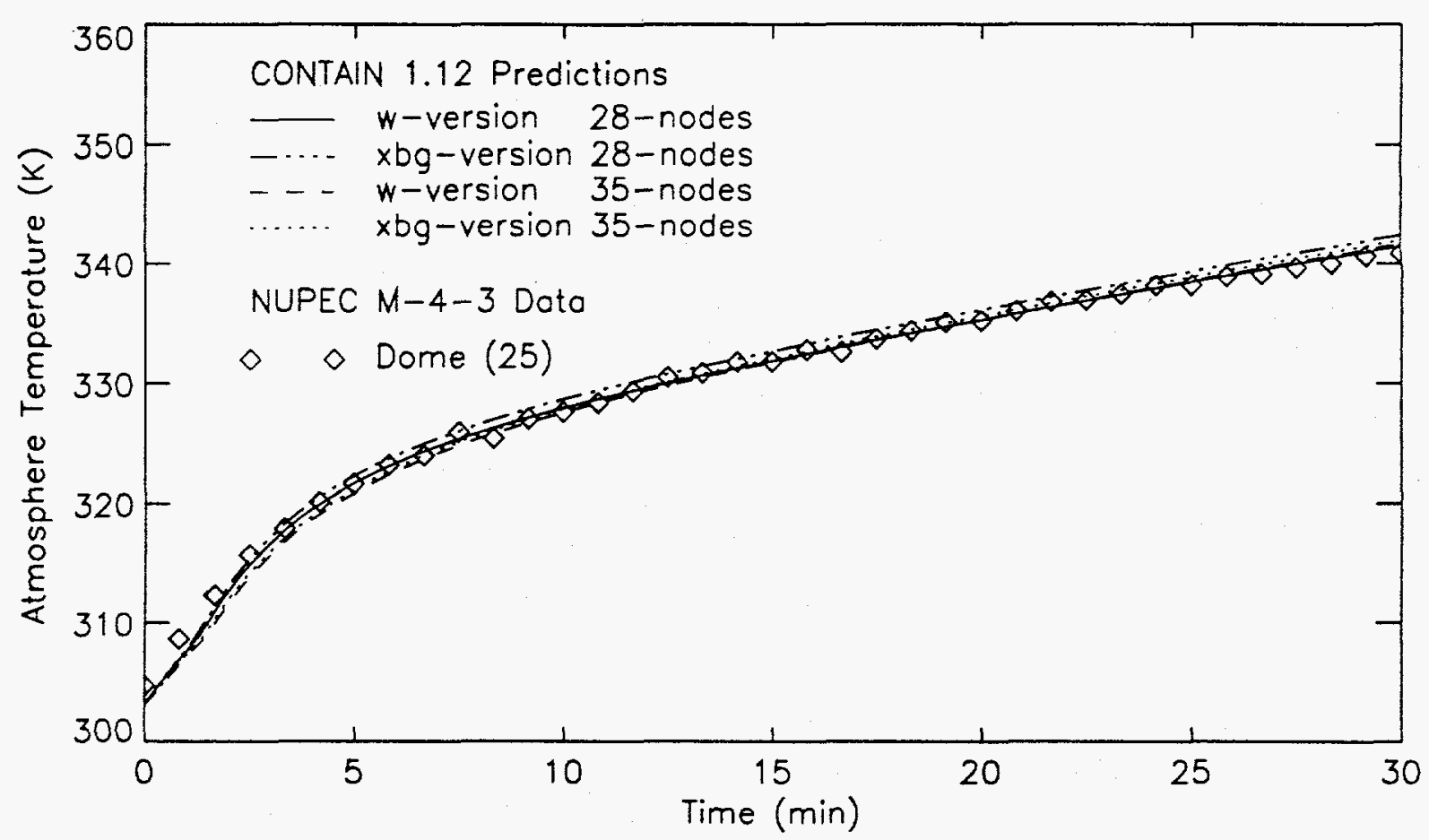

Figure 4.3. Comparison between the dome gas temperature data of NUPEC Test M-4-3 and the CONTAIN predictions using the $\mathrm{W}$ and XBG code versions and the 28 -node and 35-node schemes.

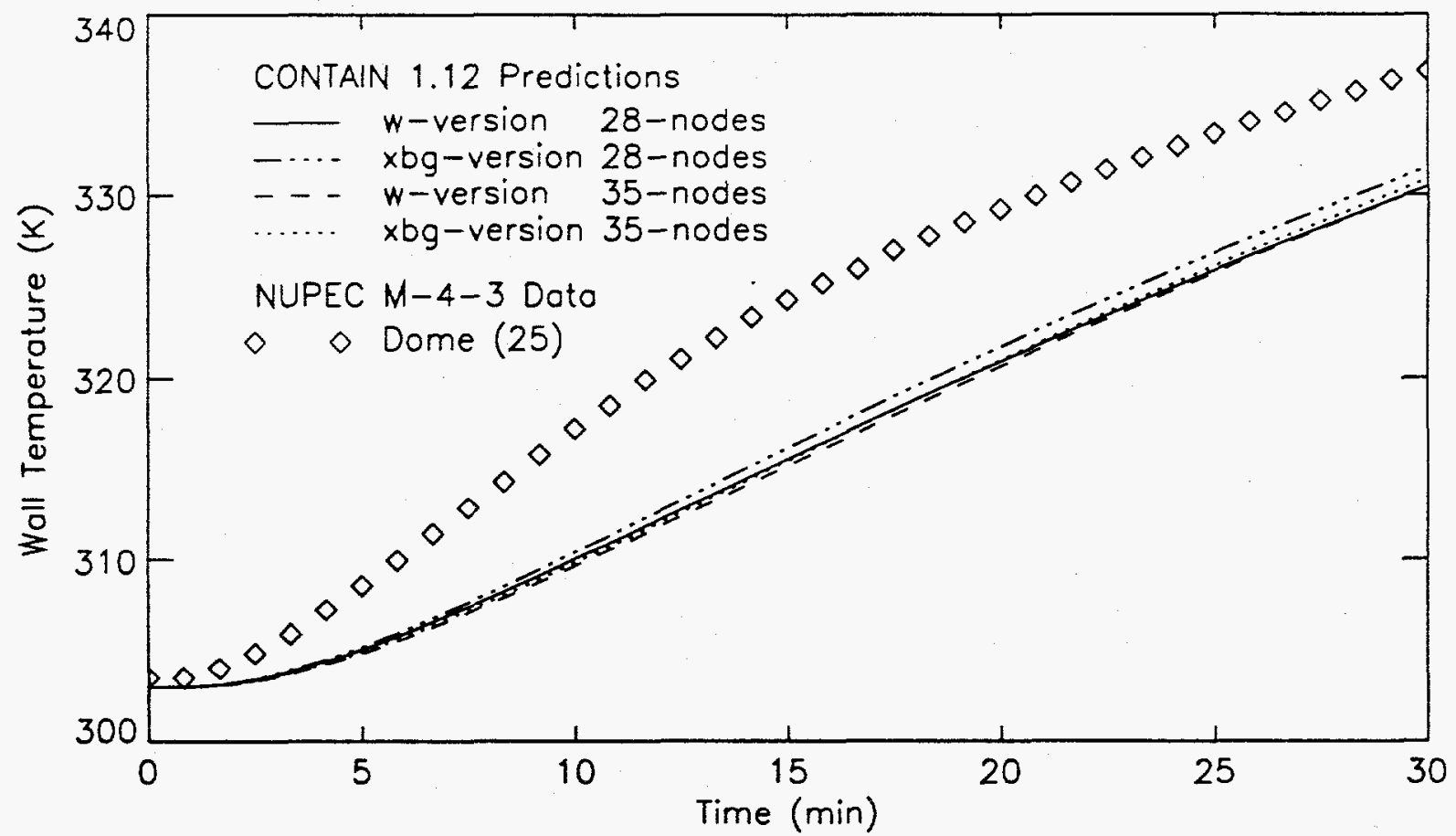

Figure 4.4. Comparison between the dome wall temperature data of NUPEC Test M-4-3 and the CONTAIN predictions using the $\mathrm{W}$ and XBG code versions and the 28-node and 35-node schemes. 


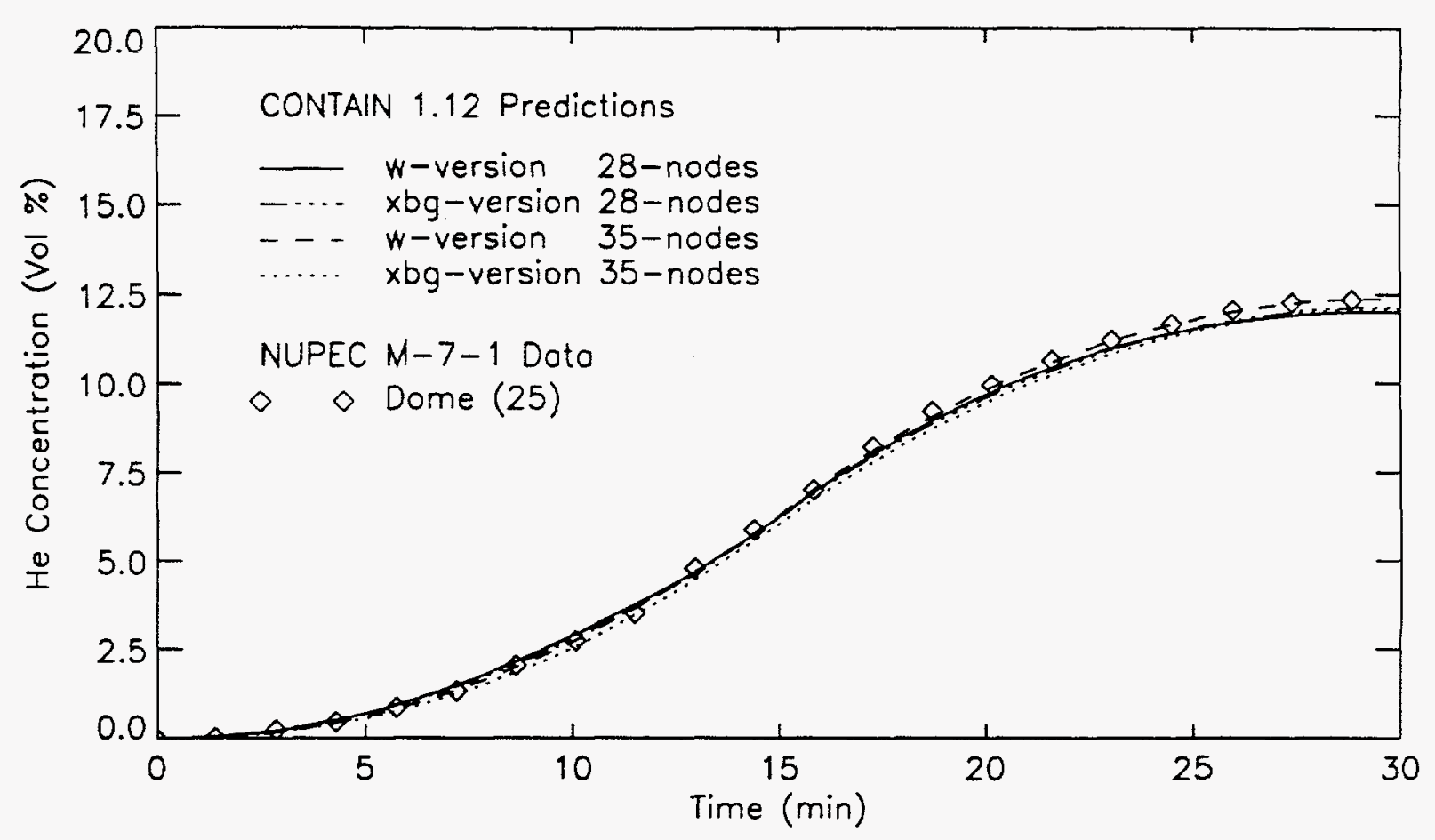

Figure 4.5. Comparison between the dome helium concentration data of NUPEC Test M-7-1 and the CONTAIN predictions using the $\mathrm{W}$ and XBG code versions and the 28 node and 35-node schemes.

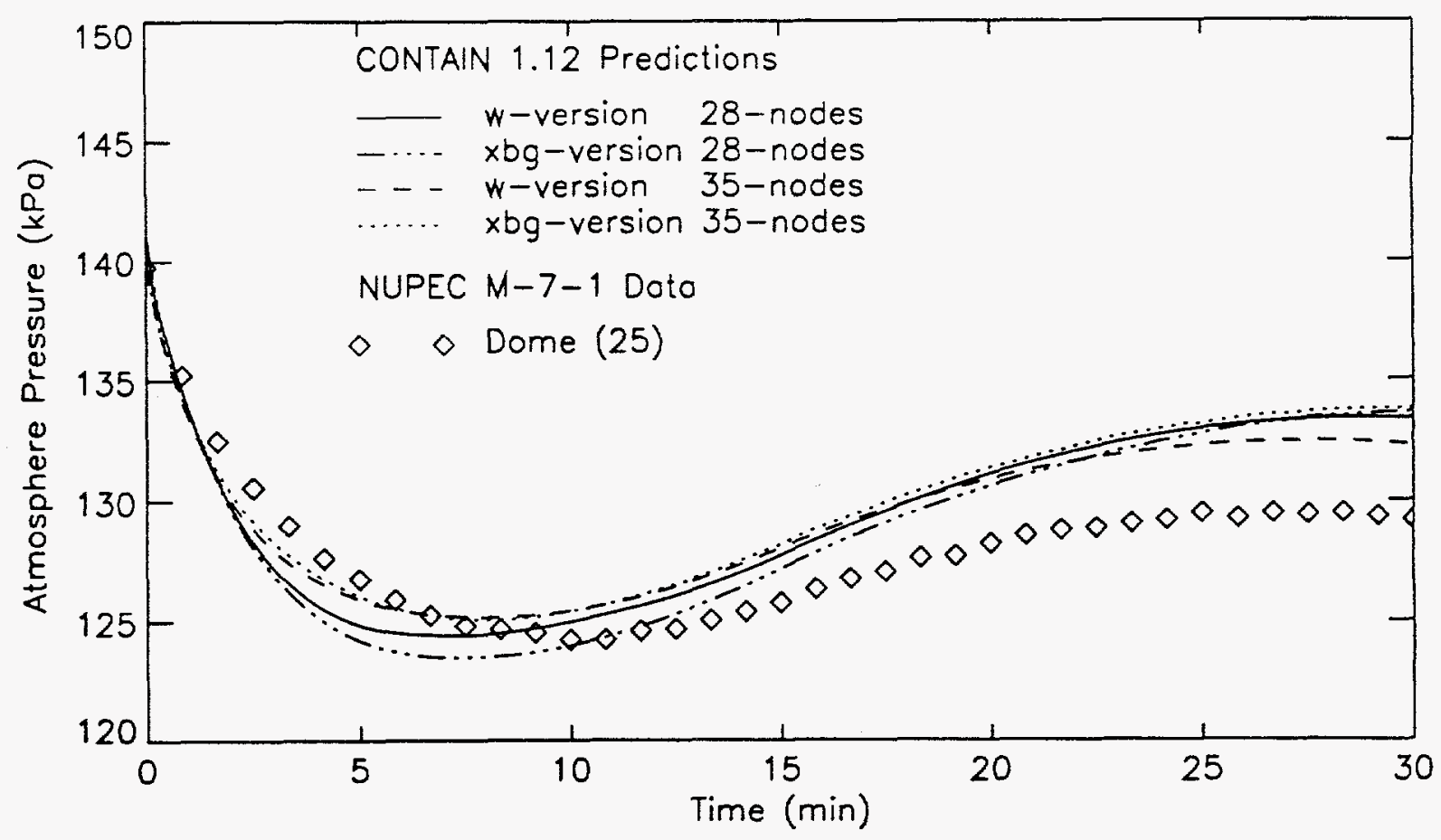

Figure 4.6. Comparison between the dome gas pressure data of NUPEC Test M-7-1 and the CONTAIN predictions using the $W$ and $X B G$ code versions and the 28 -node and 35-node schemes. 


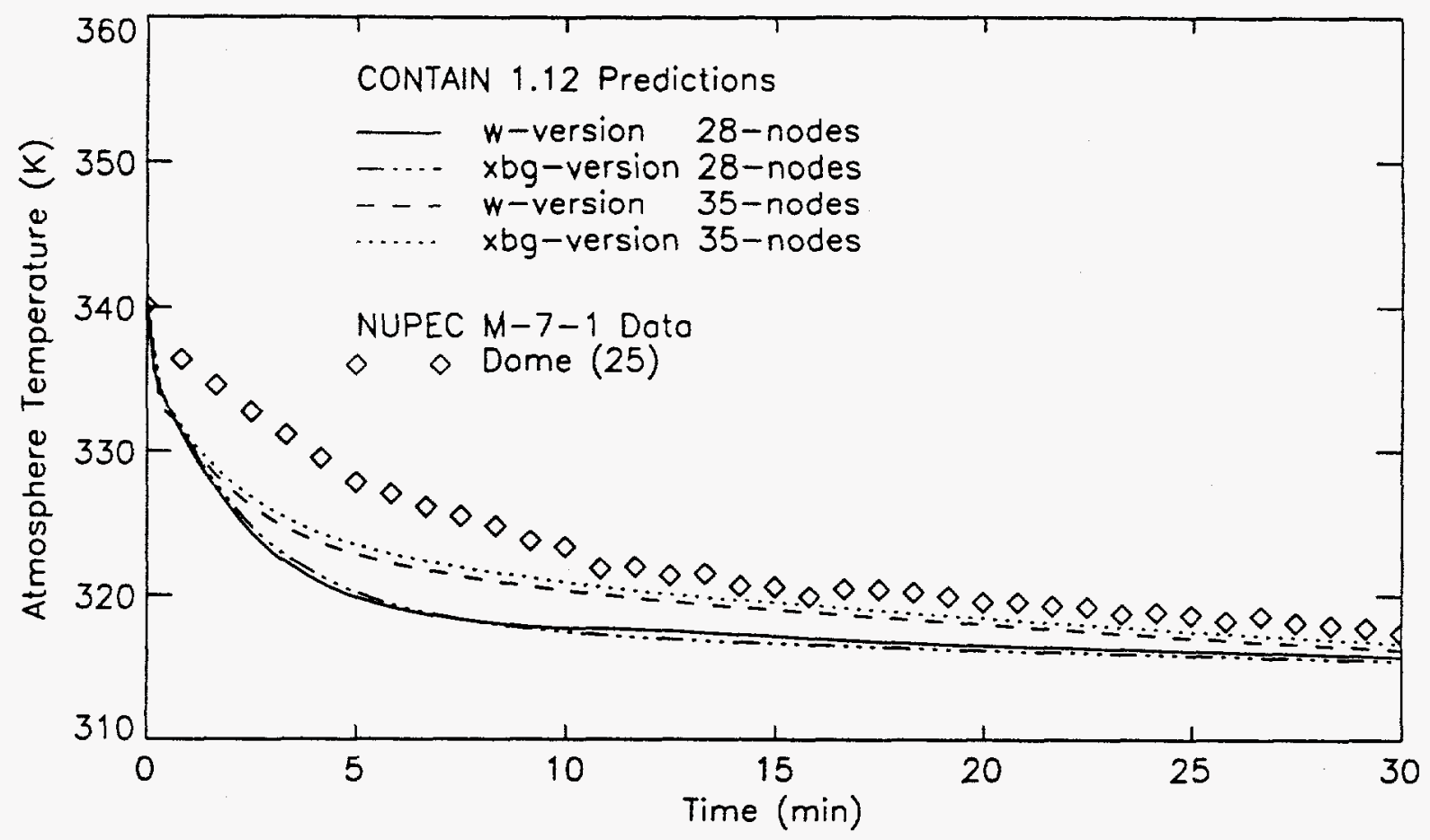

Figure 4.7. Comparison between the dome gas temperature data of NUPEC Test M-7-1 and the CONTAIN predictions using the $W$ and $X B G$ code versions and the 28 -node and 35-node schemes.

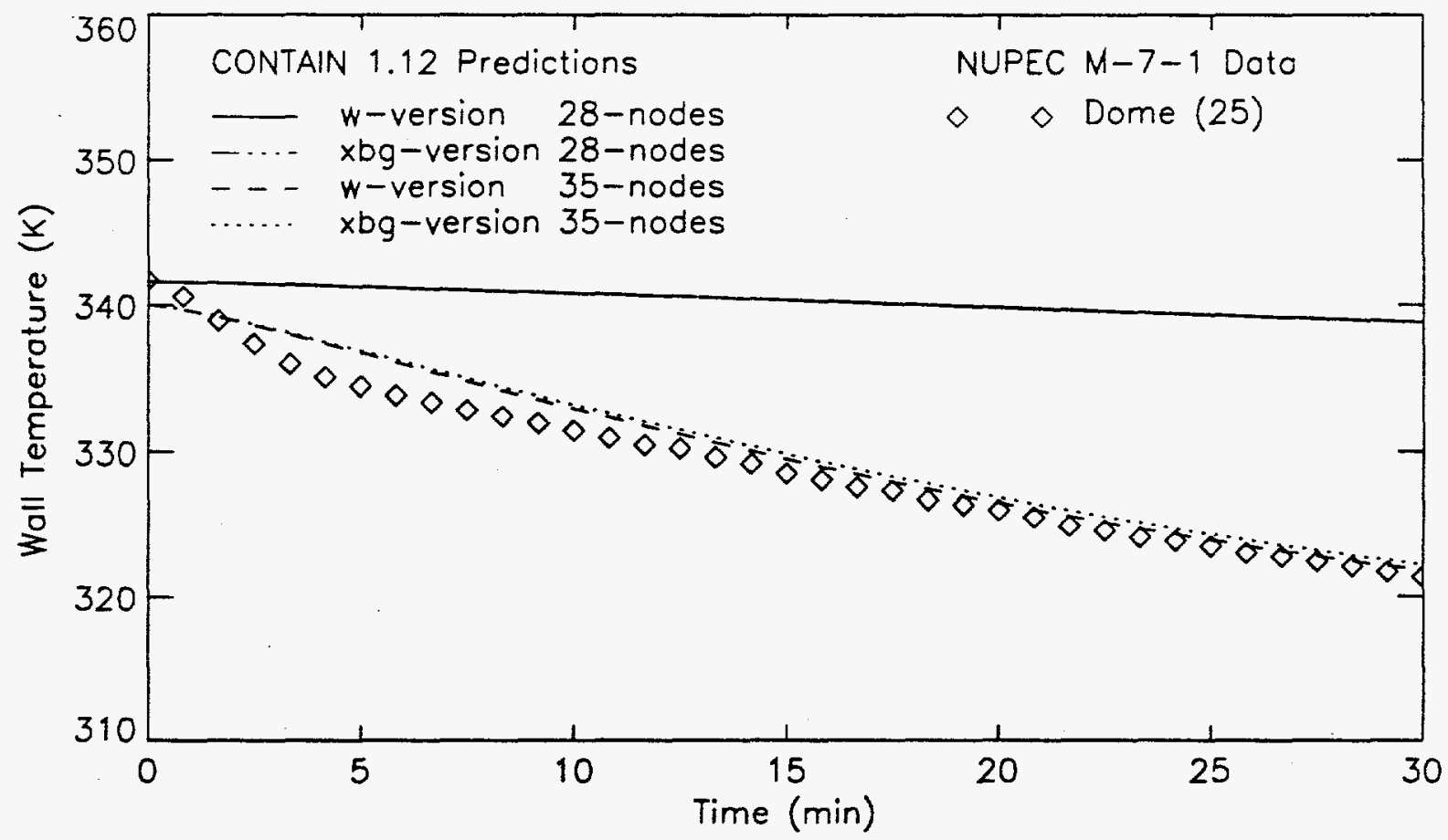

Figure 4.8. Comparison between the dome wall temperature data of NUPEC Test $\mathrm{M}-7-1$ and the CONTAIN predictions using the $\mathrm{W}$ and XBG code versions and the 28 -node and 35-node schemes. 


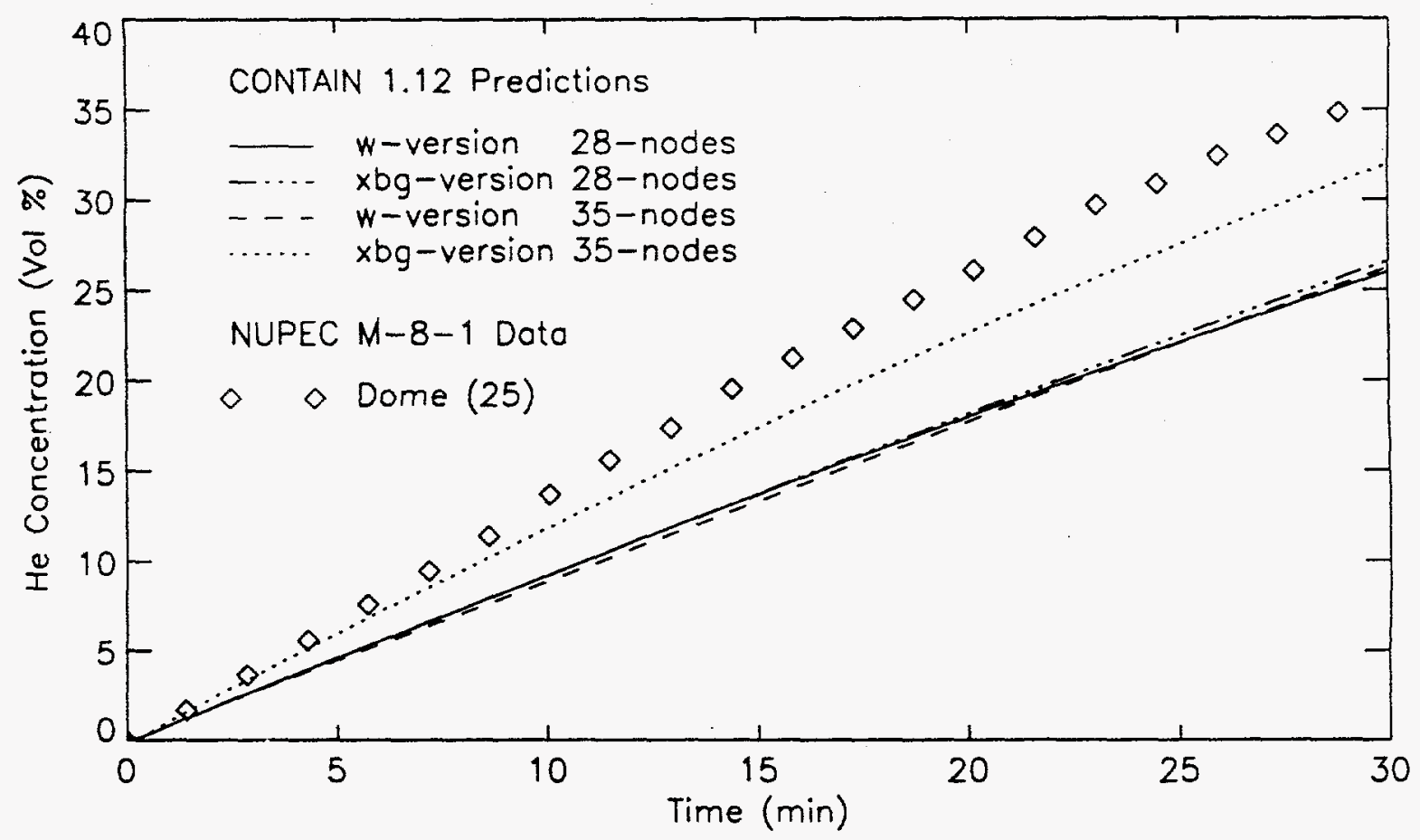

Figure 4.9. Comparison between the dome helium concentration data of NUPEC Test M-8-1 and the CONTAIN predictions using the W and XBG code versions and the 28node and 35-node schemes.

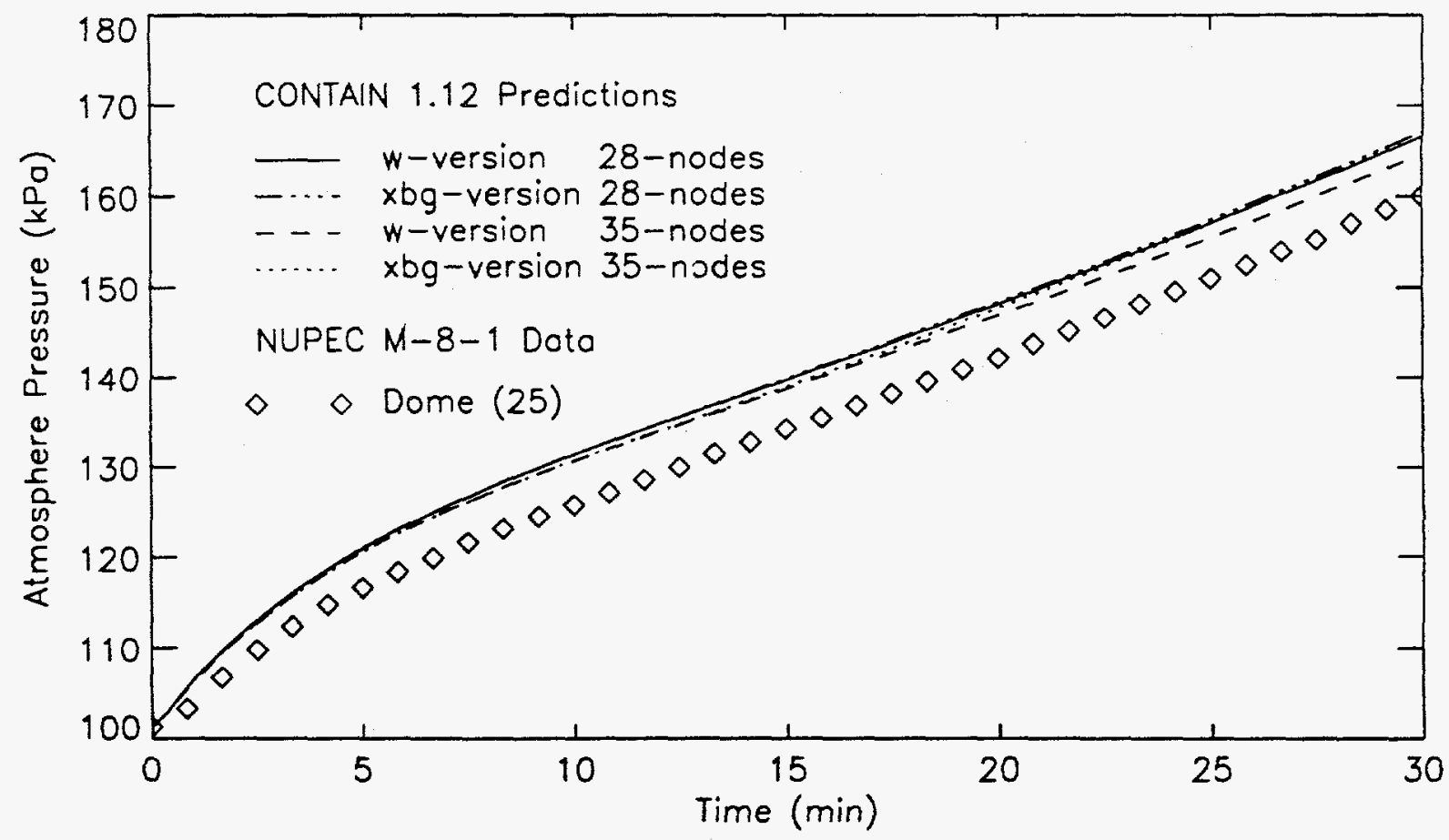

Figure 4.10.Comparison between the dome gas pressure data of NUPEC Test M-8-1 and the CONTAIN predictions using the $\mathrm{W}$ and XBG code versions and the 28 -node and 35-node schemes. 


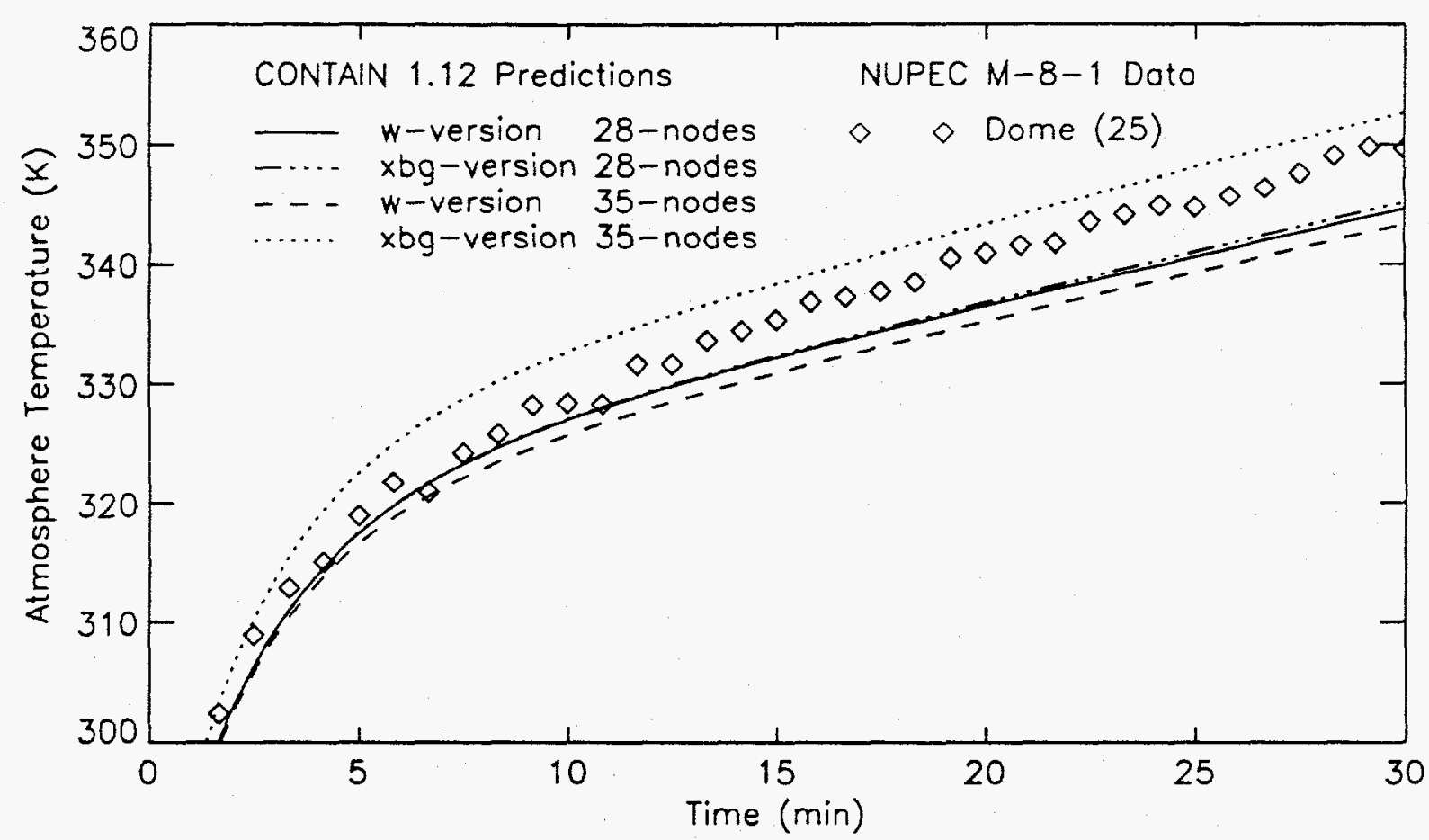

Figure 4.11.Comparison between the dome gas temperature data of NUPEC Test M-8-1 and the CONTAIN predictions using the W and XBG code versions and the 28 -node and 35-node schemes.

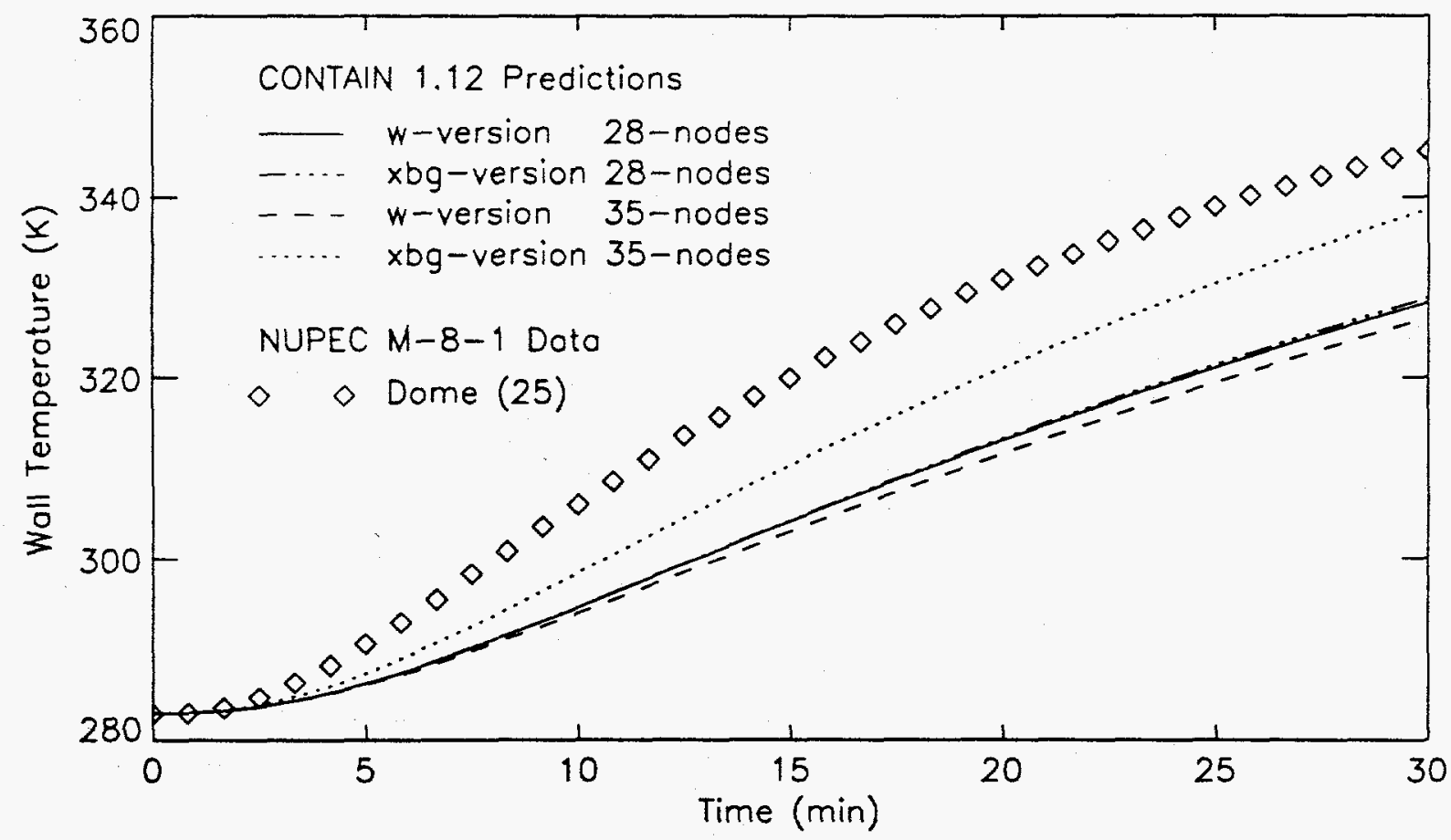

Figure 4.12.Comparison between the dome wall temperature data of NUPEC Test M-8-1 and the CONTAIN predictions using the $\mathrm{W}$ and XBG code versions and the 28-node and 35-node schemes. 


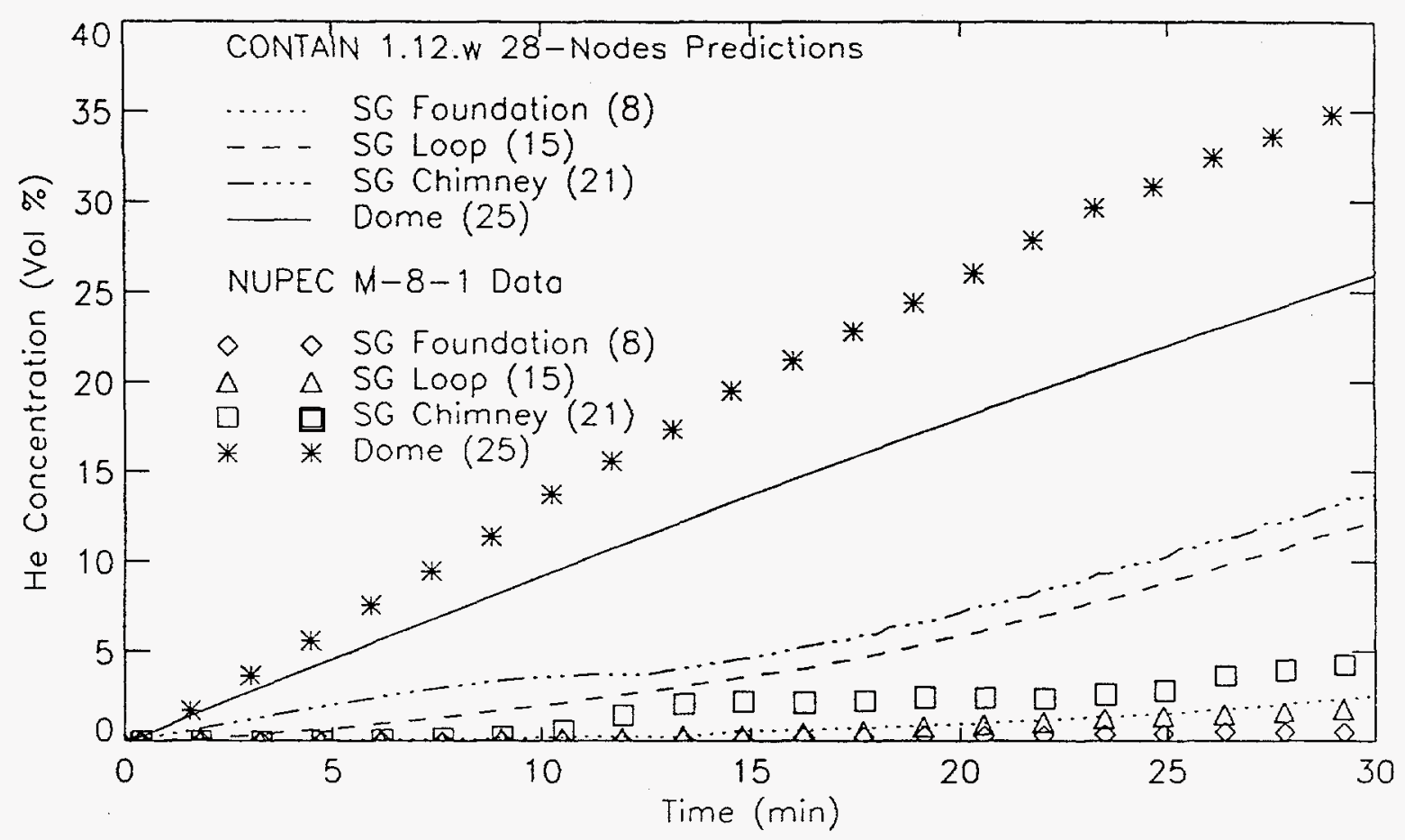

Figure 4.13.Comparison between the CONTAIN predictions using the $\mathrm{W}$ version and the 28node scheme and data of the NUPEC Test M-8-1 helium concentrations for Compartments $8,15,21$, and 25 .

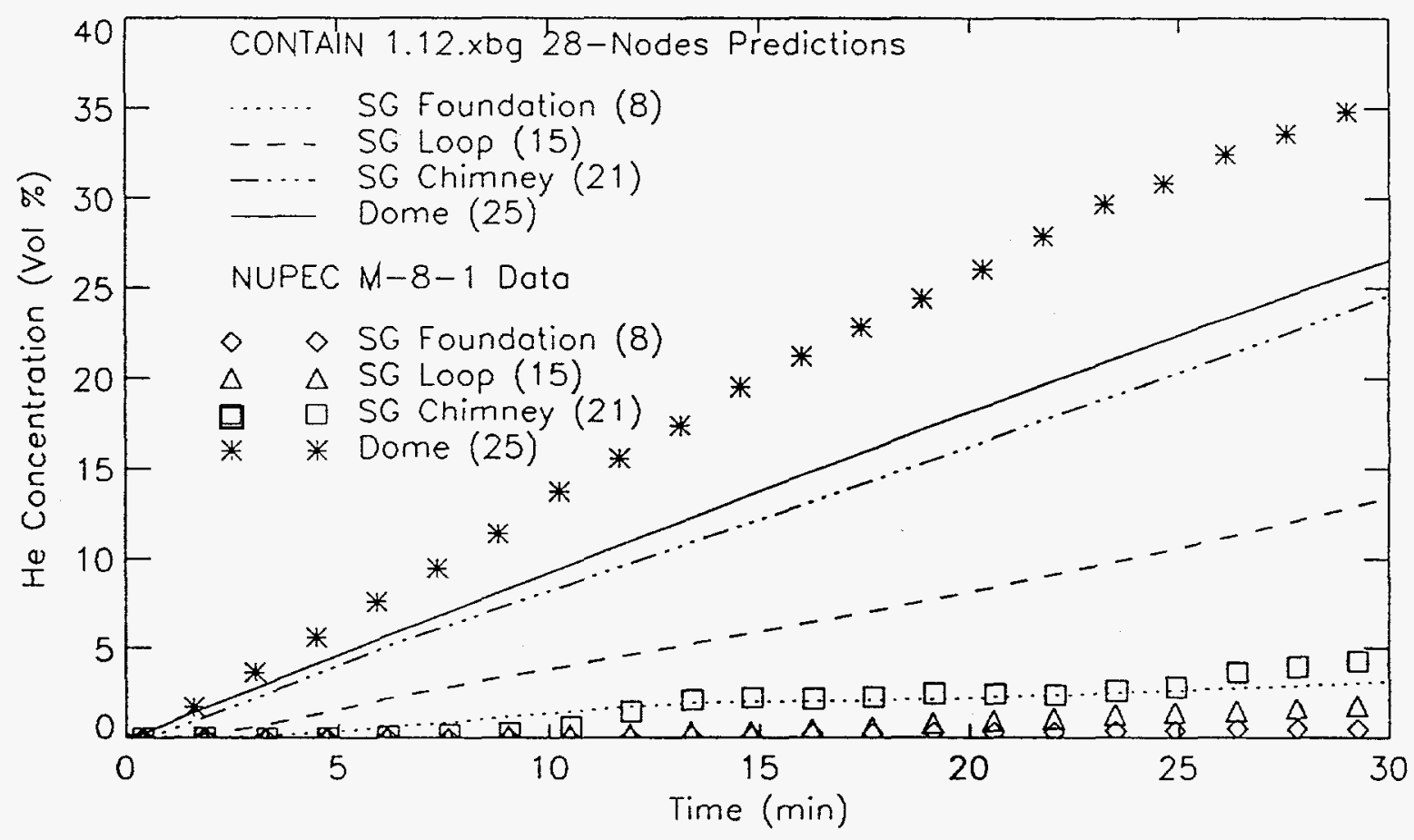

Figure 4.14.Comparison between the CONTAIN predictions using the XBG version and the 28-node scheme and data of the NUPEC Test M-8-1 helium concentrations for Compartments $8,15,21$, and 25 . 


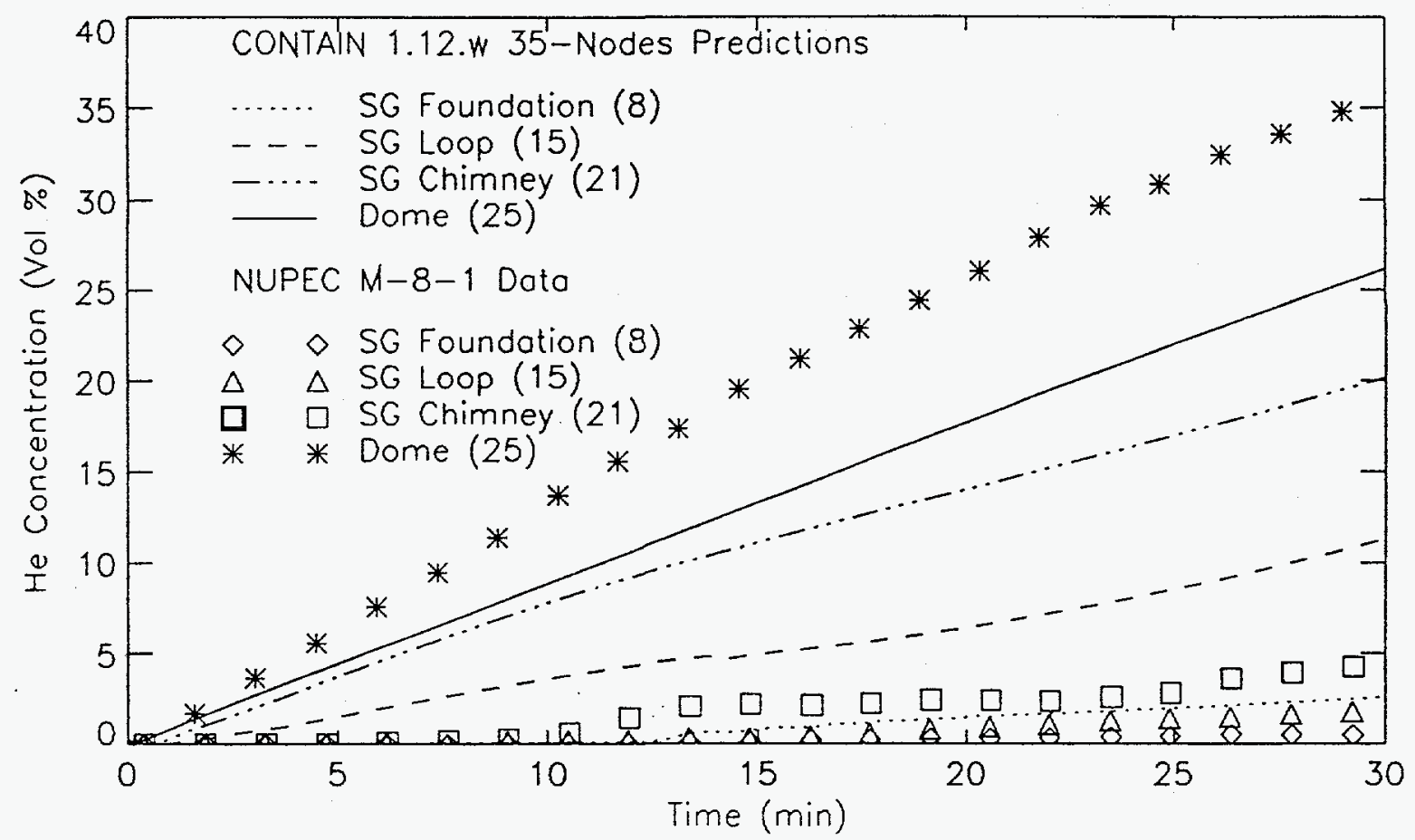

Figure 4.15.Comparison between the CONTAIN predictions using the $\mathrm{W}$ version and the 35node scheme and data of the NUPEC Test M-8-1 helium concentrations for Compartments $8,15,21$, and 25 .

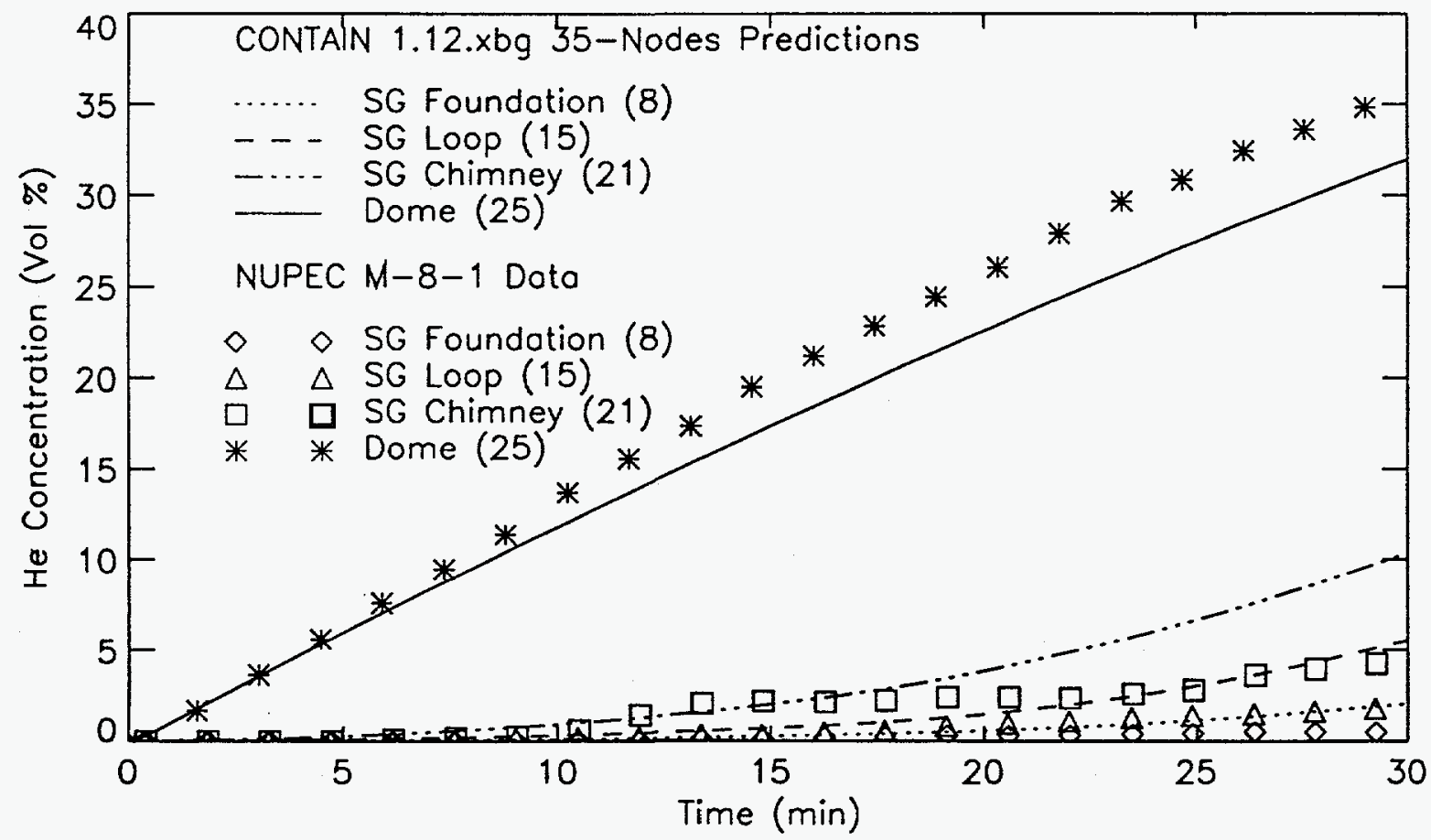

Figure 4.16.Comparison between the CONTAIN predictions using the XBG version and the 35-node scheme and data of the NUPEC Test M-8-1 helium concentrations for Compartments 8, 15, 21, and 25 . 


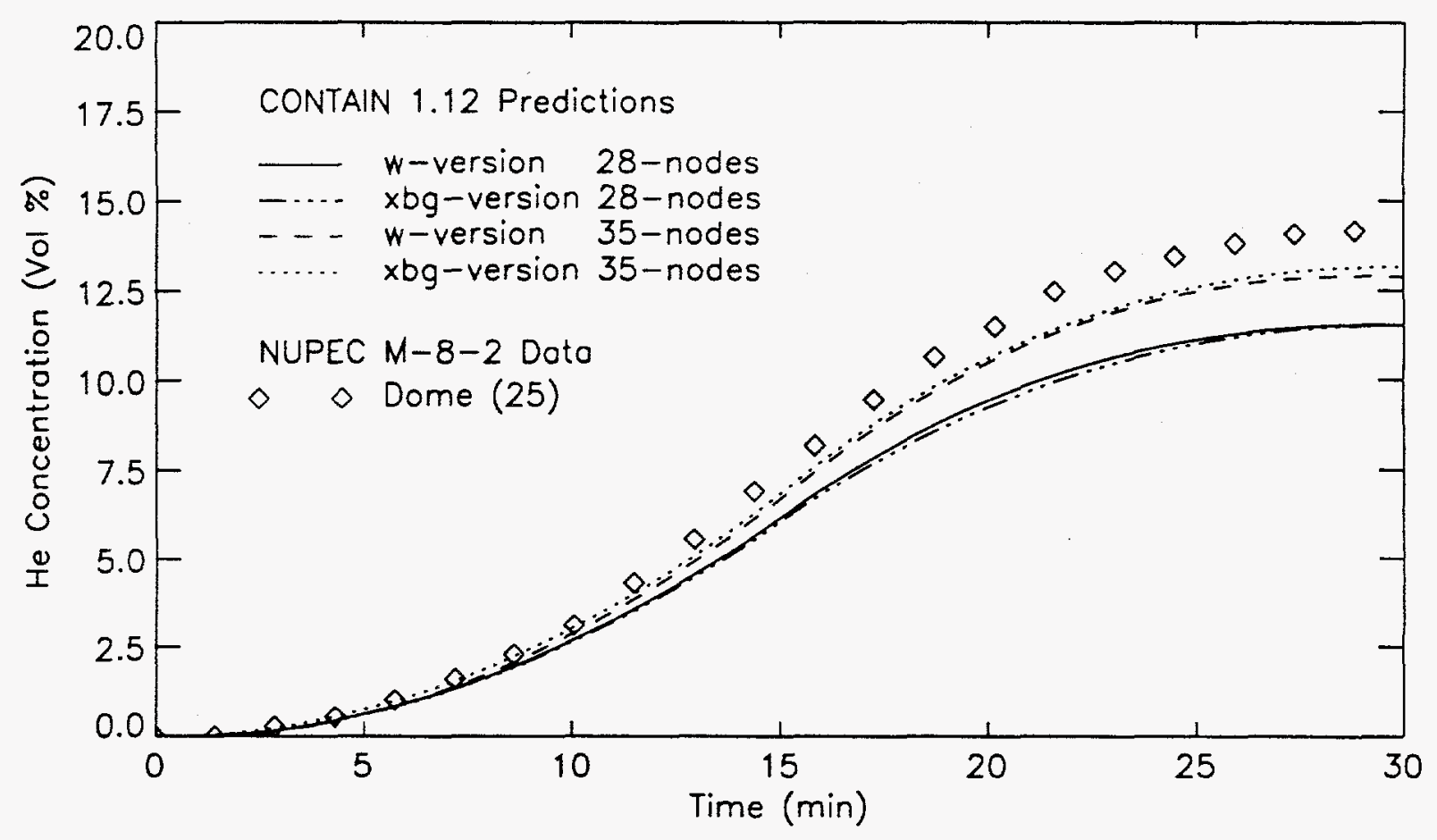

Figure 4.17.Comparison between the dome helium concentration data of NUPEC Test M-8-2 and the CONTAIN predictions using the $\mathrm{W}$ and XBG code versions and the 28 node and 35-node schemes.

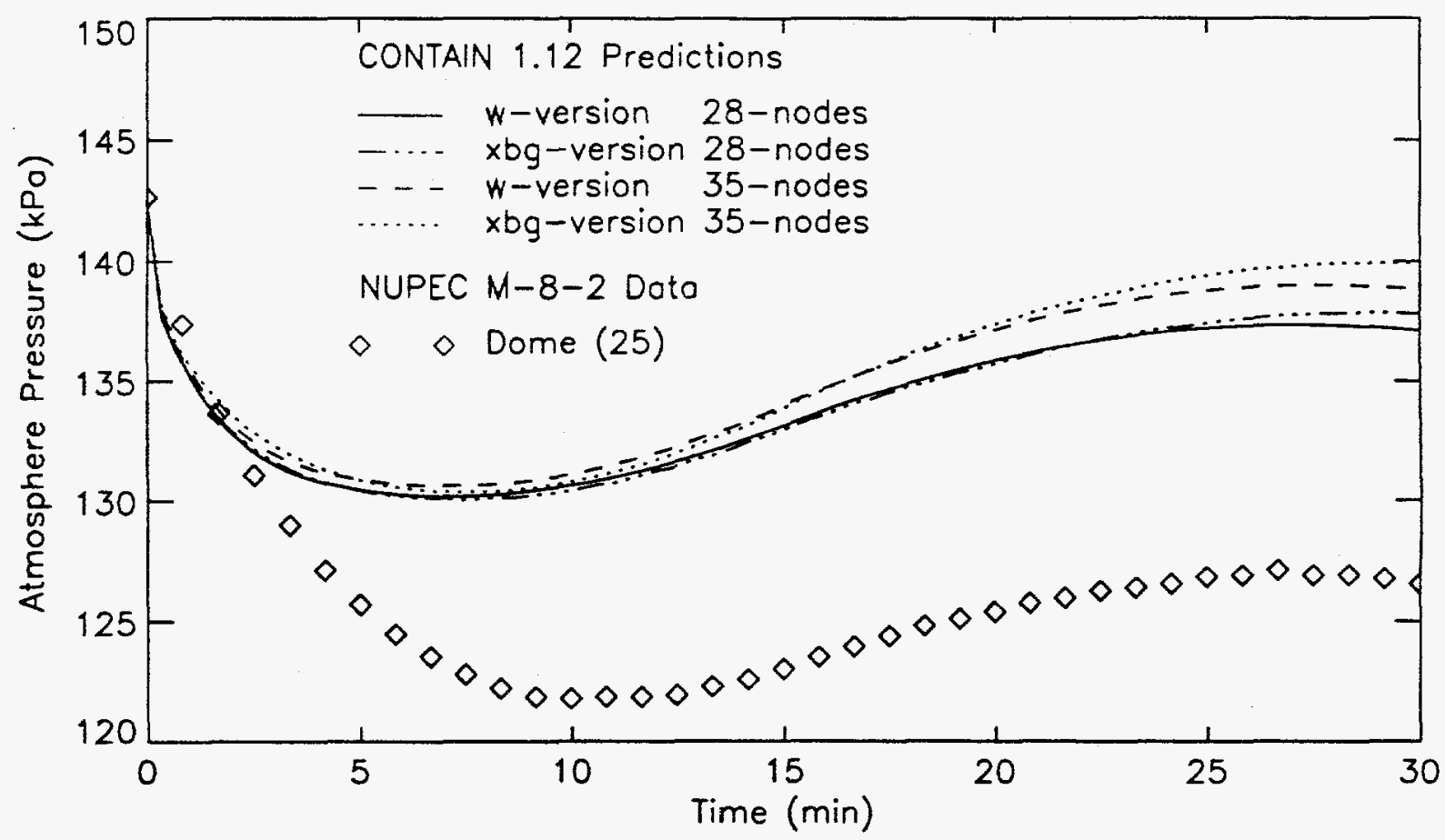

Figure 4.18.Comparison between the dome gas pressure data of NUPEC Test M-8-2 and the CONTAIN predictions using the $W$ and XBG code versions and the 28 -node and 35-node schemes. 


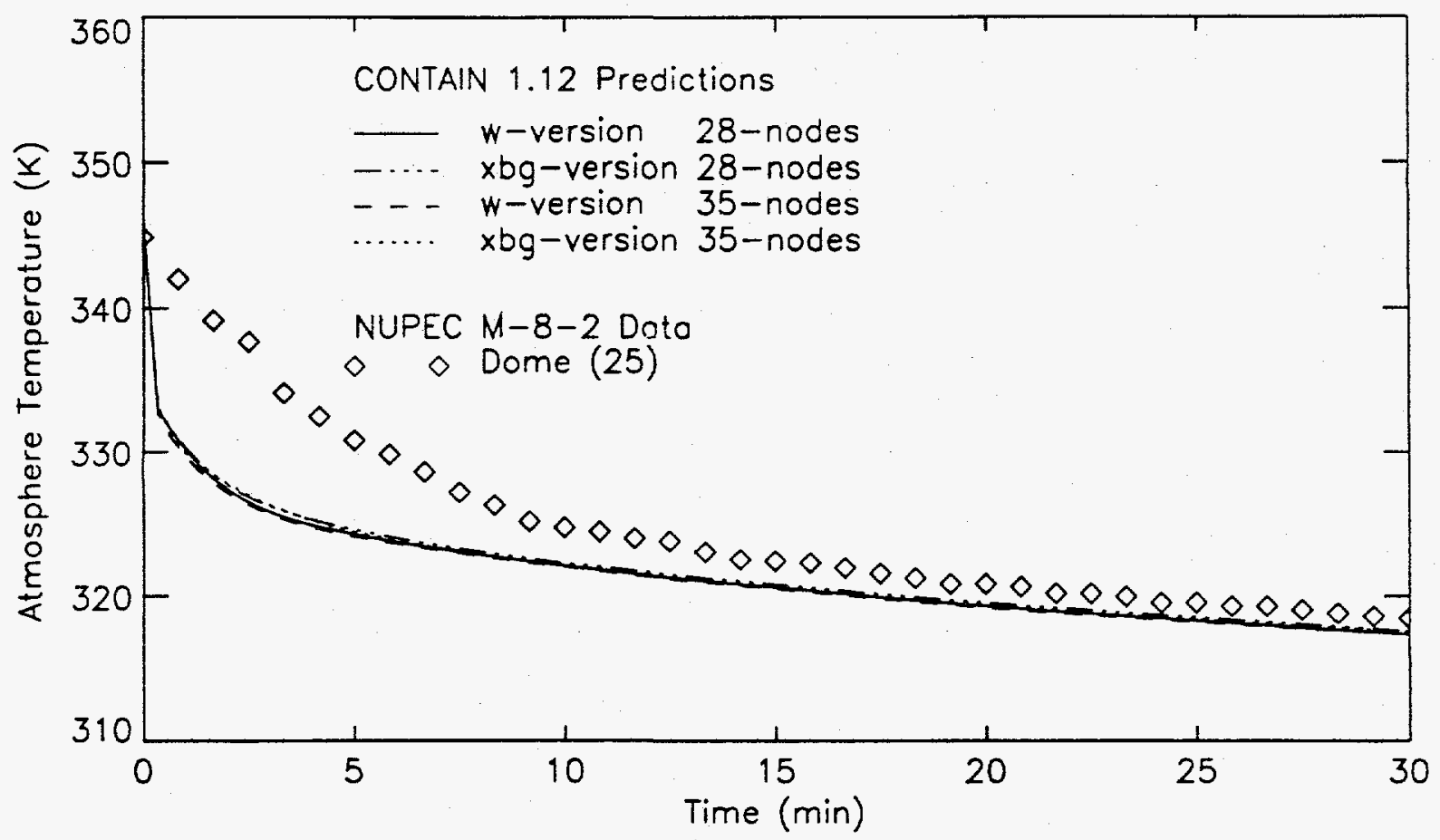

Figure 4.19.Comparison between the dome gas temperature data of NUPEC Test M-8-2 and the CONTAIN predictions using the $\mathrm{W}$ and XBG code versions and the 28 -node and 35-node schemes.

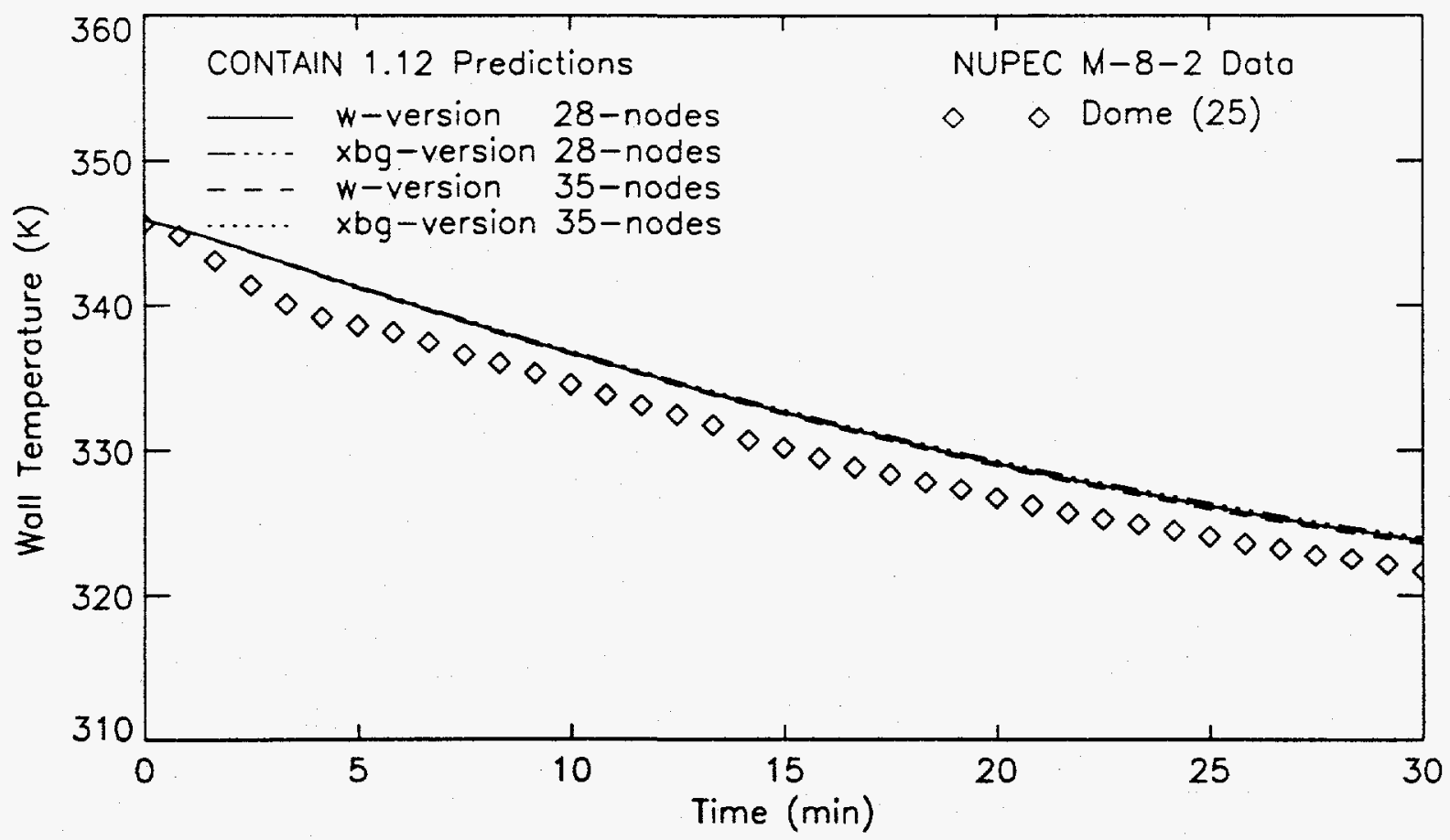

Figure 4.20.Comparison between the dome wall temperature data of NUPEC Test M-8-2 and the CONTAIN predictions using the $W$ and $X B G$ code versions and the 28 -node and 35-node schemes. 


\subsection{Sensitivity Studies of NUPEC Test M-7-1}

Test M-7-1 was designated as the International Standard Problem 35 (ISP-35). As such, a more detailed study of this test was performed than for the other NUPEC tests. Many of the ideas for the following sensitivity studies evolved from workshops on the ISP-35. Some of the modeling approaches were used in other code calculations as well. The results of these calculations are given in Reference 1. Additional analyses were performed using the CONTAIN code subsequent to the work reported in Reference 1. The results given in the present report were obtained using improved modeling techniques and are the "best estimate" predictions. The sensitivity studies were performed to better understand the differences between the predictions and the data. The preheat phase of test M-7-1 is discussed first and then the test phase.

\subsubsection{Preheat Phase}

The preheat phase of test M-7-1 was a relatively simple experiment: steam was injected into an insulated steel containment. The final gas pressure was determined by the difference between the energy added from the steam, energy absorbed by the structures, and the energy lost though the containment shell. Uncertainties from the added energy could come from two sources: the uncertainty in the steam mass flow rate and in the thermodynamic state of the steam at the injection point. Uncertainties in the energy absorbed by the structures could result from uncertainties in the heat capacity of the structures, such as in the density or specific heats of the materials, the total mass of the structures, or in the material properties, such as the thermal conductivity, that determine the rate at which energy is absorbed into the structures. Uncertainties in the energy loss through the containment shell could result from uncertainties in the heat transfer from the gas to the structures primarily through condensation, heat transfer through the structures by conduction, and heat loss from the containment shell to the environment. The nodalization scheme also affected the transport of steam throughout the containment, which could affect the heat transfer to the structures. Each of these potential contributors to the discrepancies in the predictions will be discussed in the rest of this section.

Energy was added to the containment by steam only. The uncertainty in the steam mass flow rate is estimated at $\pm 2 \%$ [1]. Two calculations were performed by decreasing and increasing the steam mass flow rate by $2 \%$ from that specified by NUPEC. Except for changes in the steam mass flow rate, these calculations were identical to the best-estimate calculation discussed in Section 3.3. The uncertainty in the steam mass flow rate only accounted for $\pm 1.4 \mathrm{kPa}$ at the point of peak pressure, which is not enough to account for the discrepancy in the predicted results. The other possible uncertainty in the energy addition was in the thermodynamic state of the steam at the injection point. The steam was specified as saturated at $165^{\circ} \mathrm{C}$ when it left the boiler but energy was lost before it was injected into the containment. The temperature of the steam at the injection point into the containment was measured at $110^{\circ} \mathrm{C}$. The quality of the steam was calculated to be saturated at the injection point based on heat loss estimates. Saturated steam was assumed for the best-estimate calculation. However, since the quality of the steam was estimated and not measured, uncertainty exists in the enthalpy of the steam. A calculation was performed in which the enthalpy of the steam was reduced by $10 \%$. The peak pressure for this calculation was $144.2 \mathrm{kPa}$, which was very close to the measured peak pressure. Furthermore, as shown in Figure 4.21, the pressure history between the predicted and measured results was quite similar. 
The total energy absorbed by the structures and the rate at which the energy was absorbed was determined by the material properties and total mass of the structures. The facility was constructed of carbon steel and material properties specified by NUPEC were used in the bestestimate calculation. Since these properties, especially the thermal conductivity, resembled those of pure iron, a calculation was performed using the material properties of plain carbon steel as specified in Reference [5]. The peak pressure was predicted to be $152.0 \mathrm{kPa}$, a difference of less than $1 \mathrm{kPa}$ greater than the best-estimate calculation. In fact, as shown in Figure 4.21 , the heat capacity $(\rho c)$ of all structures and walls composed of steel would have to be increased by $25 \%$ before agreement could be obtained between the predicted and measured peak pressures. Although the pressure history is similar to the data, a $25 \%$ deviation in material properties is well beyond any reasonable uncertainty. This result was obtained by increasing both the density and heat capacity of the steel in equal percentages so that the total heat capacity was $25 \%$ greater than that used in the best-estimate calculation. Likewise, a $25 \%$ error in the mass of the steel could also account for the difference in heat capacity although this appears to be beyond reasonable estimates of uncertainty. Of the ferrous materials, such as carbon or stainless steels, iron has the largest thermal conductivity. Calculations using values of the thermal conductivity, from the largest value for pure iron to the lowest value for stainless steel, yield only predicted peak pressures greater than the best-estimate prediction. In other words, realistic variations in the thermal conductivity result only in larger deviations between the predicted and measured peak pressures in the preheat phase. It does not appear reasonable that uncertainty in material properties accounts for the discrepancy between the predictions and the data.

There are three main thermal resistances to transferring energy from the gas to the environment through the containment shell: the heat transfer from the gas to the inside of the containment wall, heat transfer by conduction through the steel wall and insulation covering, and heat transfer from the surface of the insulation to the environment. Of these three, the thermal resistance of the insulation is the largest.

CONTAIN calculates the convective heat transfer from the gas to the structures using the temperature difference between the bulk gas and film-atmosphere temperatures and a heat transfer coefficient derived from a Nusselt correlation for either forced convection, laminar natural convection, or turbulent natural convection. Heat transfer from steam condensation is calculated using these correlations as well via the heat-mass transfer analogy. A reasonable uncertainty for the Nusselt correlations is approximately $30 \%$. When the heat transfer coefficient and the corresponding mass transfer coefficient based on these correlations were increased by $30 \%$, however, the predicted peak pressure was only $1 \mathrm{kPa}$ lower than the best-estimate prediction. In fact, to get the predicted peak pressure to match the measured peak pressure, the heat and mass transfer coefficients would have to be increased by a factor of more than 10 , an amount which is beyond any reasonable estimates of uncertainty for the heat and mass transfer coefficients. The results for the calculation in which the heat transfer coefficient was increased by a factor of ten are shown in Figure 4.21. Note that even though the predicted peak pressure nearly matched the data, the pressure history was not similar to the data.

The insulation material covering the steel shell was the controlling thermal resistance for the heat transfer through the containment shell. The thermal conductivity of the insulation must 
be increased by approximately a factor of five before the predicted peak pressure matches the data. This also appears to be beyond any reasonable range of uncertainty for the thermal conductivity of the insulation. The results for the calculation in which the insulation thermal conductivity was increased by a factor of five are shown in Figure 4.21.

The effect of the heat loss from the containment shell to the environment on the peak pressure inside the containment was determined by varying the exterior heat transfer coefficient. The latter was determined using a Nusselt correlation for cross-flow over a cylinder (Eq. 7.32 in Reference 5). A wind speed of $2-3 \mathrm{~m} / \mathrm{s}$ during the test was specified by NUPEC. A wind speed of $3 \mathrm{~m} / \mathrm{s}$ yielded a value of approximately $26.6 \mathrm{~W} / \mathrm{m}^{2} \mathrm{~K}$ for the exterior heat transfer coefficient which was used in the best-estimate calculation. When the wind speed was assumed to be $10 \mathrm{~m} / \mathrm{s}$, a measurable difference over the NUPEC specification, the exterior heat transfer coefficient was approximately $86.6 \mathrm{~W} / \mathrm{m}^{2} \mathrm{~K}$. However, using this value yielded a predicted peak pressure that was nearly identical to that predicted with the $26.6 \mathrm{~W} / \mathrm{m}^{2} \mathrm{~K}$ value used in the best-estimate calculation.

The nodalization scheme that was chosen to represent the facility also influenced the gas circulation in the containment. This can have an impact on the heat transfer to the structures. For example, a calculation was performed using the 28-cell representation. Except for the differences in nodalization schemes, this calculation was identical to the best estimate. The predicted peak pressure, shown in Figure 4.21, was $155.1 \mathrm{kPa}$, or $4 \mathrm{kPa}$ larger than the peak pressure from the best-estimate prediction. This would be expected since natural convection was reduced by a single computational cell representing the dome. What this example illustrates, however, is that a nearly $8 \%$ difference in the total change in predicted peak pressure resulted from a different nodalization scheme. While this difference was not large enough to account for the $18 \%$ difference between the best-estimate prediction of the peak pressure and the measured peak pressure, it illustrated that differences due to nodalization schemes can be a contributing factor.

It is possible that a combination of factors, rather than a single factor, contributed to the discrepancy between the predicted and measured variables. Certainly, no single factor identified in this study could account for all of the discrepancy between the predicted and measured peak pressure based on reasonable estimates of experimental errors or different calculational methods. The nodalization scheme had the largest impact although the alternative 28-cell scheme yielded a larger deviation from the data. It is possible that further subdivision of the physical rooms may improve the predicted results, although this would not be practical for a lumped-parameter analysis. Since the state of the injected steam was estimated rather than measured, a $10 \%$ uncertainty in the enthalpy is not unreasonable. This correction produced good agreement throughout the pressure history. All other calculations which yielded good agreement with the peak pressure were based on unreasonable variations in material properties or heat and mass transfer coefficients.

\subsubsection{Test Phase}

Besides the procedure described in Section 3.3 to calculate the results shown in Figures 3.1727 , two other common approaches may be used when analyzing this experiment by a lumpedparameter code such as CONTAIN. In both cases, the sprays are not assumed to create large 
convection loops in the air so that the enhanced heat transfer due to forced convection is not imposed on the heat transfer from the wall to the gas. In one case, the spray pattern from a nozzle operating in an unconfined geometry may be used to estimate the amount of spray water that impinges on the containment walls. Information on the area of spray coverage as a function of height may be obtained from the nozzle manufacturer. By assuming that the same spray pattern exists in the containment, the fraction of spray water that impinges on the containment wall can be estimated by simple geometrical considerations. Another approach is to simply activate the spray model in the code with no other modifications. In the CONTAIN code, the spray drops are assumed to be uniformly distributed throughout the computational cell and there is no direct interaction between the water sprays and the walls using the default conditions in the CONTAIN spray model. Although the sprays are injected into the upper dome (Cell 25), CONTAIN's spray model does not automatically carry the drops over into the lower compartments. Calculations were performed using both of the alternative methods and the results for the helium concentration, gas temperature, gas pressure, and wall temperature in the upper dome region are shown in Figures 4.22-25, respectively. The dome region was selected as the room for comparison since the other rooms each represent only $0.2 \%-4 \%$ of the total volume of the facility. In Figures 4.22-25, the best-estimate results using the procedure outlined in Section 3.3 are designated as Case 1. The results obtained from assuming a spray pattern identical to that obtained for the nozzles operating in an unconfined geometry are designated as Case 2. The simple application of the CONTAIN spray model is designated as Case 3. A final calculation was performed using the simple application of the CONTAIN spray model with the 28-node representation and is designated as Case 4.

Based on nozzle specifications provided by NUPEC, it was estimated that $15 \%$ of the spray water impinged on the containment wall in the dome. This estimate was obtained by assuming that the spray pattern for each nozzle in the facility was the same as the spray pattern for a nozzle operating in air at 1 atmosphere. According to NUPEC specifications, the nozzle spray angle was $65^{\circ}$ and, after a $12-\mathrm{m}$ drop, the spray covered an area with a diameter equal to approximately $6 \mathrm{~m}$. The fraction of spray water that impinged on the wall was estimated by superimposing this spray pattern for each nozzle onto the facility geometry. CONTAIN's film tracking model was then used to account for the heat and mass transfer of this liquid film between the wall and the gas. The liquid film flowed down the containment shell to the bottom of the facility.

It can be generally concluded from Figures 4.22-25 that the method based on the assumption that the spray drops interacted with the air to form convection loops yielded the best results. Except for the prediction of the wall temperature, however, all methods gave reasonable predictions of the gas temperature, pressure, and helium concentration. The main difference among the methods appeared in the dome wall temperature prediction. Figure 4.25 clearly shows that too much energy was extracted from the containment wall if spray water was allowed to impinge on it (Case 2). Likewise, not enough energy was extracted from the wall if the increased forced convection due to the spray-driven air convection loops was not accounted for (Cases 3 and 4). Accurate prediction of the wall temperature is important to account for the energy that will be released from the structures to the gas after the sprays stop. 


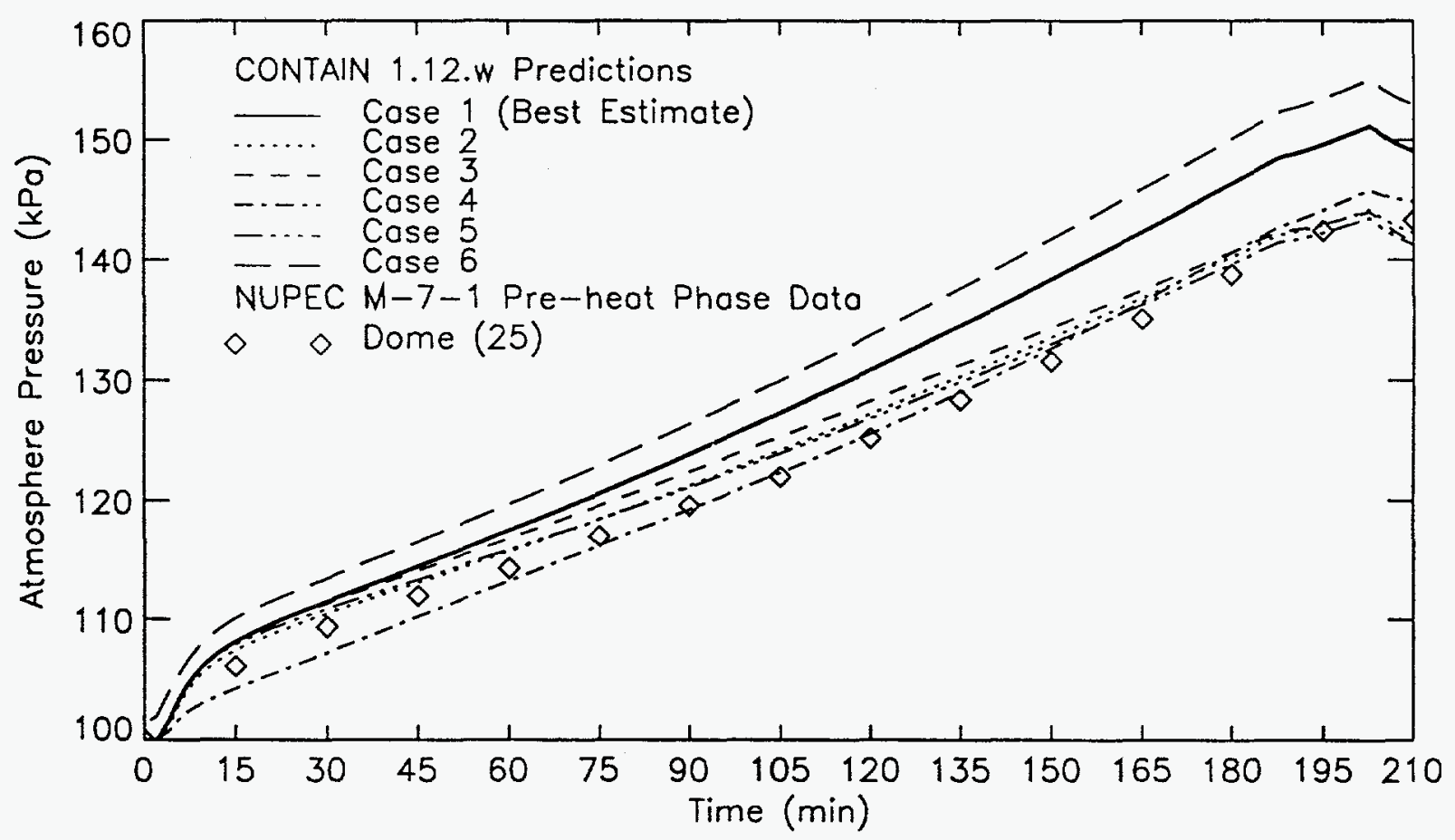

Figure 4.21.Comparison between the predicted and measured dome gas pressure in the preheat phase of test M-7-1: Case 1--best-estimate calculation; Case 2--enthalpy of the injected steam was reduced by $10 \%$; Case 3-insulation thermal conductivity was increased by a factor of 5; Case 4--heat and mass transfer coefficients were increased by a factor of 10 ; Case 5--heat capacity was increased by $25 \%$; Case $6-$ 28-cell nodalization scheme. 


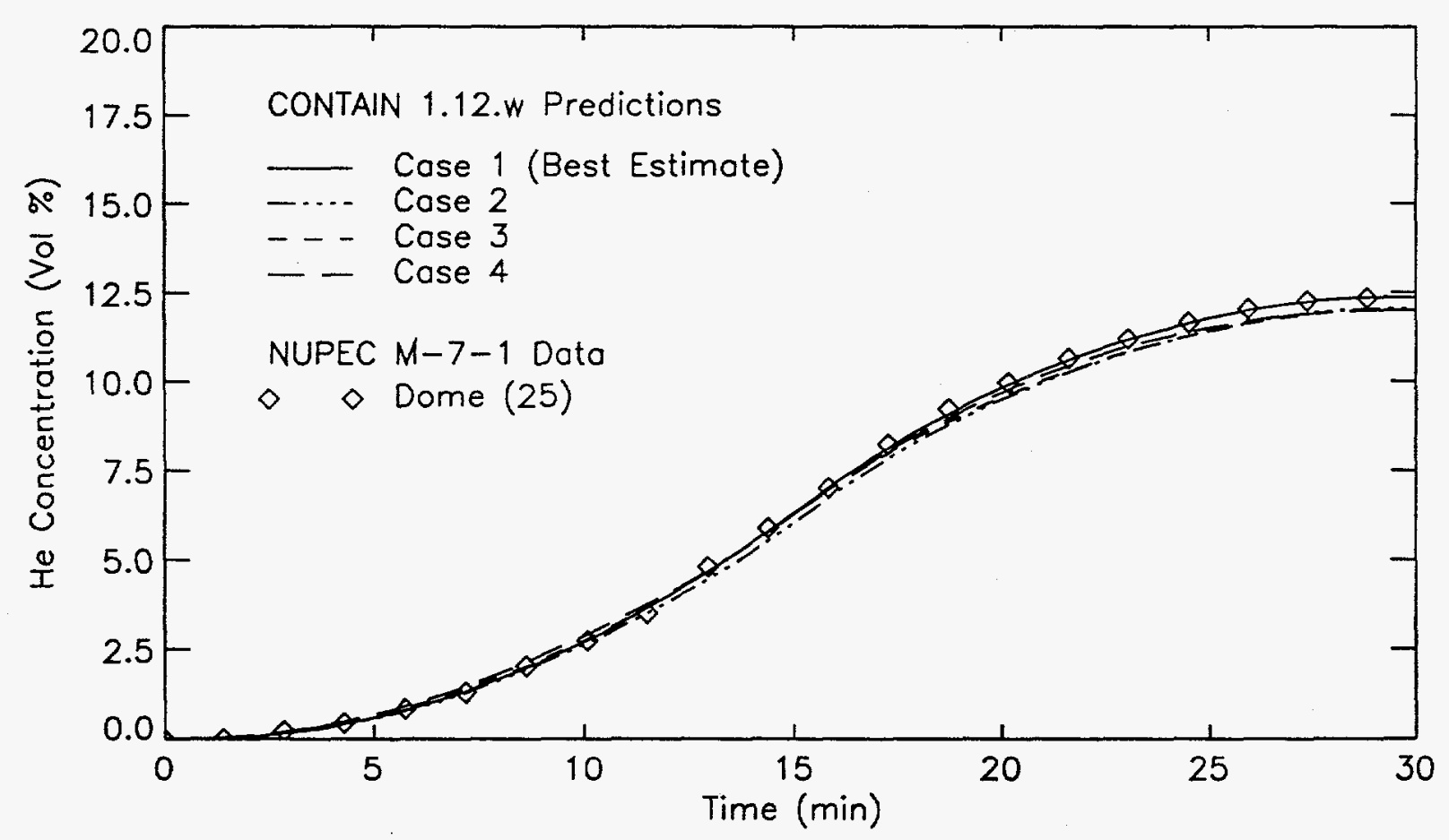

Figure 4.22.Comparison of the predicted results for the dome helium concentration using different methods for treating the water spray flow pattern in the facility: Case 1 (best estimate)--sprays were assumed to drive a large convection loop which concentrated the water drops into the center of the facility and enhanced wall to gas heat transfer; Case 2--spray pattern based on flow in unconfined geometries and included impingement of water sprays on the containment wall; Case 3-uniform spray pattern in the dome was assumed with no spray impingement or forced convection; Case 4--same as Case 3 except 28-cell nodalization was used. 


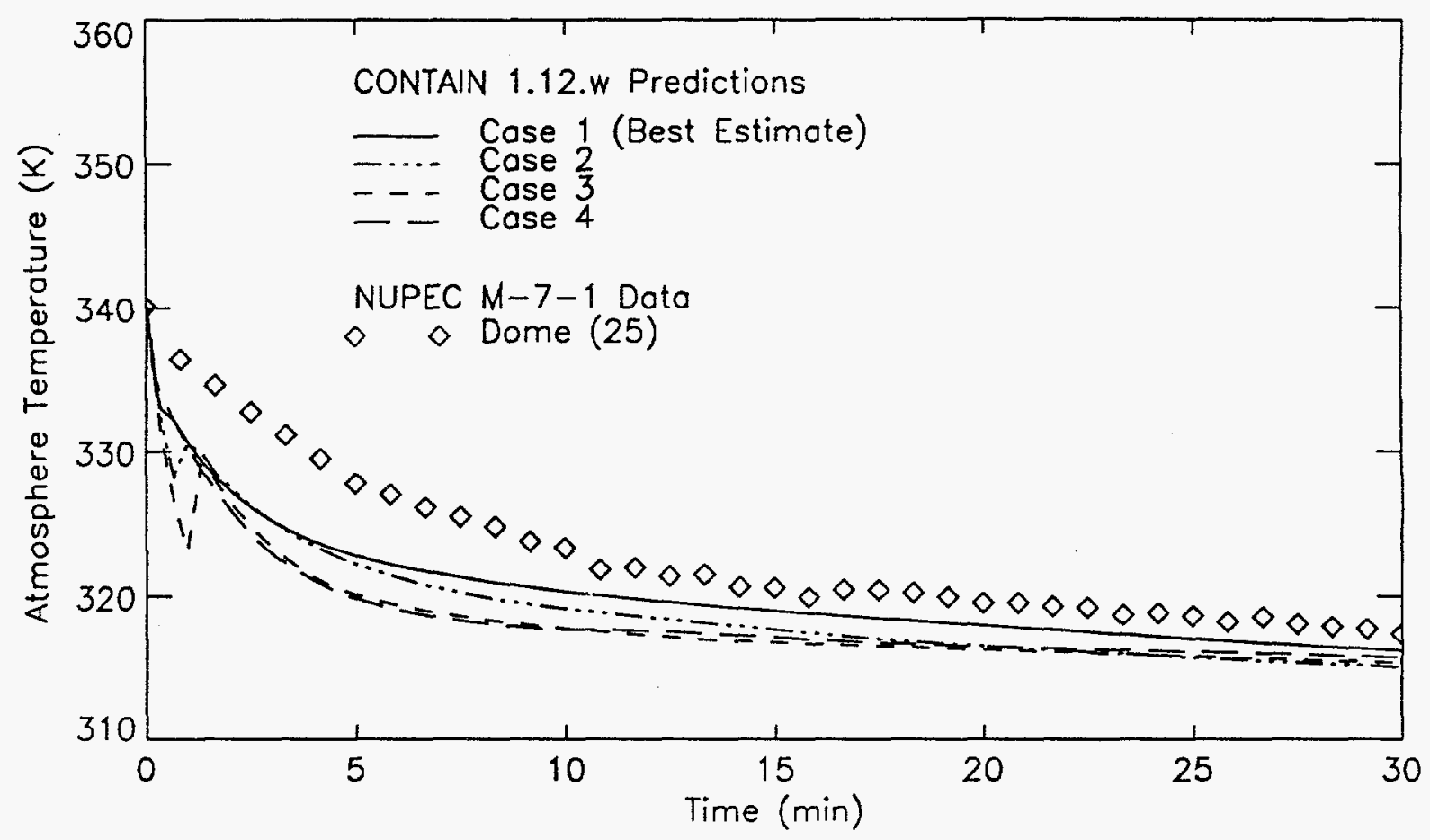

Figure 4.23.Comparison of the predicted results for the dome gas temperature using different methods for treating the water spray flow pattern in the facility. Refer to Figure 4.22 for a description of each case.

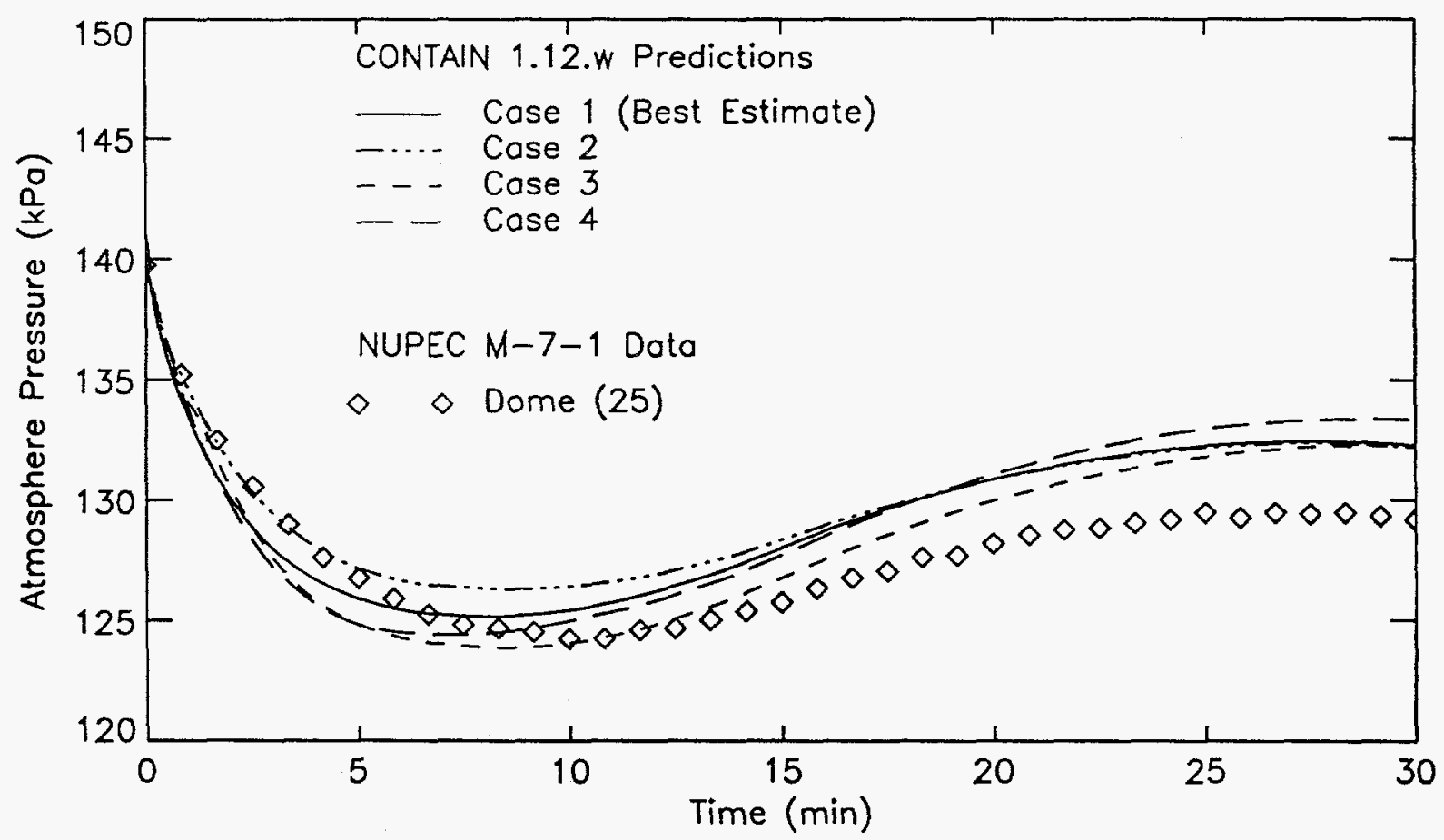

Figure 4.24.Comparison of the predicted results for the dome gas pressure using different methods for treating the water spray flow pattern in the facility. Refer to Figure 4.22 for a description of each case. 


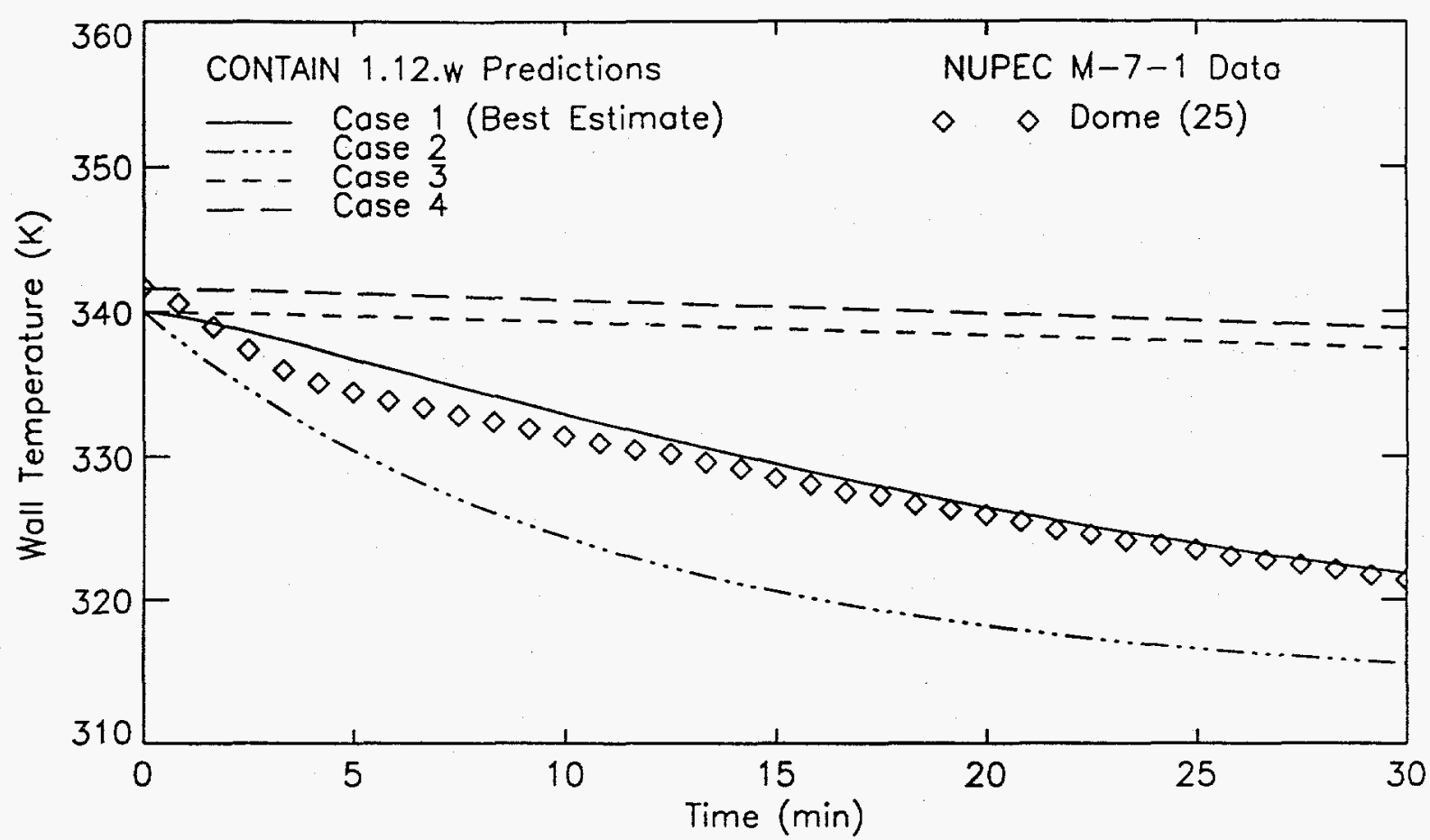

Figure 4.25.Comparison of the predicted results for the dome wall temperature using different methods for treating the water spray flow pattern in the facility. Refer to Figure 4.22 for a description of each case. 


\subsection{SUMMARY}

The CONTAIN code was used to predict the thermal hydraulics of five experiments which simulated the release of helium (as a nonflammable substitute for hydrogen) and steam in a severe accident in a nuclear power plant with and without water sprays operating during the time of helium injection. In some of the experiments, steam was injected to preheat the facility. CONTANN's ability to predict the helium concentration, gas temperature and pressure, and wall temperature was assessed and the results of the "best estimate" calculations are summarized in the rest of this section.

CONTAIN typically predicted the helium concentrations well in most of the compartments in the facility. The good agreement was due, in part, to the helium being fairly well mixed throughout the facility for one or more of the following reasons: (1) the effective mixing by the water sprays, (2) the low point injection of helium, and (3) the relatively open geometry. For example, in all of the tests, the final helium concentration in the dome was predicted to be within $10 \%$ of the experimental value and typically was much better. The dome constituted $71 \%$ of the containment volume. In some special cases, such as dead-end rooms, rooms with complicated geometries, and source rooms, large discrepancies were sometimes found although this was not always the rule. Also, different nodalization schemes or flow solvers yielded significantly different results in some of these compartments. These results may have important implications when a lumped-parameter code, such as CONTAIN, is used to guide the assessment of a hydrogen control system, for example, the total number and location of thermal glowplugs for local regions or individual rooms in a containment. When predicting stratified conditions, CONTAIN predicted helium concentrations reasonably well when the hybrid flow solver was used with a nodalization scheme that allowed mixing to occur above the source. The helium concentration was difficult to predict in the lowest compartments although the helium concentrations were low in this region.

CONTAIN typically predicted the gas temperature well in most of the compartments in the facility. For example, it predicted the change in the dome gas temperature to be within approximately $4 \%$ or less of the measured values. In some special cases, CONTAIN had difficulty predicting gas temperatures in the dead-end rooms, rooms with complicated geometries, and source rooms. This was similar to the difficulties observed in the predictions for the helium concentrations. In addition, for the tests with water sprays, CONTAIN did not predict the change in gas temperature well in the lower outer compartments. It was particularly difficult to predict the gas and wall temperatures in these rooms because the flow of gases through these compartments that was due to the spray-driven convection could not be accounted for in the code. To overcome this deficiency, the hydrodynamic drag between the spray drops and the atmosphere would have to be included in the flow solver. The inability to convect sufficient energy out of the outer lower compartments into the dome accounts, in part, for a greater predicted rate of temperature drop early in the experiment than what was actually measured.

CONTAIN's ability to predict the gas pressure was more dependent on individual tests. In some cases, such as the isothermal test M-5-5, the prediction and the measured value were in nearly perfect agreement. In other cases, such as the test M-8-2 with water sprays, the predicted change in pressure was only $16 \%$ of the actual change. For the other tests, CONTAIN predicted the change in pressure to be within $10 \%-28 \%$ of the actual change. CONTAIN 
always overpredicted the final gas pressure although the reason for this could not be explained fully using physically based sensitivity studies.

The predicted wall temperatures agreed reasonably well with the data. For example, the change in the temperature of the top of the dome region, which constituted approximately $75 \%$ of the total surface area of the containment shell, was predicted within $3 \%-15 \%$ of the measured change for all of the tests. The most difficult wall temperatures to predict were in the lower outer compartments in tests with water sprays. In one test, the predicted change in the wall temperature of one of the lower outer rooms was only one fourth of the measured change. This was because CONTAIN did not predict the forced flow of air through the lower outer rooms due to the spray-induced air convection loop.

The CONTAIN assessment of the M-7-1 test was part of an international effort to assess severe accident analysis codes. The possible reasons for the discrepancies between the predicted and measured values were examined in detail for both the preheat and test phases.

CONTAIN predicted the peak gas temperatures and pressure during the preheat phase of test M-7-1 within less than $2 \%$ and $6 \%$, respectively, on an absolute basis. The discrepancies in the changes in temperature and pressure, from the initial values to the peak values, were approximately $11 \%$ and $18 \%$, respectively, compared with the data. In an attempt to understand the source of these discrepancies, the values of parameters that controlled the energy addition to the facility, energy absorption by the facility structures, and energy loss through the facility shell were varied. No single source was identified that could account for all of the difference between the predicted and measured values. Different nodalization schemes could account for nearly half of the difference. A $10 \%$ reduction in the enthalpy of the steam at the point it was injected into the facility yielded good agreement with the measured pressure history. Although the thermodynamic state of the steam was not measured, this reduction in enthalpy was greater than the $1 \%-2 \%$ loss of enthalpy estimated by NUPEC [1] based on calculations of heat loss through the steam supply line.

Because the water sprays dominated the thermal hydraulics of test M-7-1, different ways of modelling the water sprays were assessed. The "best estimate" results were obtained assuming the sprays created a convection loop which concentrated the droplets into the center of the containment and enhanced the heat transfer from the walls to the atmosphere by the forced convection of the spray-driven circulation. Other calculations were performed assuming different spray patterns, but the results for the predicted wall temperatures did not agree with the data as well as the case assuming that the spray-driven convection loops formed. This procedure is recommended for the analysis of severe accidents in nuclear power plants or experiments in test facilities in which water sprays dominate the thermal hydraulic conditions.

The CONTAIN spray model predicted the thermal hydraulics of the tests with sprays reasonably well when the procedure described above was used; however, it was cumbersome to implement the procedure. The procedure would be much easier if the spray model and associated heat transfer models were automated. This could be accomplished by having the water sprays automatically fall from one compartment down to the next. Another improvement would be to have the code calculate a representative air velocity driven by the water sprays and impose this velocity in the form of a forced convection heat transfer coefficient on all of the pertinent structures in the containment. 
Two versions of CONTAIN, each with a different flow solver, were assessed with the NUPEC data. The flow solver in CONTAIN $1.12 \mathrm{~W}$, which is the current default flow solver, connects the ends of the flow paths to cell centers. The flow path density is assumed to be the average of the upstream and downstream cells. This flow solver is referred to as the default flow solver. The default flow solver tends to overpredict the rate and extent of mixing. The other flow solver assessed, which is referred to as the hybrid flow solver, interpolates between the average density formulation and a formulation which assumes the flow path density is equal to the upstream cell density. This flow solver is in CONTAIN 1.12 XBG. In all but one test, the different flow solvers predicted similar results. This was somewhat expected for tests with low injection points, such as M-4-3 and M-7-1, since this condition created uniform helium concentrations throughout the containment. Well-mixed conditions were also observed in both the predictions and the measurements for test M-8-2, which had a midpoint injection of helium and water sprays in the dome. In the experiment, the water sprays were effective in mixing gases because of the hydrodynamic drag between the water drops and the atmosphere. CONTAIN, however, does not model the hydrodynamic drag. Apparently, the predicted natural convection induced by condensation from the cool gases in the center of the facility due to the water sprays was sufficient to enable thorough mixing of the helium. As was expected, the hybrid flow solver (XBG version) was superior to the default flow solver (W version) for test M-8-1, which had stratified helium conditions. However, the use of the hybrid flow solver without an appropriate nodalization scheme was not sufficient to guarantee good results. The hybrid flow solver required a nodalization scheme that allowed mixing to occur above the injection point to predict the stratified conditions well.

In summary, CONTAIN predicted the thermal hydraulic variables for five tests performed in the NUPEC 1/4-scale model containment. The NUPEC facility's overall geometry and internal configuration somewhat resemble U.S. pressurized water reactors, although as has been pointed out elsewhere [1], there are important differences such as the fact that the NUPEC facility does not contain any concrete. Different flow solvers and nodalization schemes were assessed although no attempt was made to minimize the number of nodes used in the assessment. If many calculations are required using a lumped parameter code, this is generally desirable. The performance of the different modeling approaches was discussed qualitatively. If quantitative information on the relative performance of different assessment methods is desired, a fast Fourier transform method such as that described in [4] should be used. 


\subsection{REFERENCES}

1. "Final Comparison Report on ISP-35: NUPEC Hydrogen Mixing and Distribution Test (Test M-7-1)," Organization for Economic Co-Operation and Development (OCDE) report, OCDE/GD(95)29, NEA/CSNI/R(94)29, Paris, France, December 1994.

2. K. D. Marx, "Analysis and Computer Simulation of Confined Ring Vortices Driven by Falling Sprays," Physics of Fluids, Vol. 31, No. 2, pp. 263-277, February 1988.

3. K. E. Washington et. al., "Reference Manual for the CONTAIN 1.1 Code for Containment Severe Accident Analysis," Sandia National Laboratories report, NUREG/CR-5715, SAND91-0835, Albuquerque, NM, July 1991.

4. M. Leonardi, F. Oriolo, S. Paci, and A. Villotti, "ISP-35 on NUPEC M-7-1 Test: Evaluation of Codes Accuracy," University of Pisa report, Department of Mechanical and Nuclear Construction, Report RL 663(94), Pisa, Italy, 1994.

5. F. P. Incropera and D. P. DeWitt, Fundamentals of Heat Transfer, John Wiley \& Sons, New York, New York, 1981. 
EXTERNAL DISTRIBUTION:

U.S. Nuclear Regulatory Commission (8)

Division of Reactor System Safety

Office of Nuclear Regulatory Research

ATTN: C. Ader, T-10K-8
A. Drozd
C. G. Gingrich, NLN-344
R. Lee, T-10K-8
J. Monninger, OWFN 8-D
A. Notafrancesco
A. Rubin, T-10K-8
T. Spies, T-10F-12

U.S. Nuclear Regulatory Commission (3)

Office of ACRS

ATTN: M. D. Houston, T-2E-26

T. Kress, T-2E-26

I. Catton

Washington, D.C. 20555-0001

U.S. Department of Energy (2)

Albuquerque Operations Office

Post Office Box 5400

ATTN: C. E. Garcia, Director

For: C. B. Quinn

R. L. Holton

Albuquerque, NM 87185

U.S. Department of Energy

Office of Nuclear Safety Coordination

ATTN: R. W. Barber

Washington, D.C. 20545

U.S. Department of Energy

Idaho Operations Office

850 Energy Drive

ATTN: S. W. Sorrell

Idaho Falls, ID 83401

U.S. Department of Energy

Scientific and Technical Information Center

Post Office Box 62

Oak Ridge, TN 37831

Argonne National Laboratory

9700 South Cass Avenue

ATTN: B. Spencer

Argonne, IL 60439
Battelle Columbus Laboratory (2)

505 King Avenue

ATTN: R. Denning

J. Gieseke

Columbus, OH 43201

Battelle Pacific Northwest Laboratory

Post Office Box 999

ATTN: M. Freshley

Richland, WA 99352

Brookhaven National Laboratory (3)

Building 130

32 Lewis

ATTN: R. Bari

T. Pratt

N. Tutu

Upton, NY 11973

Ebasco Services Incorporated Applied Physics Department

Two World Trade Center

Attn: J. J. Shin

New York, NY 10048

EG\&G Idaho

Post Office Box 1625/MS2508

ATTN: D. L. Knudson

Idaho Falls, ID 83415

Electric Power Research Institute (2)

3412 Hillview Avenue

ATTN: A. Michaels

M. Murillo

Palo Alto, CA 94303

Energy Research, Inc. (2)

Post Office Box 2034

ATTN: H. Esmali

M. Khatib-Rahbar

Rockville, MD 20852

Fauske \& Associates, Inc. (2)

16W070 West $83^{\text {rd }}$ Street

ATTN: R. Henry

M. G. Plys

Burr Ridge, IL 60952 
General Electric Company

Advanced Boiling Water Reactor Program 175 Curtner Avenue

ATTN: W. Holtzclaw

San Jose, CA 95125

Knolls Atomic Power Laboratory

Post Office Box 1072

ATTN: J. M'Mullan

Schenectady, NY 12301

Levy \& Associates

3880 South Bascom Avenue, Suite \#112

ATTN: S. Levy

San Jose, CA 95124

Los Alamos National Laboratory

Post Office Box 1663

ATTN: B. Boyack, K-551

Los Alamos, NM 87545

Massachusetts Institute of Technology

ATTN: M. Golay

Cambridge, MA 02139

Oak Ridge National Laboratory (3)

Post Office Box 2009

ATTN: S. A. Hodge

C. Hyman

K. Smith, MS-8057

Oak Ridge, TN 37831-8057

Pennsylvania Power \& Light Company

Two North Ninth Street

ATTN: T. S. Yih

Allentown, PA 18101

Purdue University

Heat Transfer Laboratory

School of Mechanical Engineering

ATTN: R. Viskanta

West Lafayette, IN 47907-1209

Purdue University

School of Nuclear Engineering

ATTN: M. Ishii

West Lafayette, IN 47907

Rennselaer Polytechnic Institute

Department of Nuclear Engineering \& Engineering Sciences

Tibbits Avenue, NES Building

ATTN: M. Podowski

Troy, NY 12180-3590
Science Applications International Corp. 2109 Air Park Road, S.E.

ATTN: D. R. Bradley

Albuquerque, NM 87106

Stone \& Webster Engineering

Post Office B ox 2325

ATTN: J. Metcalf, MS245-2

Boston, MA 02107

Texas A\&M University

Department of Nuclear Engineering

ATTN: Y. A. Hassan

College Station, TX 77843

Jack Tills \& Associates

Post Office Box 549

ATTN: J. Tills

Sandia Park NM 87047

University of California

Department of Chemical and Nuclear Engineering

ATTN: T. Theofanous

Santa Barbara, CA 93106

University of Maryland

Department of Nuclear Engineering

ATTN: Professor K. Almenas

College Park, MD 20742

University of Missouri

Nuclear Engineering Department

ATTN: S. K. Loyalka

Columbia, MO 65211

University of New Mexico

Department of Chemistry and Nuclear Engineering

ATTN: F. E. Haskin

Albuquerque, NM 87131

University of Wisconsin

Department of Nuclear Engineering

153 Engineering Research Building

1500 Johnson Drive

ATTN: M. L. Corradini

Madison, WI 53706 
Westinghouse Bettis Atomic Laboratory

Post Office Box 79

ATTN: J. W. Wolfe, ZAP 34N

West Mifflin, PA 15122

Westinghouse Savannah River (3)

Woodside Executive Park

1359 Silver Bluff Road

ATTN: K. O'Kula

Aiken, SC 29808-0001

\section{FOREIGN DISTRIBUTION:}

IAEA

Division of Nuclear Reactor Safety

Wagranerstrasse 5

Post Office Box 100

A/1400 Vienna

ATTN: M. Jankowski

AUSTRIA

Belgonucleaire SA

Rue du Champ de Mars 25

ATTN: H. Bairiot

B-1050 Brussels

BELGIUM

Director, Research, Science Education CEC

Rue de la Loi 2000

1049 Brussels

ATTN: W. Balz

BELGIUM

Commission on the Use of Atomic Energy for

Peaceful Purposes - 69 Shipchenski

Prokhod Boulevard, 1574, Sofia

ATTN: Y. Yanev

BULGARIA

\section{AECL CANDU}

Sheridan Park Research Community

2251 Speakman Avenue

ATTN: V. J. Nath

Mississauga, Ontario L5K 1B2

CANADA

AECL Research

Chalk River Research Laboratories

ATTN: B. H. McDonald

Chalk River, Ontario KOJ 1 JO

CANADA
AECL Research

Whitshell Laboratories

ATTN: S. R. Mulpuru

Pinawa, Manitoba R0E 1L0

CANADA

Ontario Hydro

700 University Avenue

ATTN: O. Akalin

Toronto, Ontario M5G 1X6

CANADA

Nuclear Research Institute

$25068 \mathrm{Rez}$

ATTN: J. Kujal

CZECH REPUBLIC

State Office for Nuclear Safety

Slezska 9

ATTN: J. Stuller

12000 Prague 2

CZECH REPUBLIC

RISO National Laboratory

Department of Energy Technology

Post Office Box 49

DK-4000 Roskilde

ATTN: P. B. Fynbo

DENMARK

Finnish Center Radiation \& Nuclear Safety

Department of Nuclear Safety

Post Office Box 268

SF-00101 Helsinki

ATTN: J. V. Sandberg

FINLAND

Tech Research Centre of Finland (VTT)

Nuclear Engineering Laboratory (YDI)

PL 169

00181 Helsinki

ATTN: L. Mattila

FINLAND

Cadarache Center for Nuclear Studies (3)

F-13108 Sait Paul-Lez-Durance Cedex

ATTN: M. Schwartz

F. Serre

FRANCE 
Inst. de Protection et de Surete Nucleaire CEN/FAR-B.P. No. 6

F-92265, Fontenay-aux-Roses

ATTN: J. Bardelay

Cedex, FRANCE

Battelle Institute e. V.

Am Romerhof 35

D-6000 Frankfurt am Main 90

ATTN: D. T. Kanzleiter

GERMANY

Gesellschaft fur Reaktorsicherheit (3)

Forschungsgelande

8046 Garching

ATTN: K. Trambauer

G. Weber

M. Sonnenkalb

GERMANY

Gesellschaft fur Reaktorsicherheit $\mathrm{mbH}$

Postfach 101650

Glockengasse 2

D-5000 Koln 1

ATTN: J. Langhans

GERMANY

Ruhr-University of Bochum

Department of Nuclear \& New Energy System

ATTN: U. Brockmeier

GERMANY

University of Stuttgart

IKE

Pfaffenwaldring 31

ATTN: U. Bieder

D-7000 Stuttgart 80

GERMANY

Technische Universitat Munchen

Forschungsgelande

8046 Garching

ATTN: Professor Dr. I. H. Karwat

GERMANY

Kernforschungszentrum Karlsruhe (4)

Post Office Box 3640

ATTN: V. Scholtyssek

75 Karlsruhe

GERMANY
Research Centre Rossendorf, Inc.

Forschungszentrum Rossendorf

Postfach 19

ATTN: Dr. H. Funke

DO-8051 Dresden

GERMANY

Institute for Electric Power Research

Division of Nuclear \& Power Engineering

Post Office Box 233

ATTN: Z. Techy

H-1368 Budapest

HUNGARY

Hungarian Atomic Energy Commission

H-1374 Budapest, Post Office Box 565

ATTN: S. Elo

Budapest

HUNGARY

CEC Joint Research Center (3)

I-21020 Ispra (Varese)

ATTN: P. Fasoli-Stella

A. Markovina

R. Ricchena

ITALY

Nucleare e della Protezione Sanitaria

(DISP) (ENEA)

Ente Nazionale Energie Alternative

Viale Regina Margherita, 125

Cassella Postale M. 2358

ATTN: G. Petrangeli

1-00144 Roma A.D.

ITALY

ENEL-CRTN

Via Monfalcone 15

ATTN: E. Borioli

20132 Milan

ITALY

Toshiba Corporation

Nuclear Safety Engineering Section

8, Shinsugita-Cho, Isogo-Ku

Yokohama 235

ATTN: M. Naito

JAPAN 
Power Reactor Nuclear Fuel Development Corporation (PNC)

9-13, 1-Chome

ATTN: H. Hiroi

Minato-Ku, Tokyo

JAPAN

Nuclear Power Engineering Center

Fujitakanko Building

17-1, 3-Chome, Toranomon, Minato-Ku

ATTN: Kenji Takumi

Tokyo, 105

JAPAN

Japan Atomic Energy Research Institute (2)

Tokai-mura

Naku-gun

ATTN: K. Soda

J. Sugimoto

Ibaraki-ken, 319-11

JAPAN

\section{POSTECH}

Department of Mechanical Engineering

Post Office Box 125

Kyungbuk 790-600

ATTN: M. H. Kim

KOREA

Korea Atomic Energy Research Institute 150 Dukjin-dong, Yoosung-gu

ATTN: Hee-Dong Kim

Taejon 305-353

KOREA

Korea Institute of Nuclear Safety

Safety Review and Assessment Division

Post Office Box 16, Daeduk-Danji

ATTN: J. J. Lee

Taejon, 305-353

KOREA

VATESI

Gediminis Prospect 36

ATTN: P. Vaisnys

Vilnius

LITHUANIA

Com. Nacional de Seguridad Nucl. Salvag Colonia Narvarte Delegation B. Juarez

ATTN: Dr. Abrtshsm \#779

C.P. 03020

MEXICO
Atomic Energy Council

67, Lane 144 Keelung Road

Section 4, Taipei, Taiwan

ATTN: S. J. Shieh

REPUBLIC OF CHINA

Institute of Nuclear Energy Research

Post Office Box 3

Lungtan, Taiwan 325

ATTN: S. I. Chang

REPUBLIC OF CHINA

Nuclear Safety Institute

Russian Research Center KI

1 Kurchatov Square

ATTN: V. Asmolov

123182 Moscow

RUSSIA

Russian Academy of Sciences

Nuclear Safety Institute

52, B. Tulskaya

ATTN: V. F. Strizhov

113191 Moscow

RUSSIA

Nuclear Regulatory Authority, Slovak Republic

Post Office Box 24

82007 Bratislava 27

ATTN: J. Misak

SLOVAK REPUBLIC

Jozef Stefan Institute

Jamova 39

ATTN: B. Mavko

61111 Ljubljana

SLOVENIA

Catedra de Tecnologia Nuclear

E.T.S. Ingenieros Industriales

Universidad Politecnica

Jose Gutierrez Abascal, 2

28006-Madrid

ATTN: L. Herranz

SPAIN

Consejo de Seguridad Nuckan

SOR Angela de la Cruz No. 3

ATTN: J. Bagues

28056 Madrid

SPAIN 
Consejo de Seguridad Nuclear

Justo Dorado 11

ATTN: J. E. deCarlos

28040 Madrid

SPAIN

E.T.S. Ingenieros Industriales

Jost Gutierrez Abascal, 2

ATTN: A. Alonso

28006 Madrid

SPAIN

Royal Institute of Technology

Nuclear Power Safety

S-100 44 Stockholm

ATTN: B. R. Sehgal

SWEDEN

Swedish Nuclear Power Inspectorate

Post Office Box 27106

S-102 52 Stockholm

ATTN: W. Frid

SWEDEN

Studsvik Nuclear

S-611 82, Nykoping

ATTN: K. O. Johansson

SWEDEN

Swiss Federal Nuclear Safety Inspectorate CH-5303 Wurenlingen

ATTN: S. Chakraborty

SWITZERLAND

Paul Scherrer Institute

ATTN: P. Hosemann

CH-5232 Villigen, PSI

SWITZERLAND

Institute of Nuclear Energy Research

Post Office Box 3

ATTN: Sen-I Chang

Lung-Tan

TAIWAN 325

Netherlands Energy Research

Foundation (ECN) (2)

Postbus 1

1755 ZG Petten

ATTN: K. J. Brinkman

P. M. Stoop

THE NETHERLANDS
N. V. Kema

Post Office Box 9035

ATTN: P. Kloeg

6800 ET Arnhem

THE NETHERLANDS

AEA Culham Laboratory (2)

Abingdon

Oxfordshire, OX14-3DB

ATTN: B. D. Turland

D. F. Fletcher

UNITED KINGDOM

AEA Winfrith (3)

Dorchester

Dorset DT2 8DH

ATTN: S. Kinnersley

P. N. Smith

B. Bowsher

UNITED KINGDOM

Nuclear Electric

Berkeley Nuclear Laboratory, Berkeley

ATTN: C. Chapman

Gloucestershire GL 13 9PB

UNITED KINGDOM

CEGB, Booths Hall

Chelford Road, Knutsford

Cheshire WA16 8QG

ATTN: N.E. Buttery

UNITED KINGDOM

AERE Harwell

Didcot

ATTN: A. L. Nichols

Oxfordshire OX11 ORA

UNITED KINGDOM

UKAEA, Risely Nuclear Laboratories (2)

Risley, Warrangton

ATTN: A. T. D. Butland

I. H. Dunbar

Cheshire WA3-4NE

UNITED KINGDOM

INTERNAL DISTRIBUTION:

MS0619 Print Media (12615)

MS0736 N. R. Ortiz (6400)

MS0739 K. D. Bergeron (6421) (5)

MS0739 R. K. Cole, Jr. (6421)

MS0739 R. G. Gido (6421)

MS0739 R. O. Griffith (6421) 


$\begin{array}{ll}\text { MS0739 } & \text { K. K. Murata (6421) } \\ \text { MS0739 } & \text { R. C. Smith (6421) } \\ \text { MS0739 } & \text { D. W. Stamps (6421) } \\ \text { MS0739 } & \text { E. L. Tadios (6421) } \\ \text { MS0739 } & \text { D. C. Williams (6421) } \\ \text { MS0742 } & \text { J. E. Kelly (6414) } \\ \text { MS0744 } & \text { D. A. Powers (6404) } \\ \text { MS0747 } & \text { A. L. Camp (6412) } \\ \text { MS0747 } & \text { S. E. Dingman (6412) } \\ \text { MS0748 } & \text { F. E. Harper (6413) } \\ \text { MS0899 } & \text { Tech Library (13414) (5 cys) } \\ \text { MS1137 } & \text { M. D. Allen (6422) } \\ \text { MS1137 } & \text { T. K. Blanchat (6422) } \\ \text { MS1137 } & \text { M. M. Pilch (6422) } \\ \text { MS1139 } & \text { K. O. Reil (6423) } \\ \text { MS1139 } & \text { R. O. Gauntt (6423) } \\ \text { MS0100 } & \text { Document Processing (7613-2) for } \\ & \text { DOE/OSTI (2 cys) } \\ \text { MS9018 } & \text { Central Technical Files (8523-2) }\end{array}$

